\title{
PHASED ARRAY 802.11g ANTENNA
}

\author{
A Thesis \\ presented to the Faculty of \\ California Polytechnic State University, \\ San Luis Obispo
}

\author{
In Partial Fulfillment \\ of the Requirements for the Degree \\ Master of Science in Electrical Engineering \\ by \\ Allen Gregory Peters \\ June 2010
}


(C) 2010

Allen Gregory Peters

ALL RIGHTS RESERVED 


\section{COMMITTEE MEMBERSHIP}

TITLE:

AUTHOR:

DATE SUBMITTED:

COMMITTEE CHAIR:

COMMITTEE MEMBER:

COMMITTEE MEMBER:
PHASED ARRAY 802.11g ANTENNA

Allen Gregory Peters

June 2010

Dr. Dean Arakaki, Associate Professor

Dr. Dennis Derickson, Assistant Professor

Dr. Cheng Sun, Professor 


\section{ABSTRACT}

\section{PHASED ARRAY 802.11g ANTENNA}

\section{Allen Gregory Peters}

This thesis involves the development of a $2.4 \mathrm{GHz}$ phased array antenna for consumer wireless applications. $802.11 \mathrm{~g}$ specifications include 11 channels from $2.412 \mathrm{GHz}$ to $2.472 \mathrm{GHz}$. Each channel has a $22 \mathrm{MHz}$ minimum bandwidth with a $5 \mathrm{MHz}$ center-to-center interchannel spacing. Design goals for the phased array include an operating frequency of $2.437 \mathrm{GHz}$ (channel 6 center frequency). The array antenna design procedure can be integrated into a future antenna laboratory experiment.

Design considerations for the antenna array include cost, producibility, compatibility with $802.11 \mathrm{~b} / \mathrm{g}$ devices, and performance. Dipole antenna elements are arranged in a linear array to simplify calculations and to provide an intuitive understanding of array fundamentals. A linear array can maximize signal to interference ratio (SIR) by placing pattern nulls in the directions of noise sources. The design includes eight radiating elements mounted at $\lambda / 2$ intervals. Design specifications include a scanning range of 360 degrees in the $\mathrm{H}$-plane. Each element's phase and gain is controlled by a network capable of 180 degrees of phase delay and up to $15.5 \mathrm{~dB}$ of attenuation to enable sidelobe cancellation.

This project includes array design, simulations and theoretical calculations, antenna array construction, and final design characterization. Measurements are compared to theoretical predictions yielding good results. The antenna array was connected to an access point and tested on a lab network. Successfully associating a laptop to the wireless router and browsing the router configuration pages confirm connectivity. Array functionality is evaluated at channel 6 , the $802.11 \mathrm{~g}$ center frequency. The array is also tested at the lower and upper frequencies of channel 6 to ensure less than $3 \mathrm{~dB}$ SNR variation.

The thesis includes a sample lab, which includes: A prelab, a procedure, and sample questions.

Keywords: Phased Array Antenna, Signal to Interference Ratio (SIR), Signal to Noise Ratio (SNR), Sidelobe Cancellation (SLC), Array Factor (AF) 


\section{ACKNOWLEDGMENTS}

First, and foremost, I would like to thank my God and Savior, Jesus Christ, who died for me while I was still a sinner (Romans 5:8). I would also like to thank my thesis advisor, Dean Arakaki, whose attention to detail and dedication to excellence were an inspiration throughout this project. I would like to thank my dad for letting me bounce countless ideas off him, and who helped me through some rough patches in troubleshooting. And finally, a special thank you to Jianbiao (John) Pan, who provided guidance in how to solder the digital step attenuator and provided access to the Heller reflow oven. 


\section{TABLE OF CONTENTS}

LIST OF TABLES

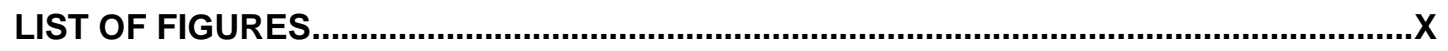

I. BEAM SHAPING IN WIRELESS NETWORKING ................................................

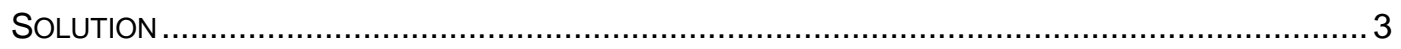

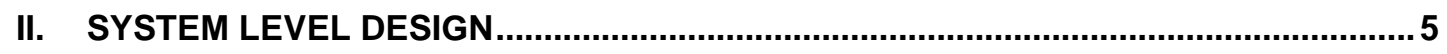

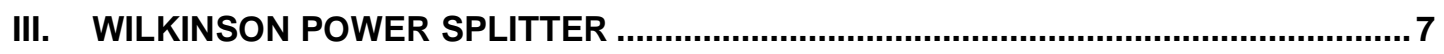

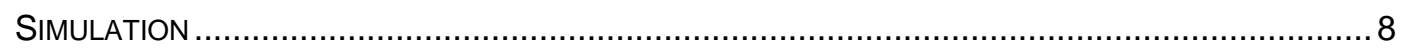

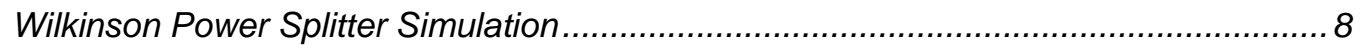

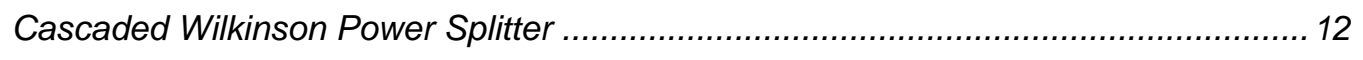

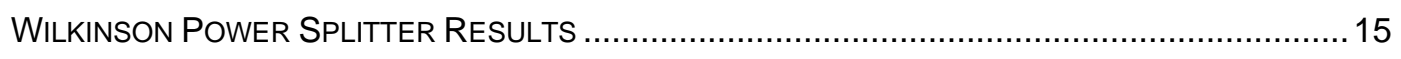

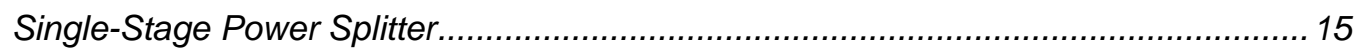

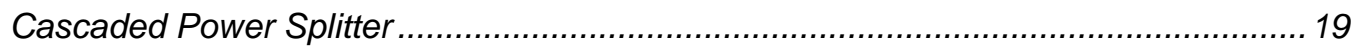

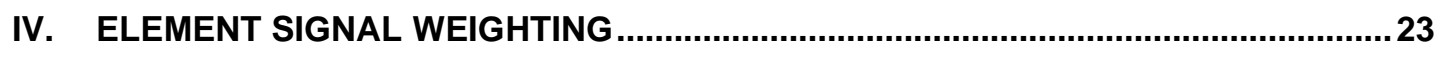

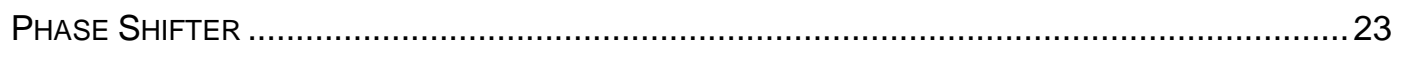

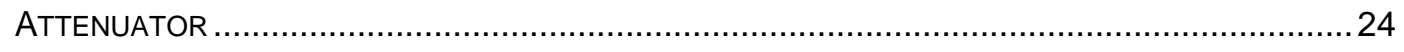

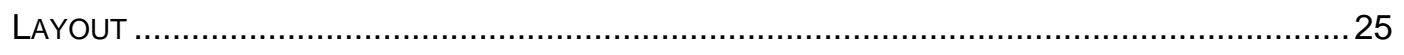

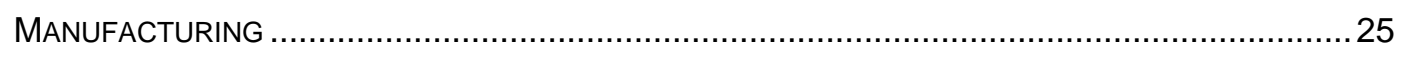

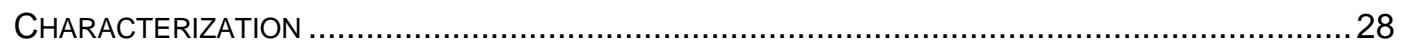

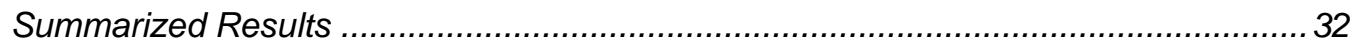

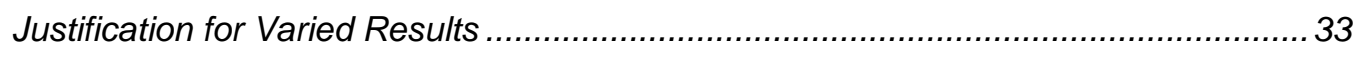

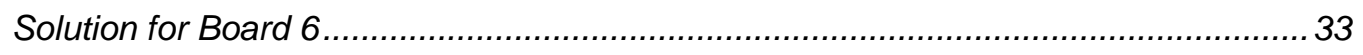


V. ANTENNA ELEMENT AND ANTENNA MOUNT ASSEMBLY

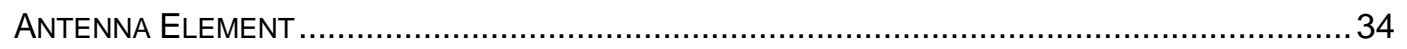

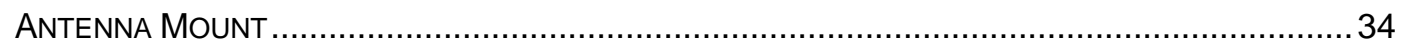

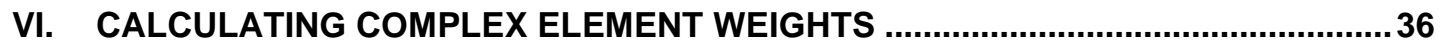

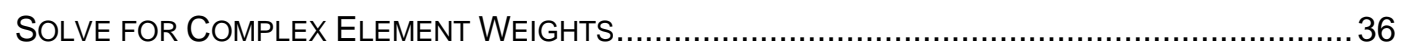

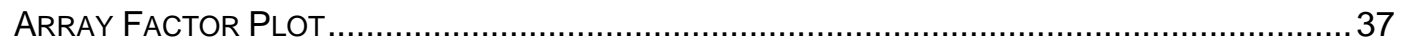

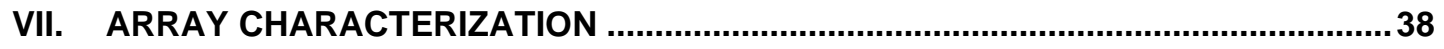

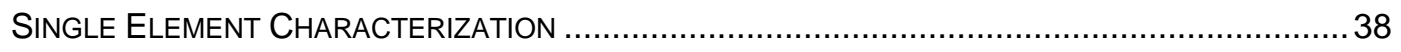

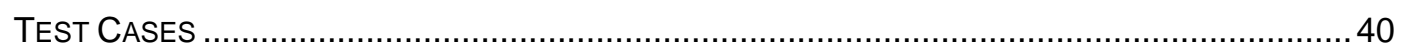

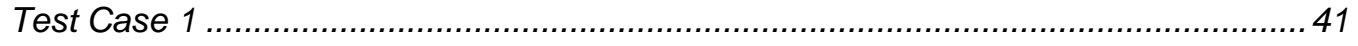

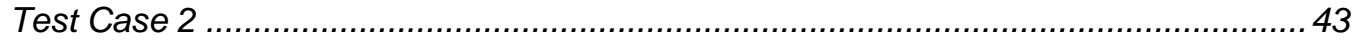

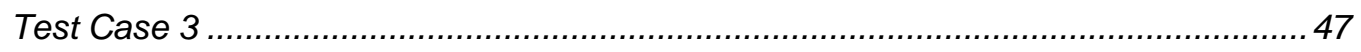

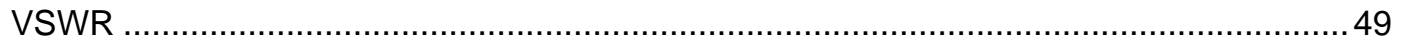

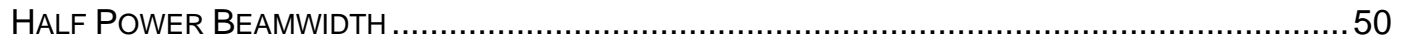

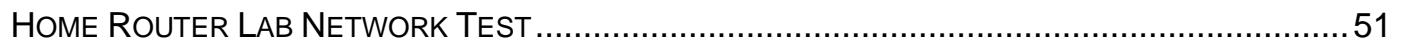

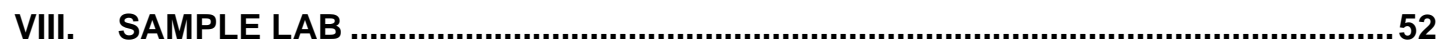

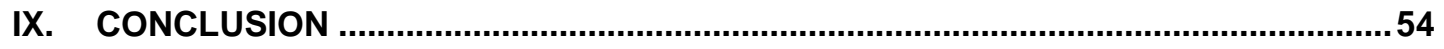

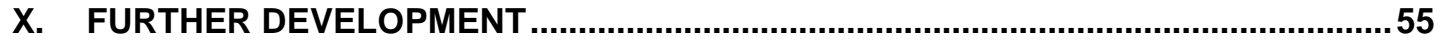

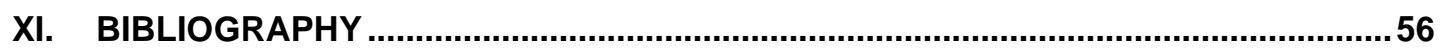

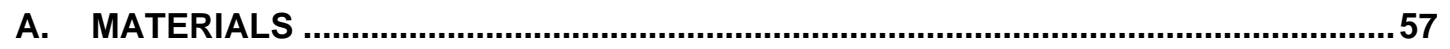

B. MATLAB SIMULATION CODE

Apendices

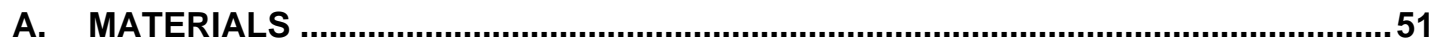


B. MATLAB SIMULATION CODE 


\section{LIST OF TABLES}

Table

Page

TABLE 1 ANTENNA TYPES AND TYPICAL OPERATING SPECIFICATIONS ...........................

TABLE 2 SLC PHASED ARRAY DESIGN SPECIFICATIONS …....................................... 4

TABLE 3 TYPICAL PERFORMANCE DATA (FROM MINI-CIRCUITS), JSPHS-2484+

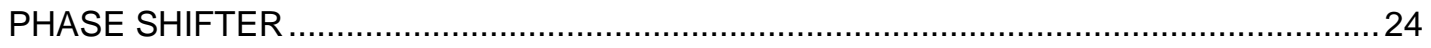

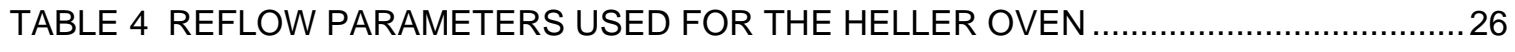

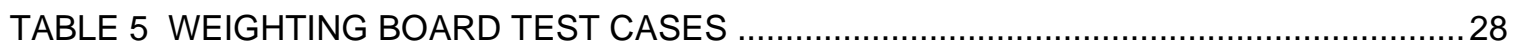

TABLE 6 SUMMARIZED RESULTS OF KEY MEASUREMENTS FROM ALL 8

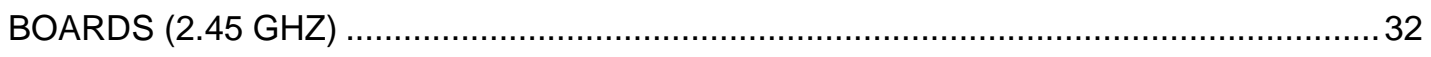

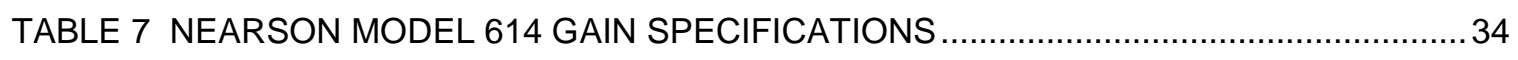

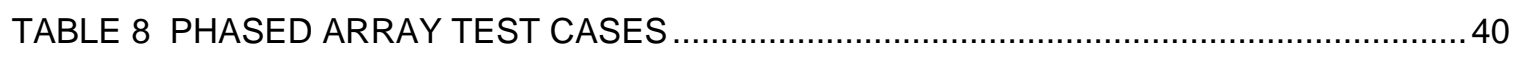

TABLE 9 SNR IMPROVEMENTS, TEST CASE 2 …..................................................... 44

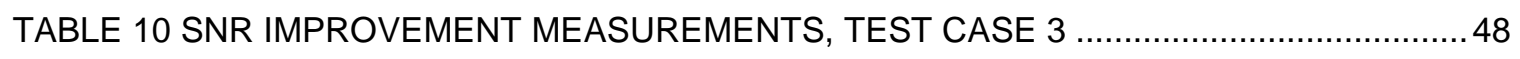

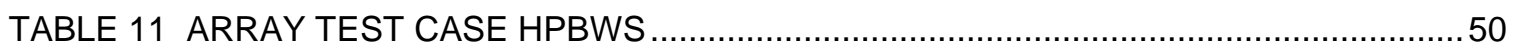

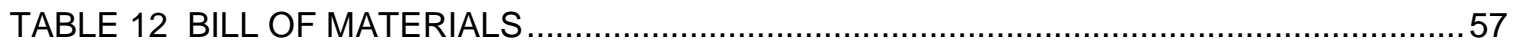




\section{LIST OF FIGURES}

Table

Page

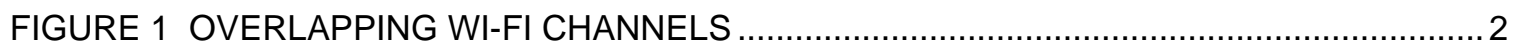

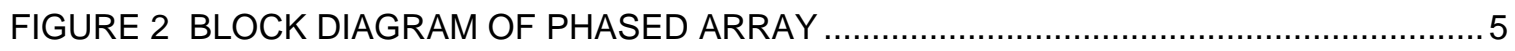

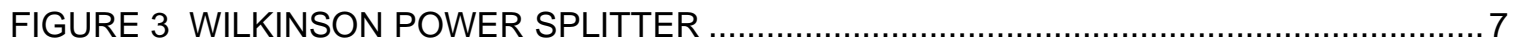

FIGURE 4 ADS MODEL OF SINGLE STAGE WILKINSON POWER SPLITTER ..................... 9

FIGURE 5 MICROSTRIP WILKINSON POWER SPLITTER, SIMULATION AND

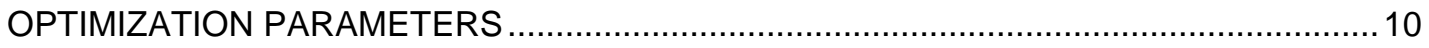

FIGURE 6 WILKINSON POWER SPLITTER ADS SIMULATION RESULTS ..........................11

FIGURE 7 CASCADED WILKINSON POWER SPLITTER LAYOUT ...................................... 12

FIGURE 8 CASCADED WILKINSON POWER SPLITTER VSWR AND ATTENUATION

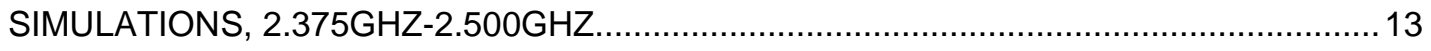

FIGURE 9 CASCADED WILKINSON POWER SPLITTER VSWR AND ATTENUATION

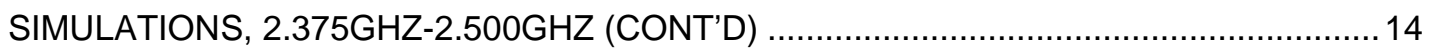

FIGURE 10 TRANSMISSION PHASE DELAYS, CASCADED WILKINSON POWER

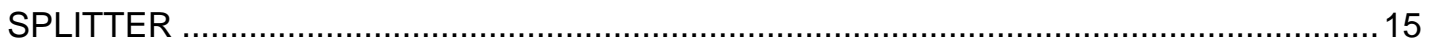

FIGURE 11 CONSTRUCTED SINGLE STAGE WILKINSON POWER

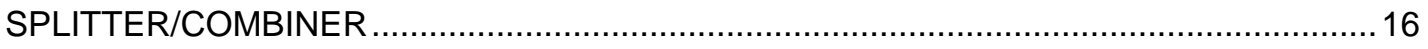

FIGURE 12 WILKINSON SINGLE-STAGE POWER SPLITTER, INPUT AND

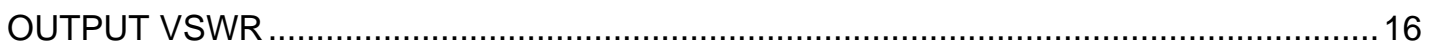

FIGURE 13 TRANSMISSION S-PARAMETERS, SINGLE STAGE WILKINSON POWER

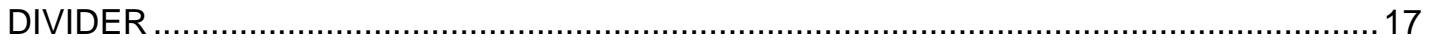

FIGURE 14 ISOLATION MEASUREMENTS BETWEEN PORTS TWO AND THREE FOR A

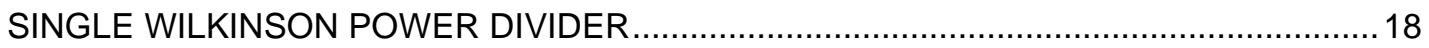

FIGURE 15 PHASE SHIFT THROUGH SINGLE WILKINSON POWER SPLITTER .................. 19

FIGURE 16 CONSTRUCTED, CASCADED WILKINSON POWER SPLITTER/COMBINER ......20

FIGURE 17 CASCADED WILKINSON POWER SPLITTER INPUT AND OUTPUT VSWRS .....20 
FIGURE 18 TRANSMISSION S-PARAMETERS, CASCADED WILKINSON

POWER SPLITTER.

FIGURE 19 ISOLATION MEASUREMENTS, PORT 2 TO PORTS 3 THROUGH 5...................22

FIGURE 20 PHASE SHIFT, CASCADED WILKINSON POWER SPLITTER …........................ 22

FIGURE 21 BLOCK DIAGRAM OF BASIC WEIGHTING BOARD ...........................................2

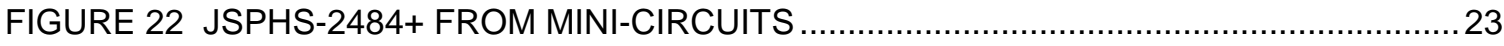

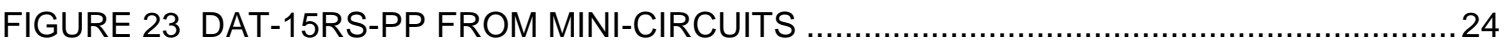

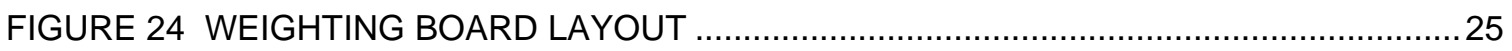

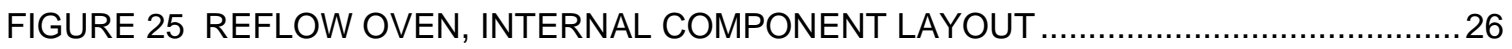

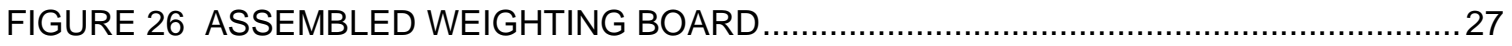

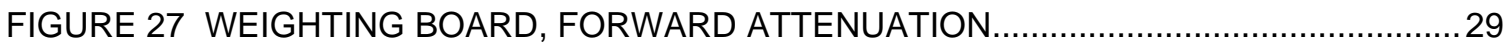

FIGURE 28 WEIGHTING BOARD, REVERSE ATTENUATION ...........................................29

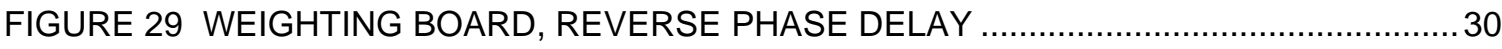

FIGURE 30 WEIGHTING BOARD, FORWARD PHASE DELAY .......................................... 30

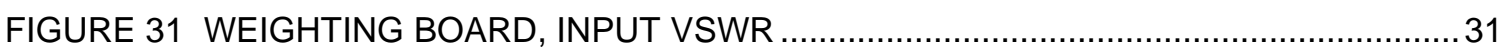

FIGURE 32 WEIGHTING BOARD, FORWARD AND REVERSE PHASE DELAY

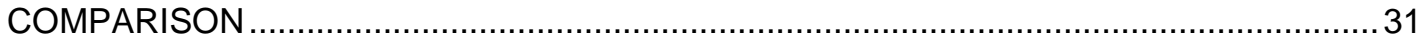

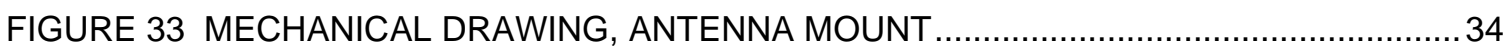

FIGURE 34 FULLY ASSEMBLED PHASED ARRAY IN ANECHOIC CHAMBER ........................35

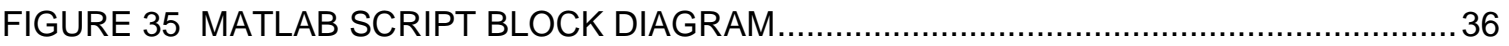

FIGURE 36 CO-POL H-PLANE RADIATION PATTERN, SINGLE ANTENNA ELEMENT ...........38

FIGURE 37 CROSS-POL E-PLANE RADIATION PATTERN, SINGLE ANTENNA ELEMENT ..39

FIGURE 38 CROSS-POL H-PLANE RADIATION PATTERN, SINGLE ANTENNA ELEMENT ... 39

FIGURE 39 CO-POL E-PLANE RADIATION PATTERN, SINGLE ANTENNA ELEMENT ........... 40

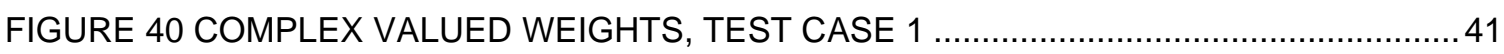

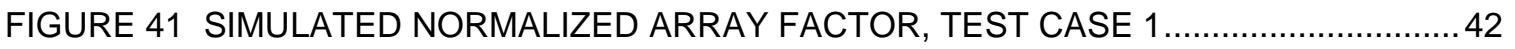

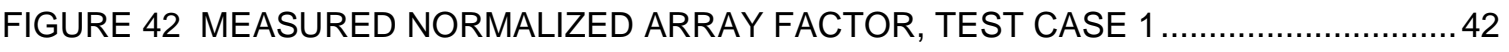

FIGURE 43 MEASURED RADIATION PATTERN (DBI), TEST CASE 1 ................................... 43 


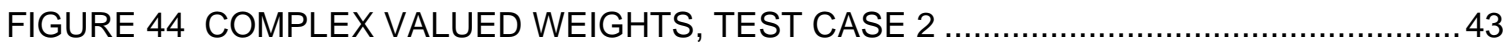

FIGURE 45 SIMULATED NORMALIZED ARRAY FACTOR, TEST CASE 2 ............................... 45

FIGURE 46 SIMULATED NORMALIZED ARRAY FACTOR USING ACTUAL WEIGHTING

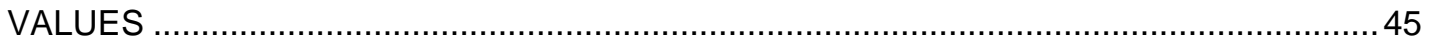

FIGURE 47 MEASURED NORMALIZED ARRAY FACTOR, TEST CASE 2 ..............................46

FIGURE 48 MEASURED RADIATION PATTERN (DBI), TEST CASE 2 …............................. 46

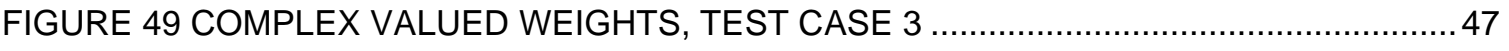

FIGURE 50 SIMULATED NORMALIZED ARRAY FACTOR, TEST CASE 3..............................48

FIGURE 51 SIMULATED NORMALIZED ARRAY FACTOR USING ACTUAL WEIGHTING

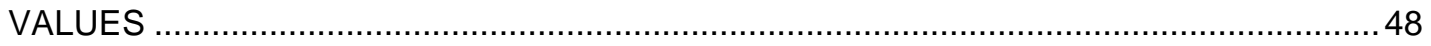

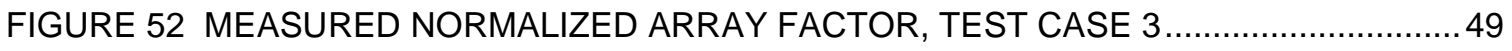

FIGURE 53 MEASURED RADIATION PATTERNS (DBI), TEST CASE 3 ............................... 49

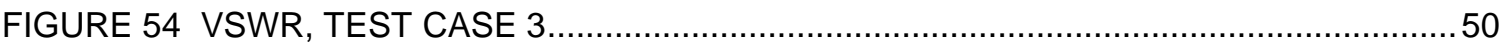




\section{Beam Shaping in Wireless Networking}

Electronic communications began via copper wire, a controlled medium with minimal interference from outside sources. Wireless technology, however, uses a common transmission medium, over-the-air communications, for multiple users, which today encounters congestion.

IEEE standard 802.11 defines specifications for consumer wireless networking and operates under FCC regulations on the ISM (Industrial Scientific Medical) S-band. Licensing is not required if maximum transmit output power is $1 \mathrm{~W}(30 \mathrm{dBm})$ and maximum effective isotropically radiated power (EIRP) is $4 \mathrm{~W}(36 \mathrm{dBm})$ (i.e.: for every $\mathrm{dB}$ of antenna gain above $6 \mathrm{dBi}$, transmitter output must be reduced by $1 \mathrm{~dB}$ ). In fixed, point-to-point operation, this requirement is reduced to $1 \mathrm{~dB}$ reduction in transmit power per 3dBi antenna gain increase.

Home routers use a contention-based system for medium sharing [1]. A router must verify the channel is clear before sending a message. If two routers verify the channel is clear and transmit any part of their messages simultaneously, both messages are lost and both routers wait a random time period before attempting to retransmit. Again, each router will verify the channel is clear before attempting to transmit. Two system commands used to prevent collisions caused by blind nodes (nodes that are in transmit range of the receiver but not the transmitter) are the Request to Send (RTS) and Clear to Send (CTS) messages [1]. In this system, the transmit device sends out an RTS, and the receiving node replies with a CTS 
acknowledging RTS receipt. The blind node will receive the CTS, but not the RTS message. Any device in range of the RTS or CTS message waits the transmission duration (contained inside the RTS and CTS messages) before attempting to transmit.

While the $802.11 \mathrm{~g}$ specification enables a contention-based shared transmission medium, interference sources can severely limit connection throughput. The standard defines 11 channels at $5 \mathrm{MHz}$ spacing, in the ISM S-band. The 11 channels (additional channels are available outside the United States) are shown in Figure 1. Because the channel bandwidth is $22 \mathrm{MHz}$, or five channels wide, access points must operate in five channel increments (five channels between center frequencies) to avoid cross-channel interference. Therefore, a maximum of three channels $(1,6,11)$ can be used without cross-channel interference [1]. If two routers operate on neighboring channels, they will perceive each other as interferers, creating co-channel or adjacent channel interference [2]. Other interference sources include microwave ovens, cordless phones, wireless game controllers, and fluorescent lights. "RF interference can be a major inhibitor to wireless [system] performance, creating security vulnerabilities and wireless network instability." [2]

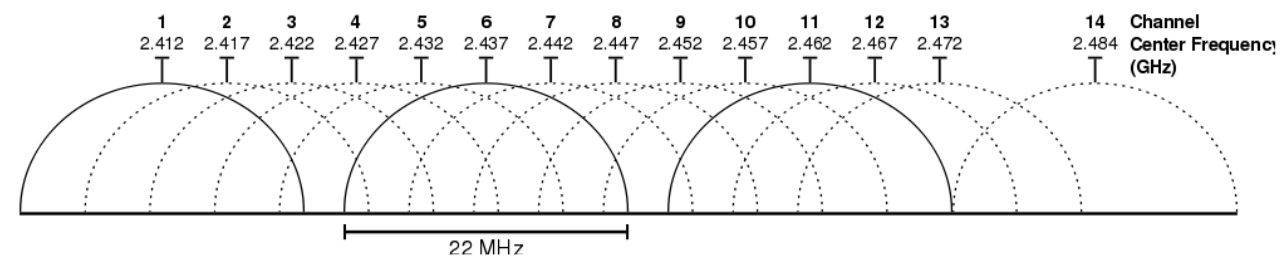

Figure 1 Overlapping Wi-Fi Channels 


\section{Solution}

Access point antenna directivity can be increased to mitigate service degradation in interfering environments. This approach can provide $10 \mathrm{~dB}$ of gain, but only doubles the access point to interferer perceived distance [2]. Table 1 defines approximate operating ranges for a few common antenna types [1].

Table 1 Antenna types and typical operating specifications

\begin{tabular}{|l|l|l|l|l|}
\hline Antenna & Type & Gain & Beamwidth & $\begin{array}{l}\text { Range (with } \mathrm{P}_{\text {TX }} \text { adhering to } \\
\text { FCC regulations) }\end{array}$ \\
\hline Dipole & $\begin{array}{l}\text { Horizontally } \\
\text { Unidirectional }\end{array}$ & $3-10 \mathrm{dBi}$ & 360 degrees & $<1$ mile \\
\hline Yagi & Directional & $12-18 \mathrm{dBi}$ & $20-30^{\circ}$ & $1-3$ miles \\
\hline Parabolic & Highly Directional & Up to $24 \mathrm{dBi}$ & 6.5 degrees & 20 miles or more \\
\hline
\end{tabular}

Yagi and parabolic antennas have a single mainlobe and are unsuitable for multiple mobile users; they are generally used for site-to-site links. To track a mobile user, these antennas are usually mechanically scanned. Beamshaping enables electronically scanned mainlobes which can track multiple users without physical repositioning. Phased array antenna service is redirected more quickly than physically adjusted antenna service.

Parabolic antennas are difficult to direct due to narrow beamwidth; another reason they are not recommended for mobile users [1]. Directional antennas rely on a narrow mainlobe and attenuation in other directions to enhance signal to noise ratio (SNR).

A phased array with sidelobe cancellation (SLC) can enhance signal to interference ratio $(\mathrm{SIR})$ by placing nulls at incident interference angles. Note that SIR and SNR can be used interchangeably; however SIR is more 
commonly used with distinct interference sources. Unlike directive antennas, phased arrays can create multiple mainlobes. Ideally, a "smart" array is employed to dynamically identify desired signal and interference incident angles. However, due to complexity and cost, "smart" arrays are outside the scope of this thesis. For more information on smart antennas, see [3].

Table 2 SLC phased array design specifications

\begin{tabular}{|l|l|}
\hline Characteristic & Value \\
\hline Frequency Range & $2.401-2.473 \mathrm{GHz}$ \\
\hline Center Frequency & Channel 6- $2.437 \mathrm{GHz}$ \\
\hline Impedance (at center frequency) & $50 \Omega$ \\
\hline Gain & $0-10 \mathrm{dBi}$ \\
\hline HPBW & $20^{\circ}<\mathrm{HPBW}<360^{\circ}$ \\
\hline Max Steering Step Size & $5^{\circ}$ \\
\hline VSWR & $<3$ \\
\hline Connector Type & $\mathrm{SMA}(\mathrm{F})$ \\
\hline Max Input Power & $29 \mathrm{dBm}$ \\
\hline
\end{tabular}




\section{System Level Design}

Phased array designs are composed of three key elements: a distribution network, weighting channels, and radiating elements. The block diagram for the phased array is shown in Figure 2.

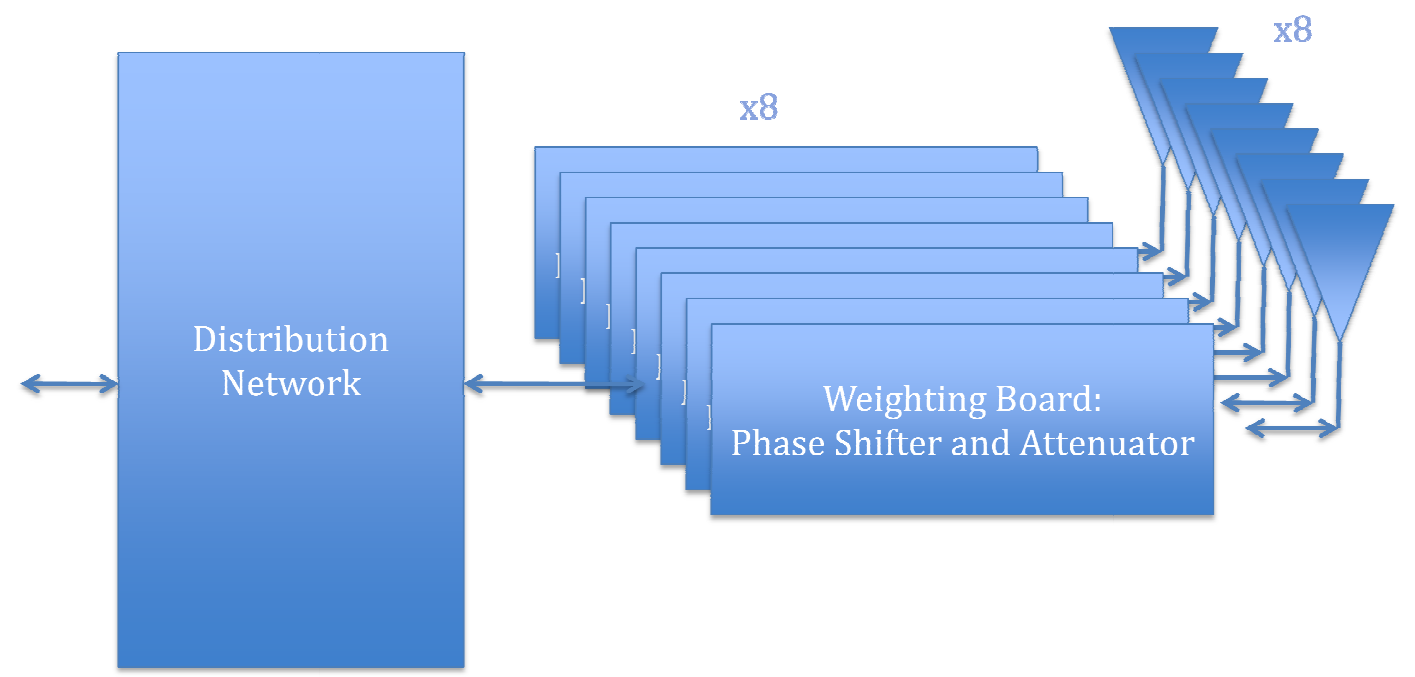

Figure 2 Block diagram of phased array

Phased antenna arrays require a feed network to distribute a signal from a single source. Common feed networks include series, corporate, and hybrid. For all but the series feed, power splitter/combiners are required. Available microwave power splitter designs include Wilkinson power dividers and branch-line and hybrid couplers. The Wilkinson power splitter/combiner offers several advantages over other designs: equal phase shift (critical), higher efficiency, and greater isolation between output ports 2 and 3. This project utilizes a corporate feed network comprised of seven Wilkinson power splitters.

Phased arrays generally require variable phase shift between elements to control mainbeam direction. SLC requires variable attenuation per element in addition to variable phase shift. Therefore, each weighting board 
is composed of a phase shifter and attenuator. Weighting boards are positioned between the distribution network and radiating elements. The project utilizes $\mathrm{H}$-plane omnidirectional dipole antennas since directional patterns adversely affect the array's steerability. 


\section{Wilkinson Power Splitter}

The Wilkinson power splitter includes two quarter-wave, $\sqrt{2} Z_{0}$ characteristic impedance transmission lines and a $2 Z_{0}$ resistor: see Figure 3. Because the Wilkinson power splitter is linear and symmetric, even and odd mode analysis is employed which specifies a resistor value of $2 Z_{0}$ and quarter wave transformer characteristic impedance of $\sqrt{2} Z_{0}$. With these specifications, each network port is matched to $Z_{0}$. For forward splitter operation, power at port 1 is evenly split between ports 2 and 3 with equal phase. Equal amplitude, in-phase inputs received at ports 2 and 3 are combined at port 1 . If the incident signal appears only at port 2 (or similarly: only at port 3), half the power received at the port is transmitted to port 1 , the other half is dissipated through the $2 Z_{0}$ resistor. Ports 2 and 3 are isolated.

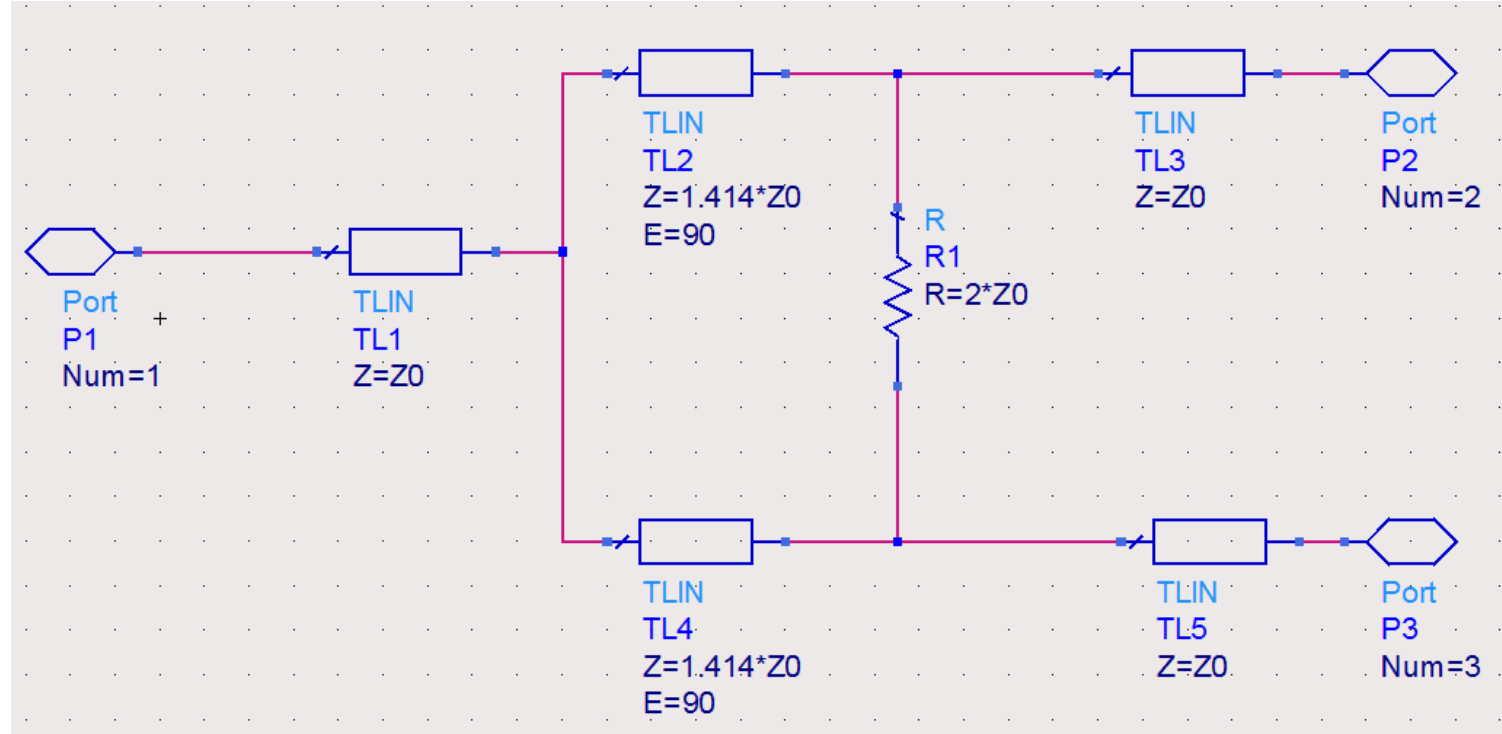

Figure 3 Wilkinson Power Splitter 


\section{Simulation}

The microstrip Wilkinson design is defined in ADS for design optimization and Gerber file export for PCB milling.

Wilkinson Power Splitter Simulation

The ADS model for a realizable Wilkinson power splitter is shown in Figure 4, while Figure 5 defines simulation and optimization parameters. Termination blocks, substrate information, and additional microstrip lines to accommodate a chip resistor and SMA connectors are all added for construction on FR-4 with 59 mil height and 4.4 relative permeability. 


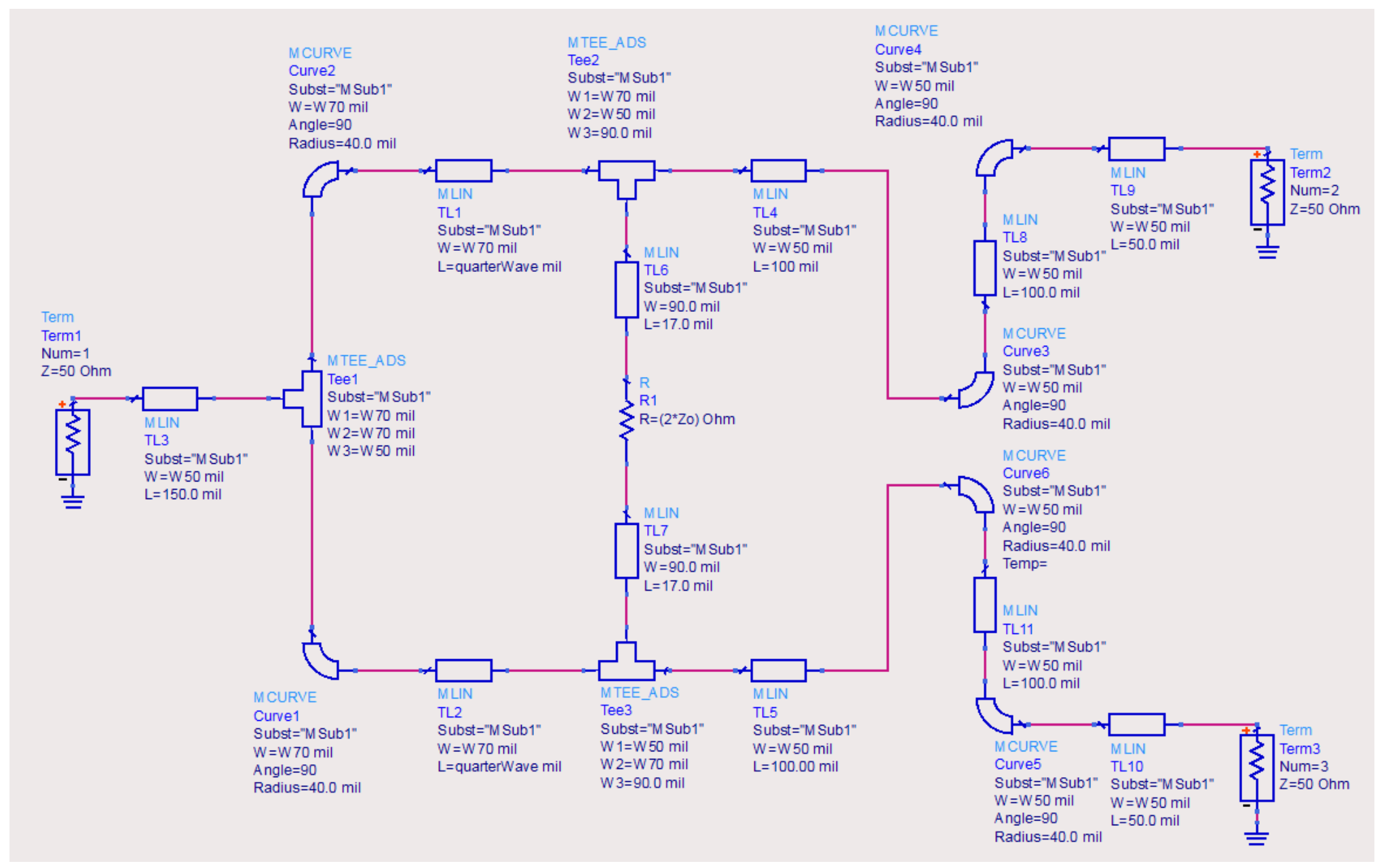

Figure 4 ADS Model of Single Stage Wilkinson Power Splitter 


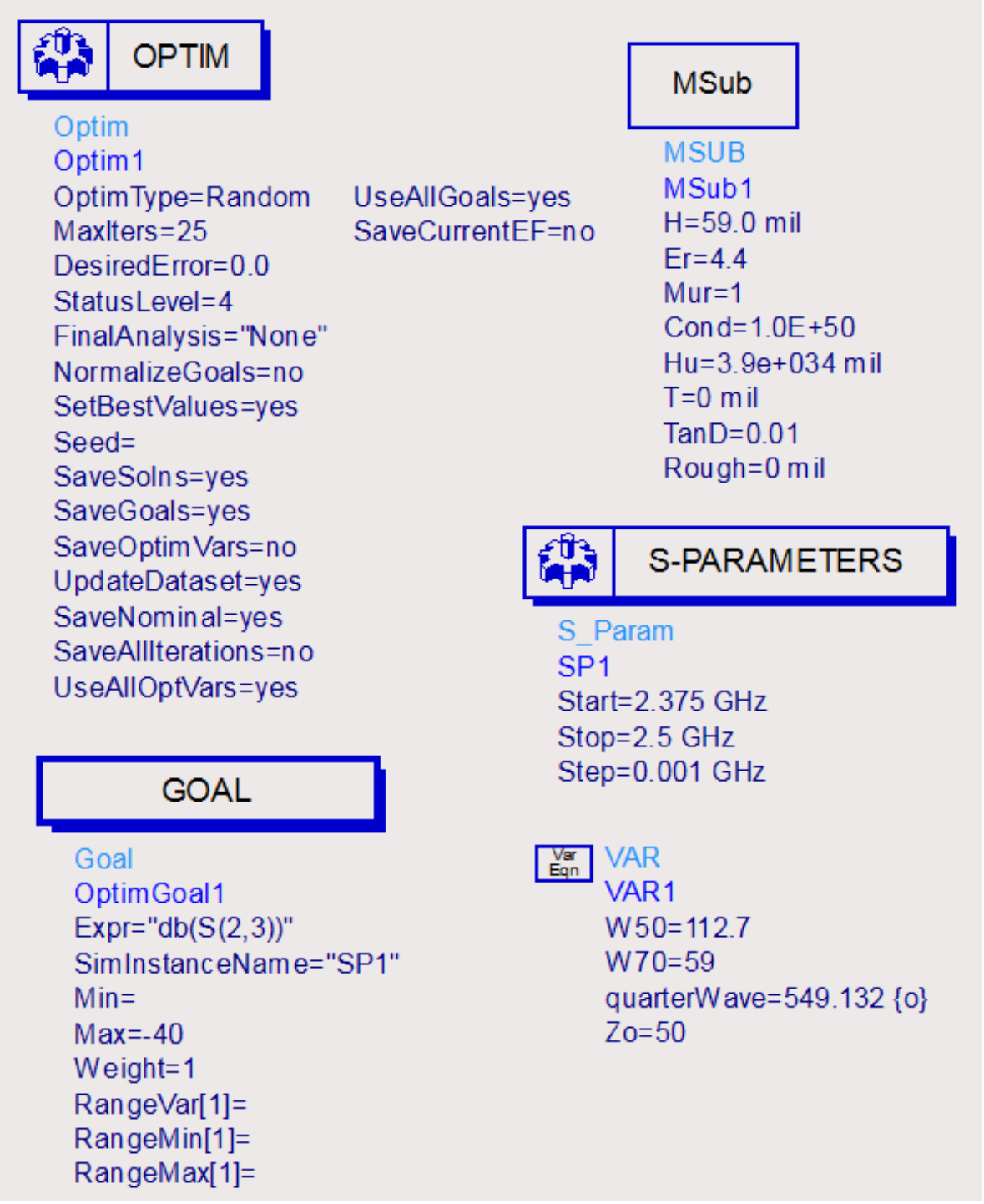

Figure 5 Microstrip Wilkinson Power Splitter, Simulation and Optimization Parameters

Simulation results indicate equal phase shift from input to both outputs, ranging from $159^{\circ}$ to $165^{\circ}$ over the WiFi band $(2.401-2.473 \mathrm{GHz})$ : see Figure 6. Forward transmission gain is $-3.1 \mathrm{~dB}$ and port 2 to port 3 isolation is greater than $40 \mathrm{~dB}$ over the entire frequency range. 


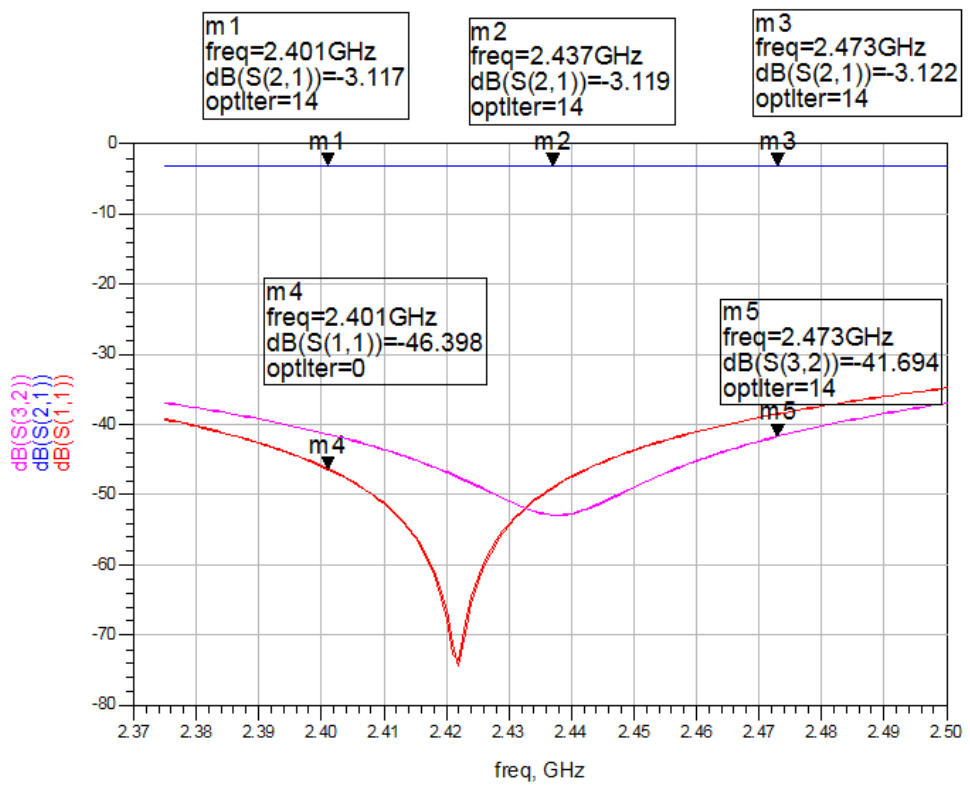

EqnVSWRin $=(1+\operatorname{mag}(S(1,1)))(1-\operatorname{mag}(\mathrm{S}(1,1)))$
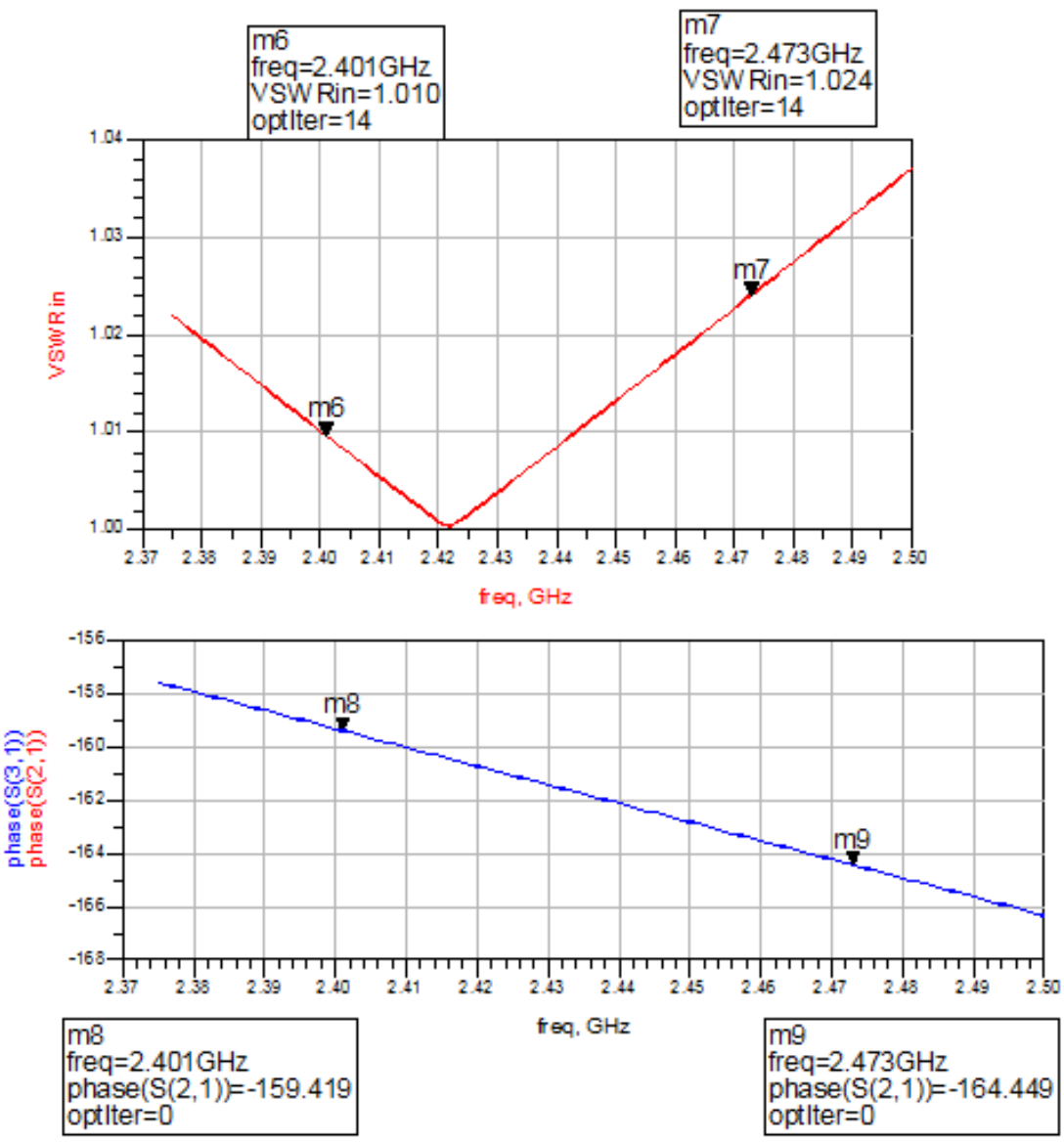

Figure 6 Wilkinson Power Splitter ADS Simulation Results 


\section{Cascaded Wilkinson Power Splitter}

Three single-stage Wilkinson dividers are cascaded to create a one-port to four-port splitter/combiner; see Figure 7. Cascaded Wilkinson power splitters decrease the number of required connectors and boards. For an 8-element array, one single-stage Wilkinson is followed by two cascaded designs. ADS simulation results are shown in Figure 8 and Figure 9. Transmission gain coefficients are $-6.3 \mathrm{~dB}$, approximately $3 \mathrm{~dB}$ greater than a single Wilkinson splitter and $0.3 \mathrm{~dB}$ less than an ideal 5 port splitter. Isolation between output ports is between $40 \mathrm{~dB}$ and $59 \mathrm{~dB}$. Figure 10 shows the phase shift between the input and each output, which exhibit equal phase delay.

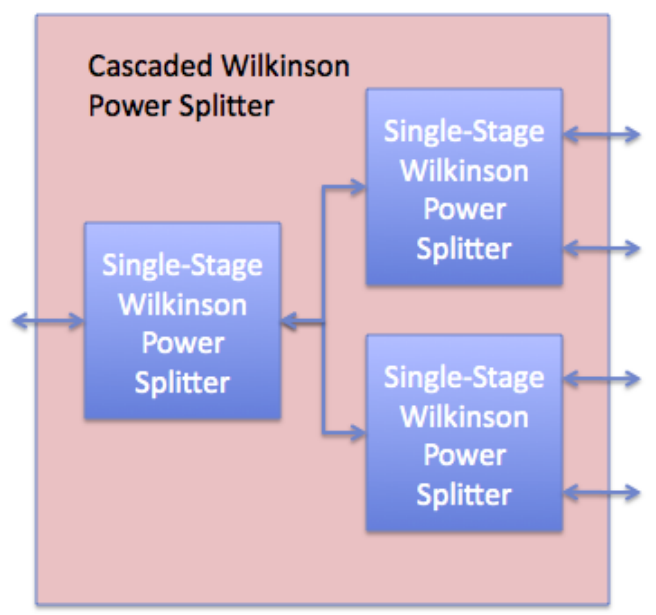

Figure 7 Cascaded Wilkinson Power Splitter Layout 

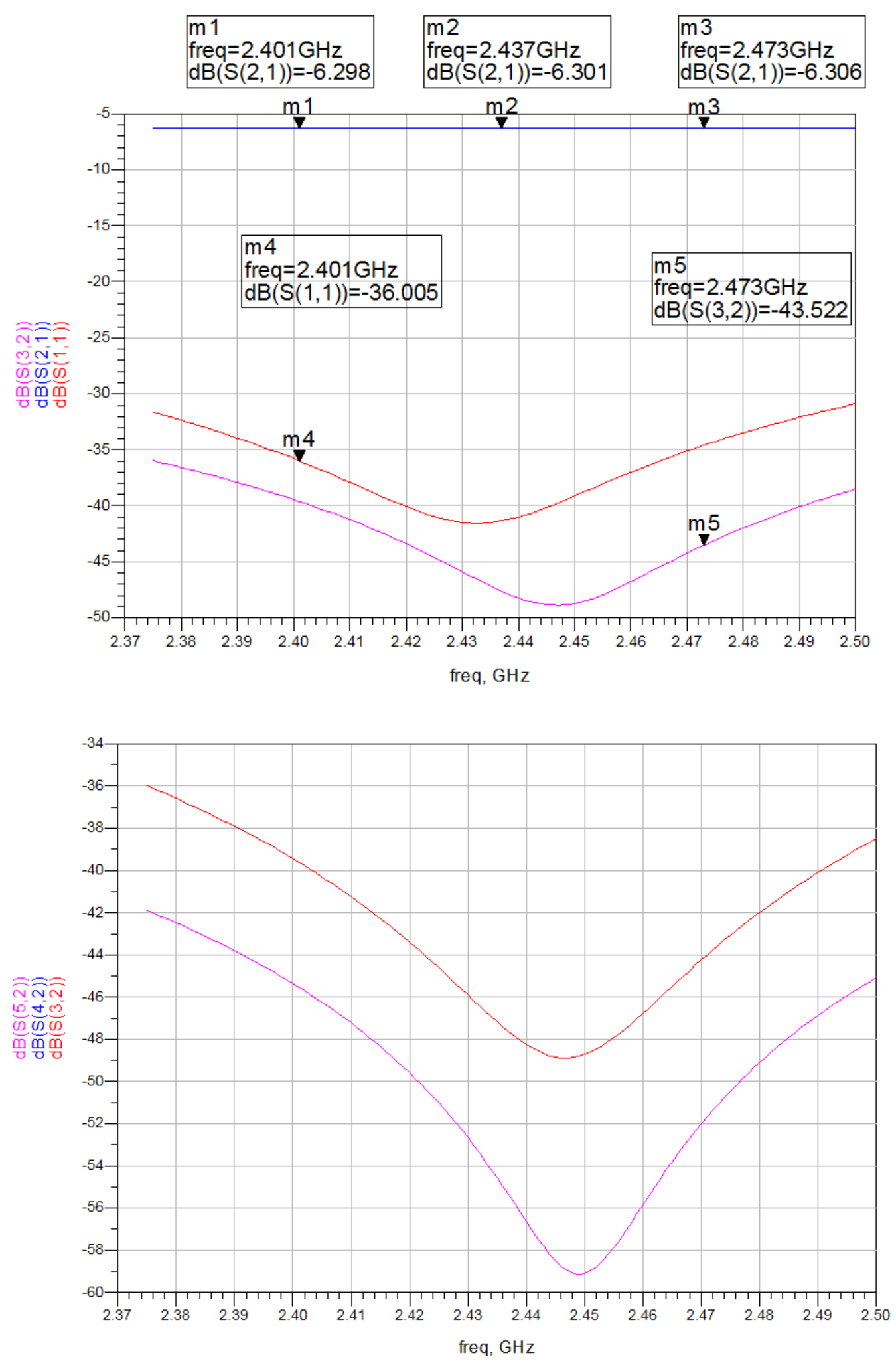

Figure 8 Cascaded Wilkinson Power Splitter VSWR and Attenuation Simulations, 


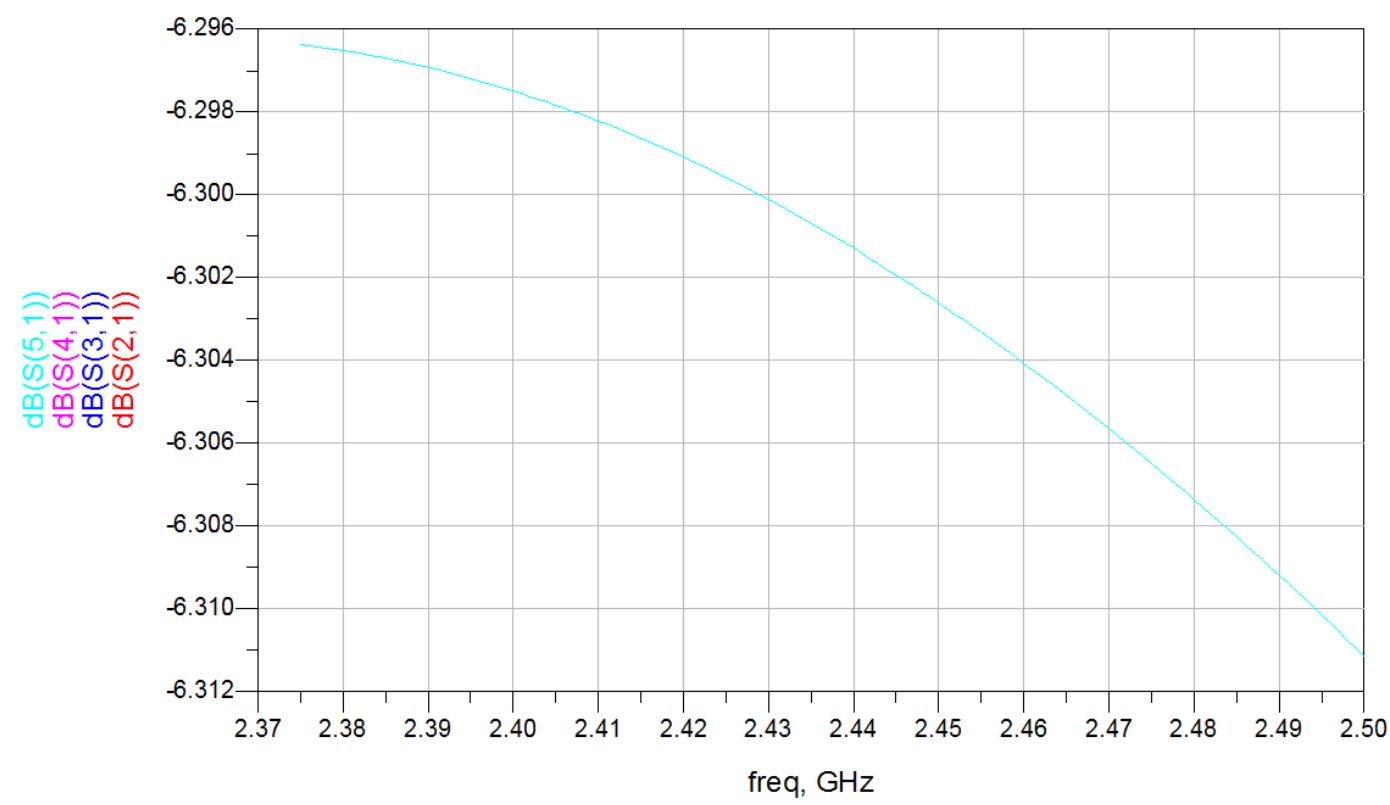

EqnVSWRin $=(1+\operatorname{mag}(S(1,1))) /(1-\operatorname{mag}(S(1,1)))$

\section{m6}

freq $=2.401 \mathrm{GHz}$

VSWRin $=1.032$ m7

freq $=2.473 \mathrm{GHz}$

VSWRin=1.038

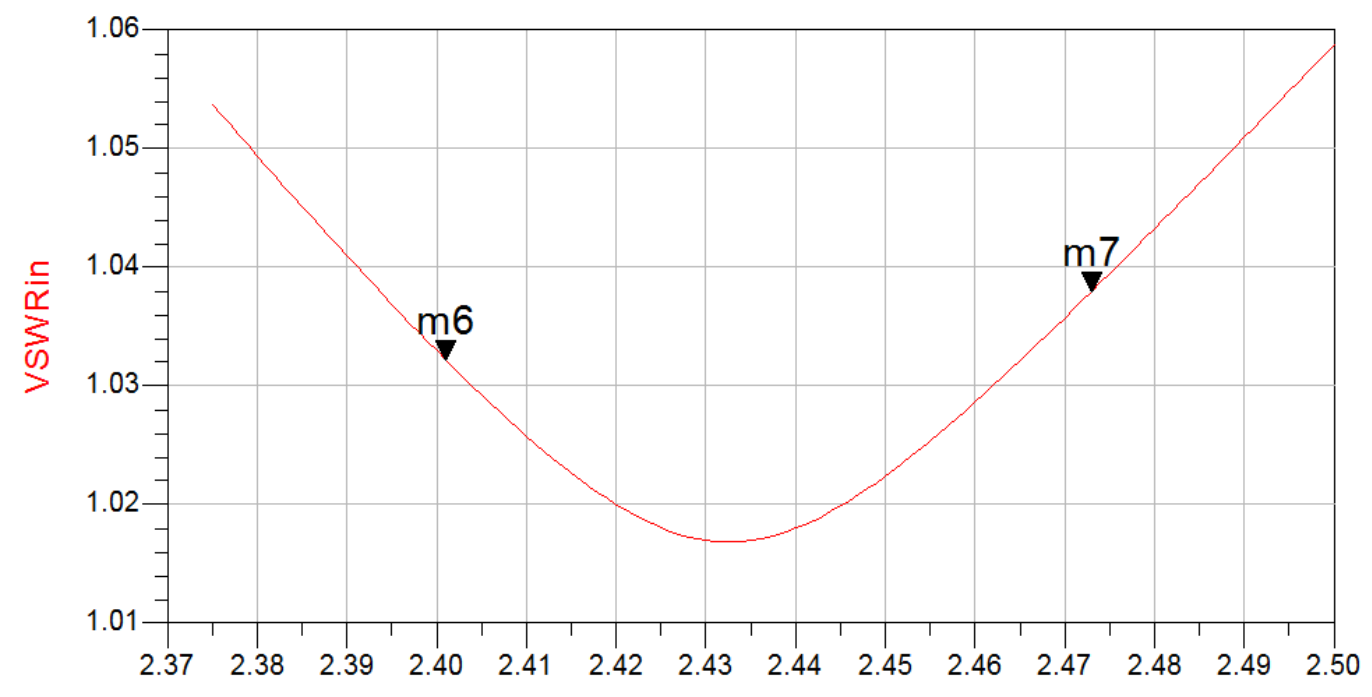

Figure 9 Cascaded Wilkinson Power Splitter VSWR and Attenuation Simulations,

2.375GHz-2.500GHz (cont'd) 


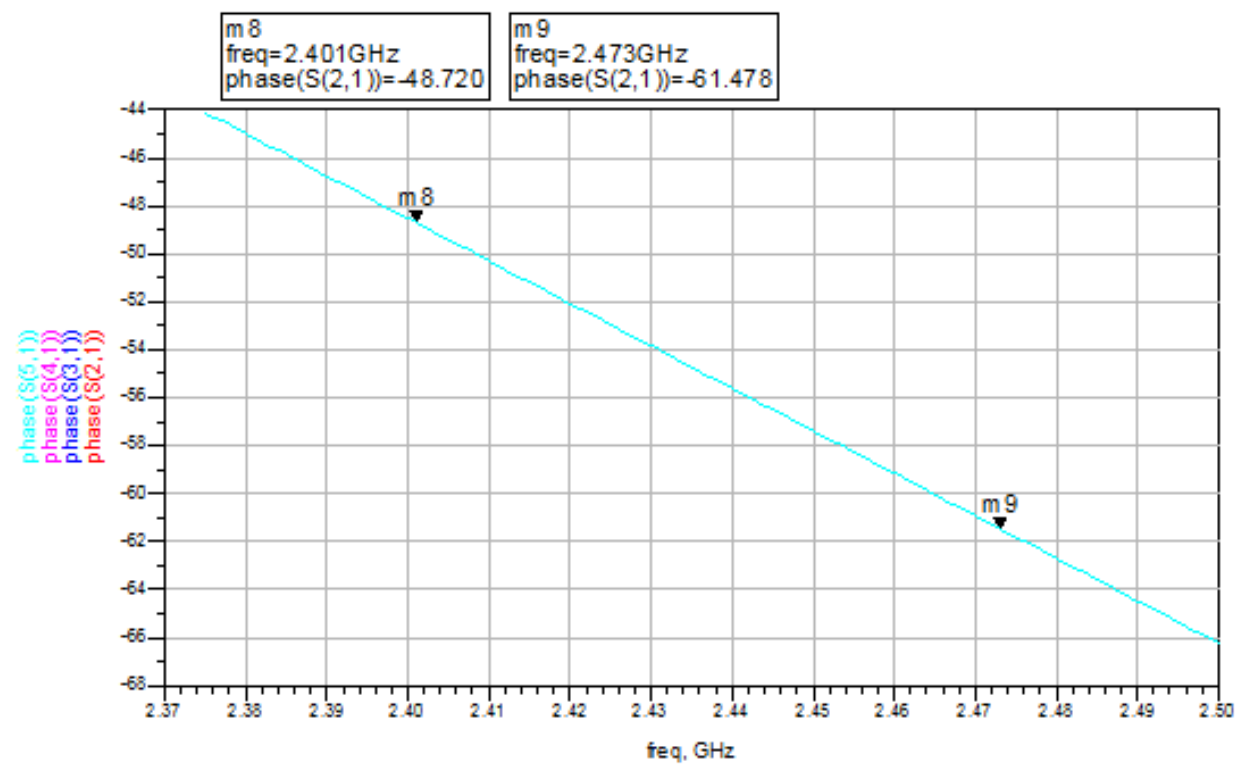

Figure 10 Transmission Phase Delays, Cascaded Wilkinson Power Splitter

\section{Wilkinson Power Splitter Results}

Both a single-stage and a cascaded 5-port splitter are characterized from 2.4 to $2.5 \mathrm{GHz}$.

\section{Single-Stage Power Splitter}

The constructed Wilkinson power splitter/combiner is shown in Figure 11. Input and output VSWR measurements are shown in Figure 12. The "stair-stepping" effect occurs because the measurement resolution approaches that of the VNA. 


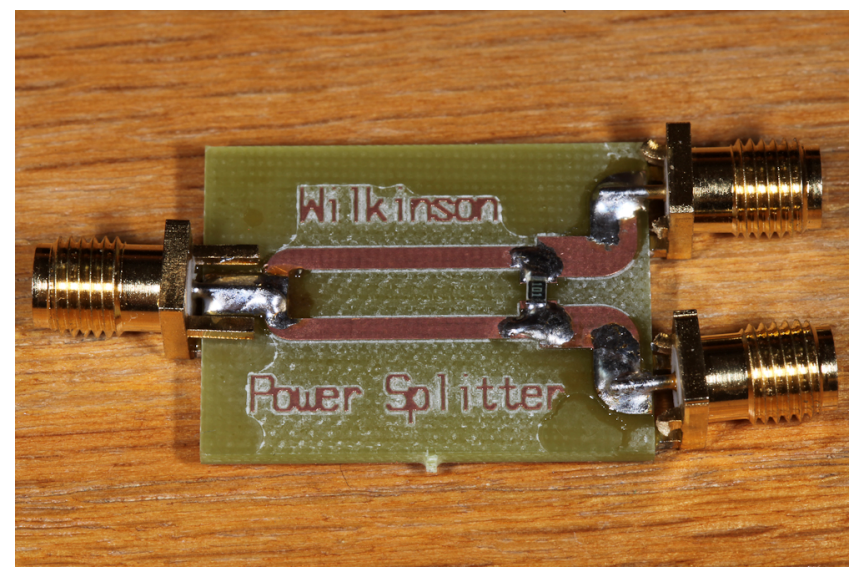

Figure 11 Constructed Single Stage Wilkinson Power Splitter/Combiner

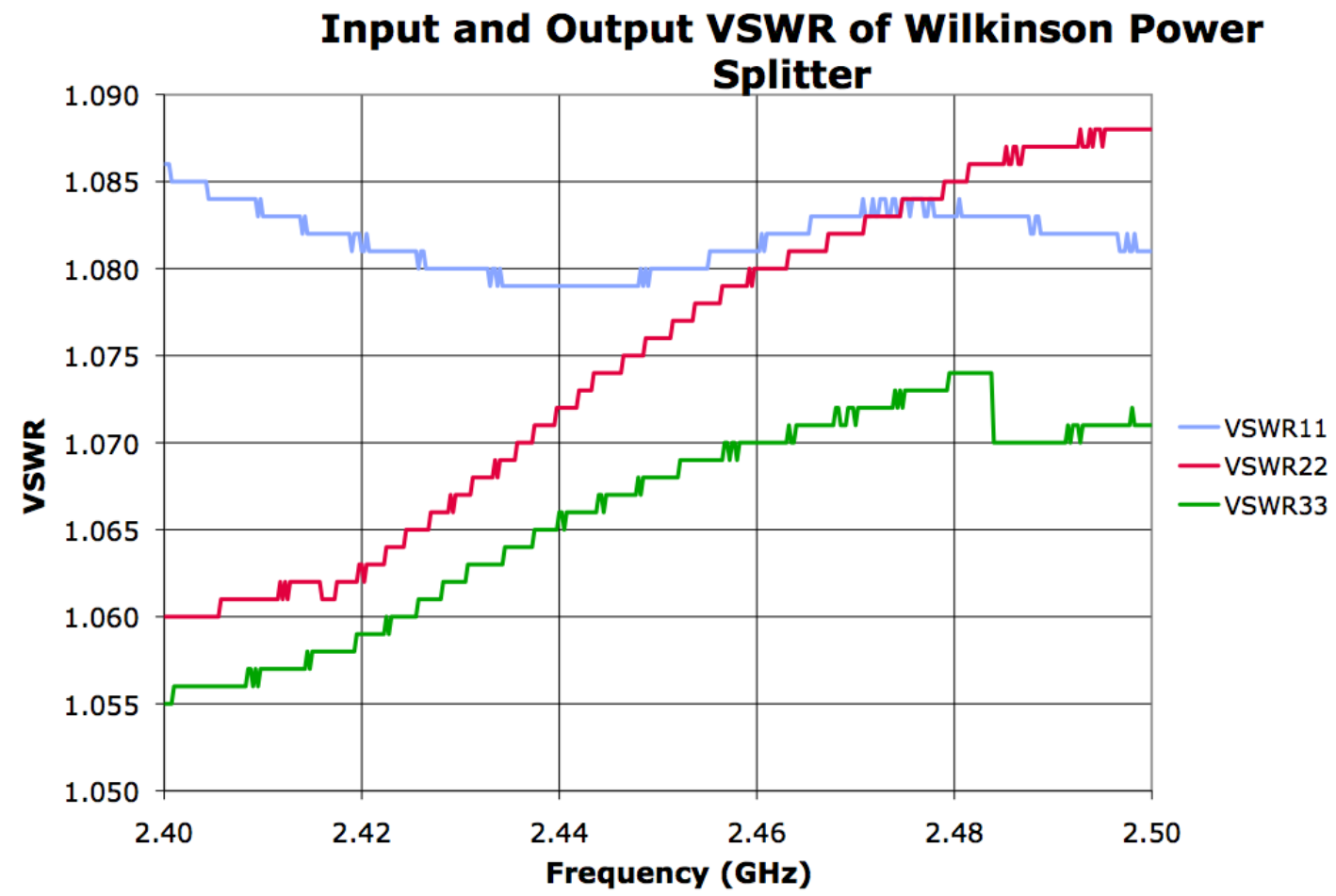

Figure 12 Wilkinson Single-Stage Power Splitter, Input and Output VSWR

Worst-case VSWR, 1.088 , occurs at port 2 at $2.5 \mathrm{GHz}$. Best-case VSWR, 1.055, occurs at port 3 at $2.4 \mathrm{GHz}$. Transmission S-parameters, including $S_{21}, S_{12}, S_{31}$, and $S_{13}$, are plotted in Figure 13, and isolation 
parameters, $S_{23}$ and $S_{32}$, in Figure 14. Forward gain ranges between

$-3.177 \mathrm{~dB}$ and $-3.589 \mathrm{~dB}$, and reverse gain between $-3.145 \mathrm{~dB}$ and $-3.525 \mathrm{~dB}$.

Measured gain was up to $0.4 \mathrm{~dB}$ less than simulated forward and reverse gains of $-3.1 \mathrm{~dB}$.

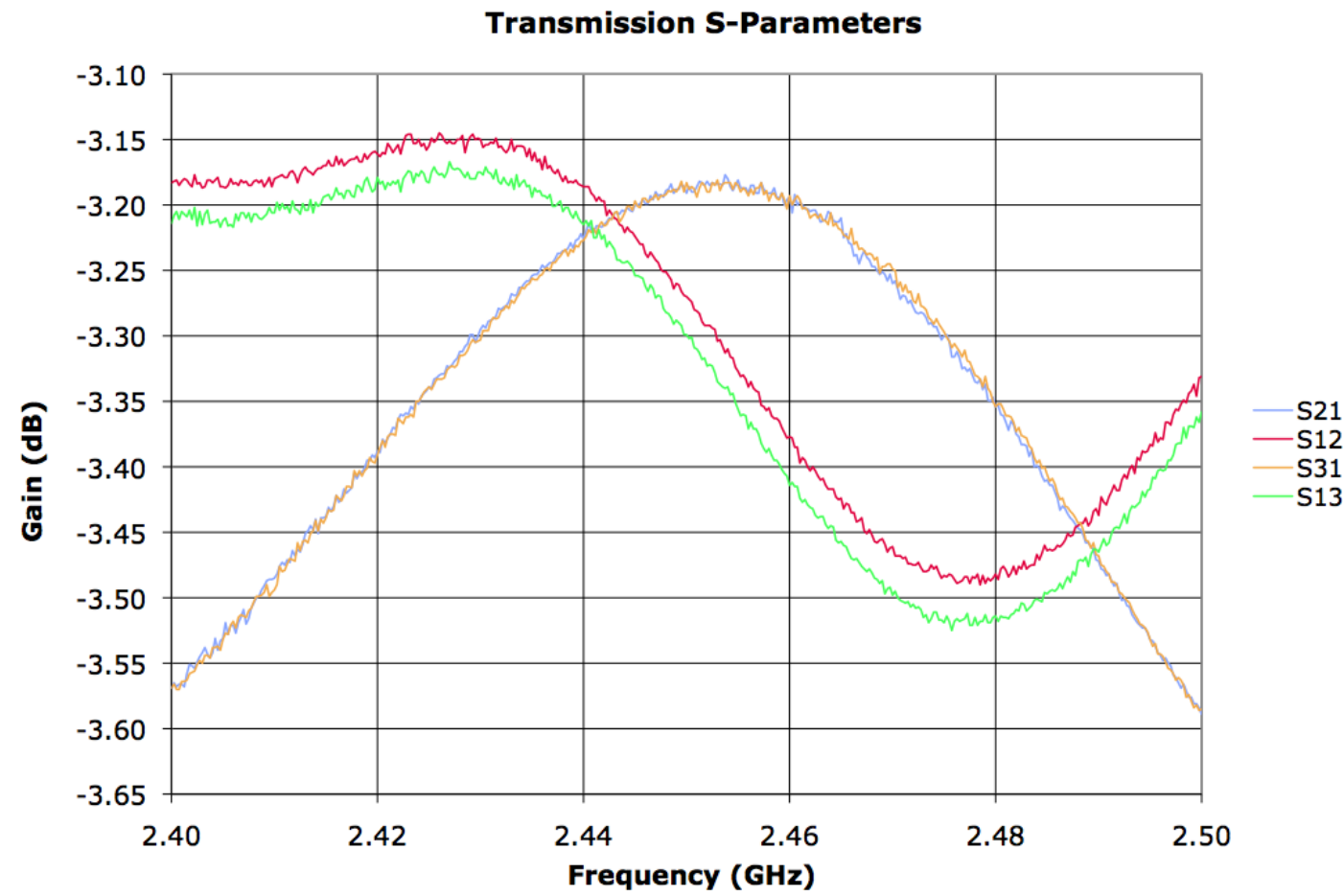

Figure 13 Transmission S-Parameters, Single Stage Wilkinson Power Divider

Figure 14 shows isolation ranges from $25.73 \mathrm{~dB}$ to $29.24 \mathrm{~dB}$ despite simulations indicating greater than $40 \mathrm{~dB}$ isolation. High isolation values are dependent on Wilkinson power splitter symmetry: an off-center chip resistor placement is the most likely cause for the discrepancy. Figure 15 shows phase shift through the power splitter from port 1 to both ports 2 and 3 and ports 2 and 3 to port 1 . In the forward direction, the difference in phase delay between ports 1 and 2 and between ports 1 and 3 at any given 
frequency is $1.12^{\circ} \pm 0.14^{\circ}$ and in the reverse direction is $0.60^{\circ} \pm 0.14^{\circ}$. This is compensated for in the final configuration with phase shifter delay.

Port 2 and 3 Issolation

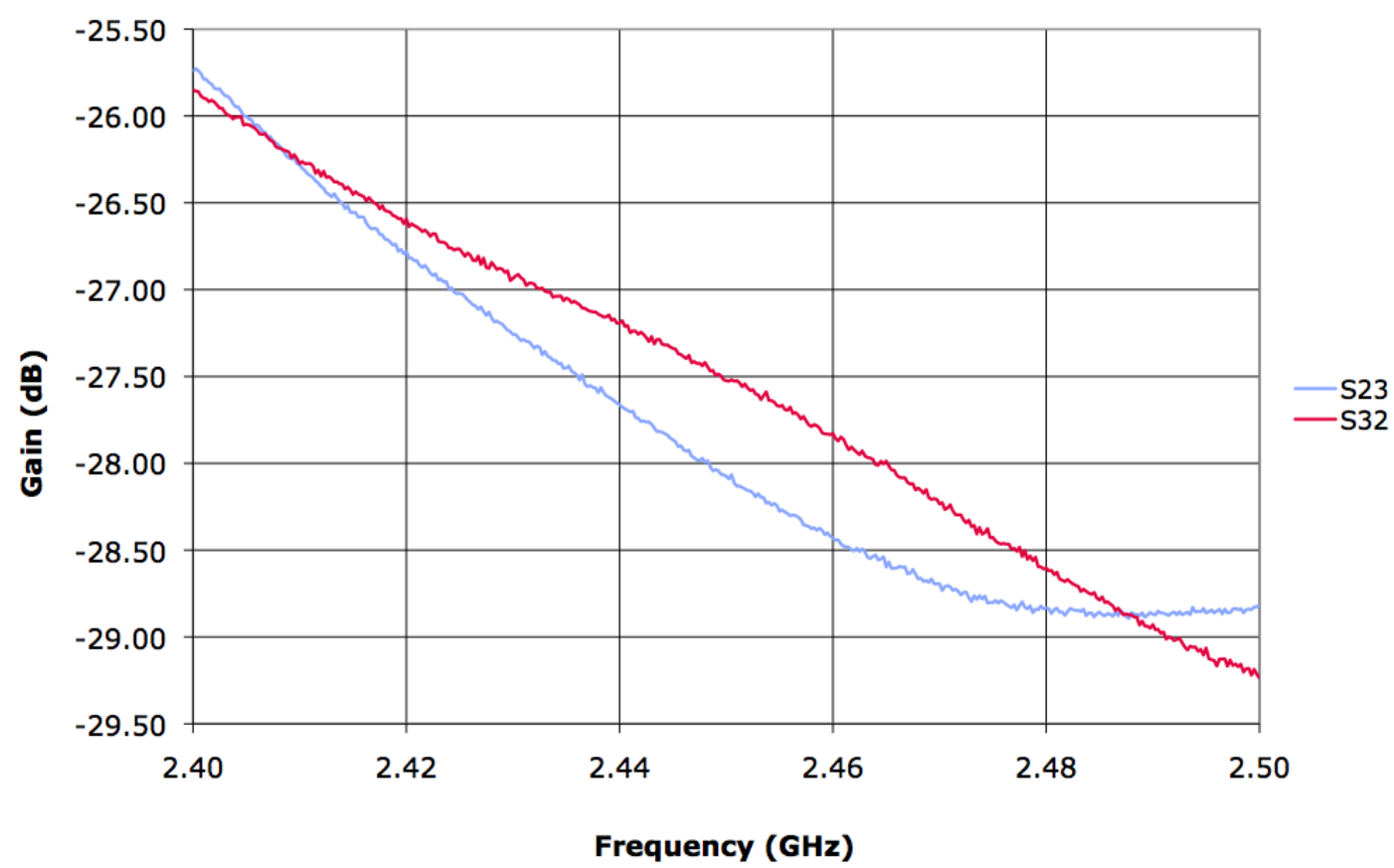

Figure 14 Isolation Measurements Between Ports Two and Three for a Single Wilkinson Power Divider 


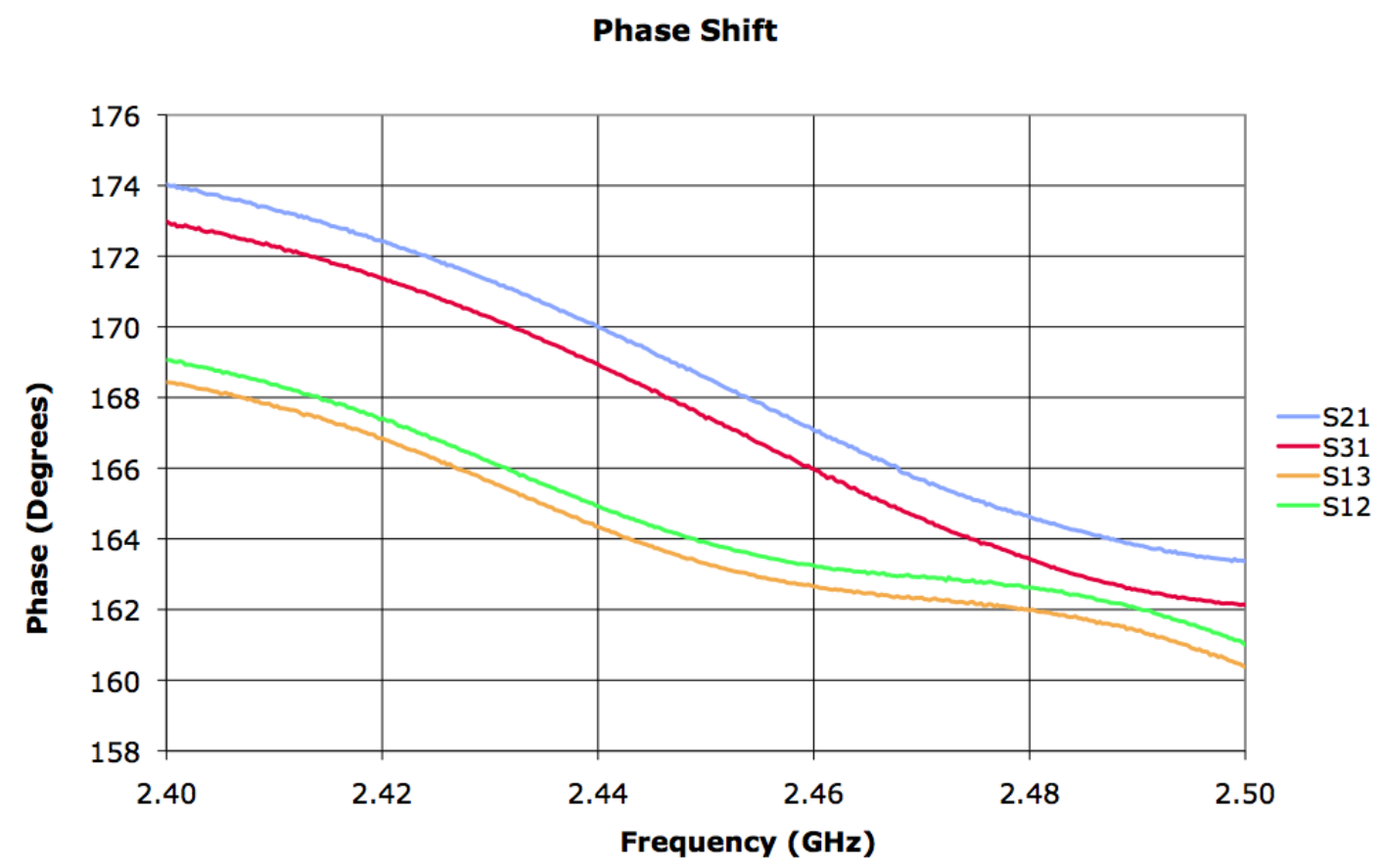

Figure 15 Phase Shift Through Single Wilkinson Power Splitter

\section{Cascaded Power Splitter}

The cascaded power splitter consists of two Wilkinson power splitters, cascaded from the outputs of a third splitter, see Figure 16. Figure 17 shows measured VSWR at each port (other ports 50 terminated). The largest VSWR, 1.25, occurs at the input port. 


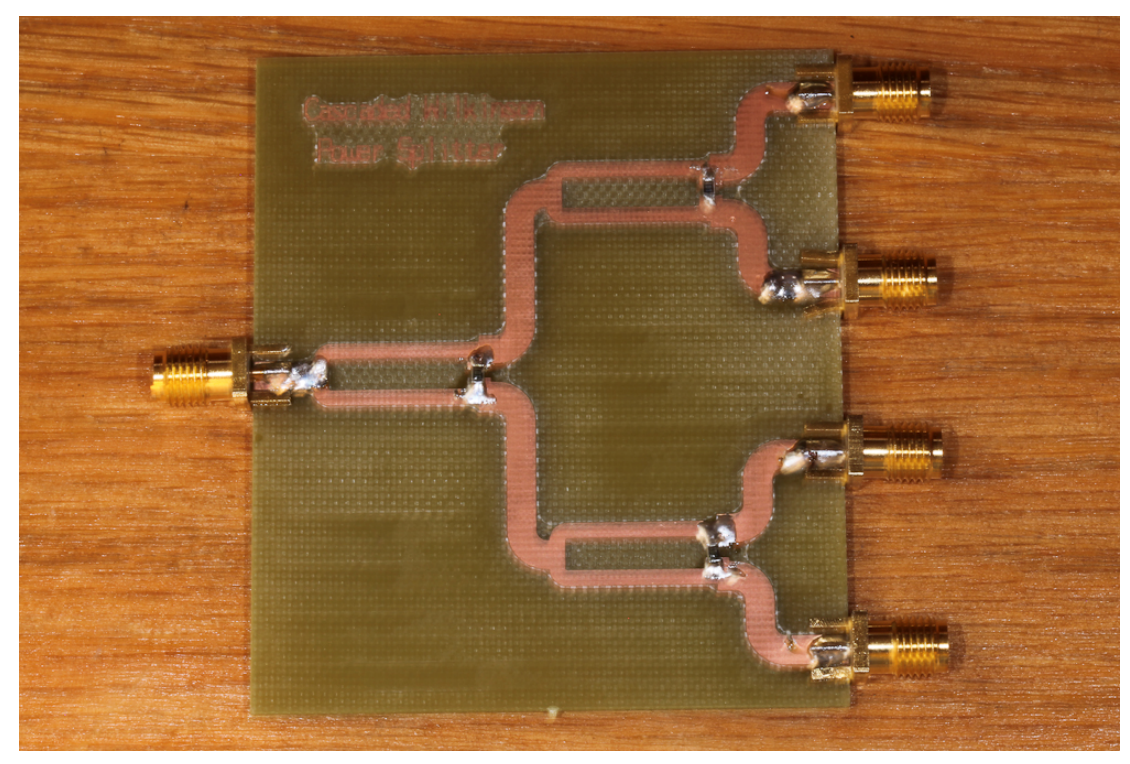

Figure 16 Constructed, Cascaded Wilkinson Power Splitter/Combiner

Cascaded Wilkinson Power Splitter VSWR

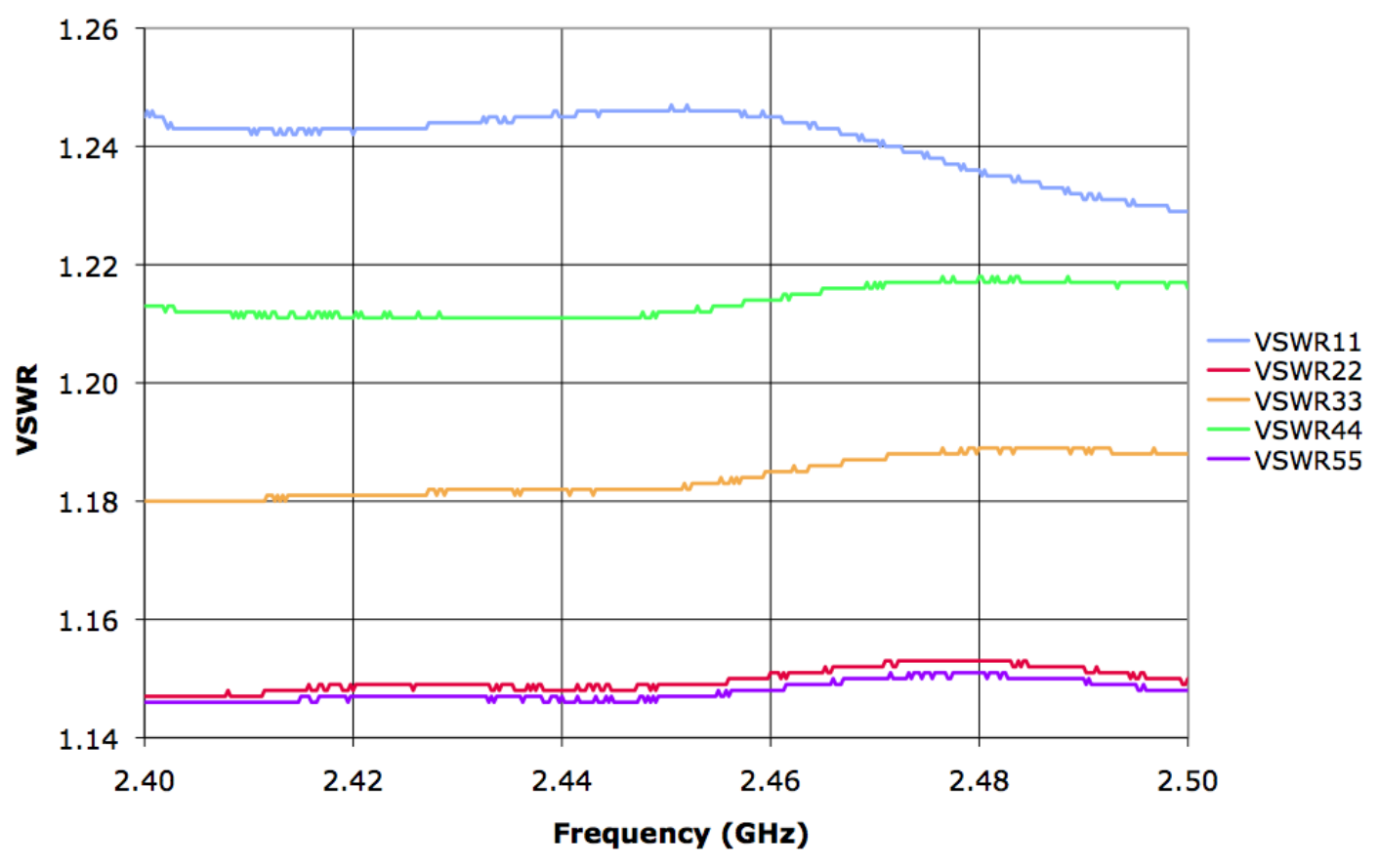

Figure 17 Cascaded Wilkinson Power Splitter Input and Output VSWRs 
Figure 18 shows cascaded Wilkinson power splitter measured forward and reverse gain. Measured results show forward IL between $-6.65 \mathrm{~dB}$ and $-7.15 \mathrm{~dB}$. Measurements are $0.3 \mathrm{~dB}-0.8 \mathrm{~dB}$ less than simulated values.

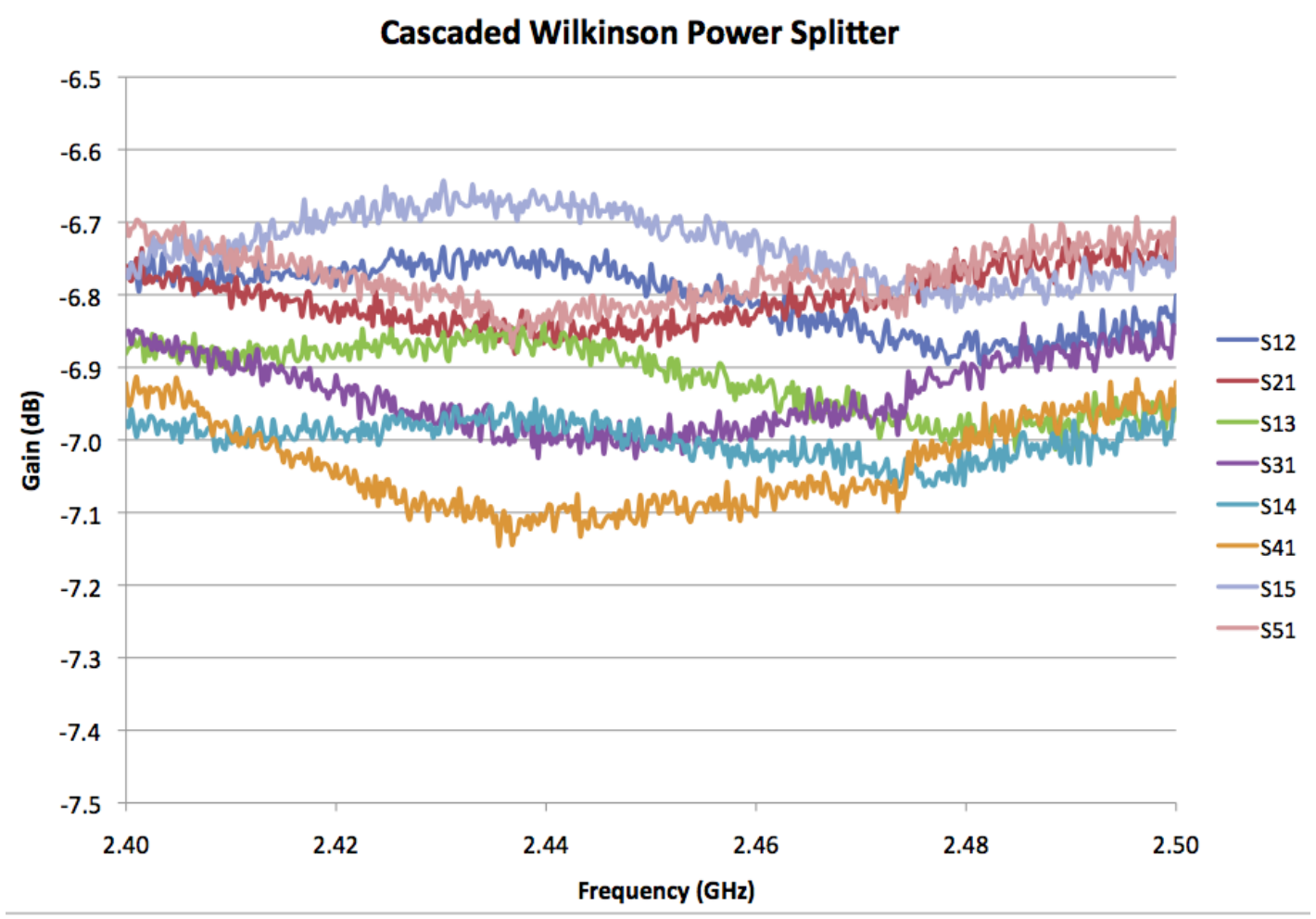

Figure 18 Transmission S-Parameters, Cascaded Wilkinson Power Splitter

Isolation measurements (Figure 19) indicate minimum 26dB attenuation between any two output ports. Minimum isolation, $26 \mathrm{~dB}$, is noted between ports 2 and 3 . Maximum isolation, $34 \mathrm{~dB}$, occurs between ports 2 and 5 , which is expected due to maximum separation distance and multiple resistors. In the cascaded configuration, the $1.12^{\circ} \pm 0.14^{\circ}$ phase shift difference observed between port 1 and each of the two output ports in the single Wilkinson power splitter increases to $2.2^{\circ} \pm 0.3^{\circ}$ in the cascaded 
power splitter, as shown in Figure 20. This difference is compensated for in the phase shifter component.

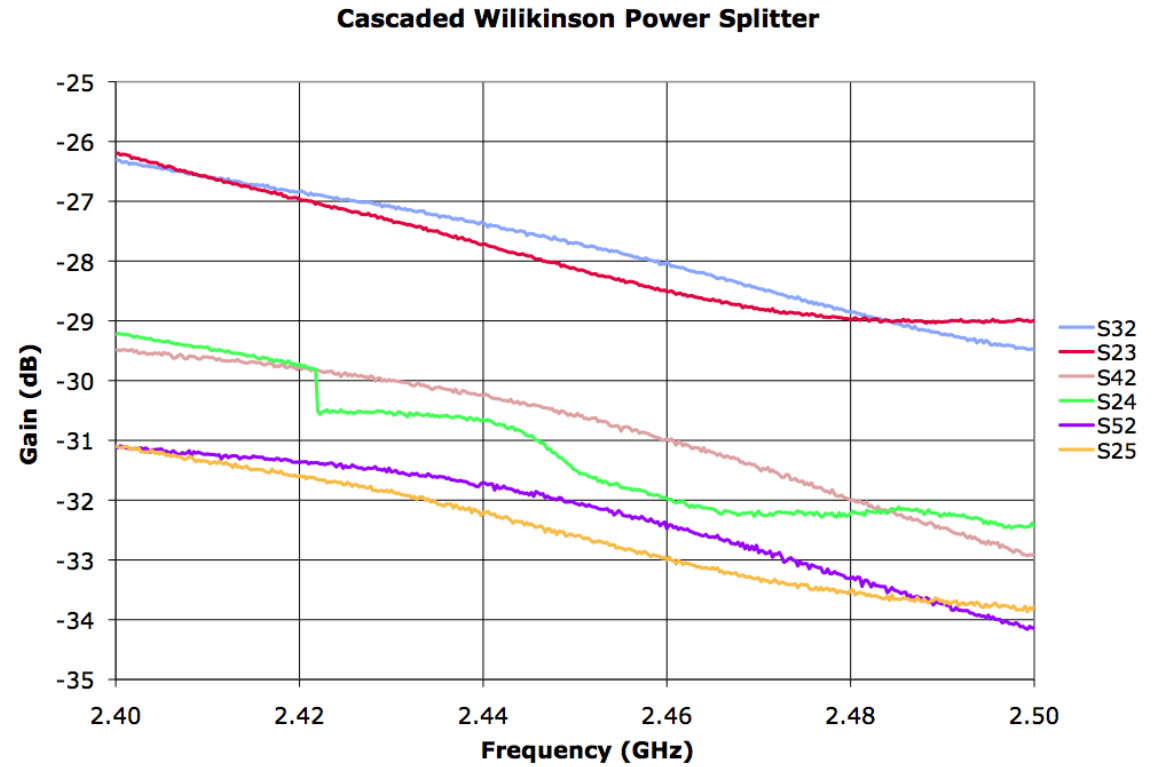

Figure 19 Isolation Measurements, Port 2 to Ports 3 Through 5

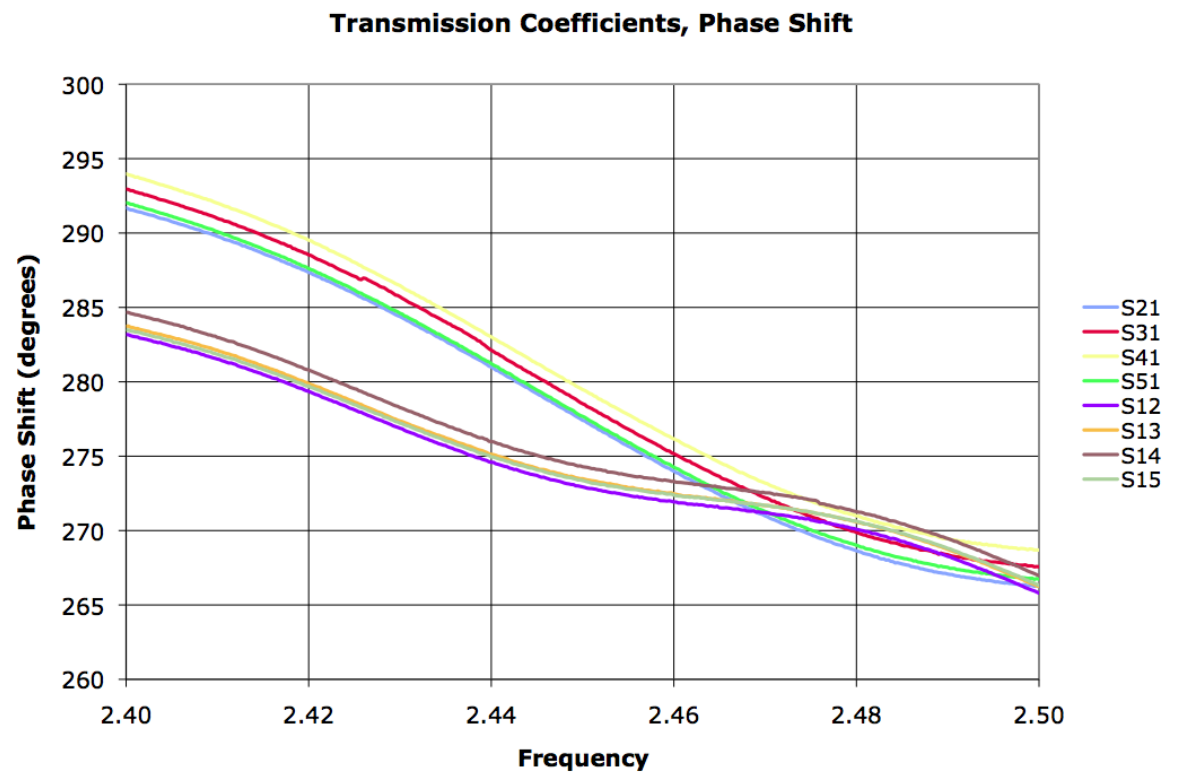

Figure 20 Phase Shift, Cascaded Wilkinson Power Splitter 


\section{Element Signal Weighting}

Each array element requires a complex valued weight to produce desired pattern maximums and nulls. Hence, each channel includes a weighting board comprised of a phase shifter and attenuator; see Figure 21.

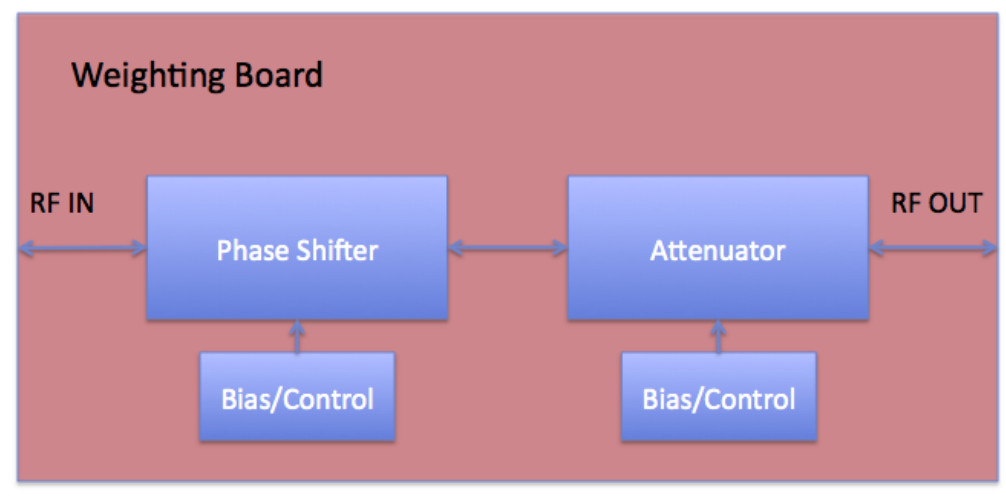

Figure 21 Block Diagram of Basic Weighting Board

\section{Phase Shifter}

The Mini-Circuits JSPHS-2484+, shown in Figure 22, is a $180^{\circ}$ maximum phase shift, J-lead, surface mount phase shifter designed to operate from $2.150 \mathrm{GHz}$ to $2.484 \mathrm{GHz}$, with a maximum input power of $20 \mathrm{dBm}$, which satisfies phased array specifications. Typical performance data for swept control frequencies is shown in Table 3.

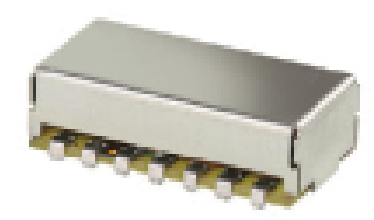

Figure 22 JSPHS-2484+ from Mini-Circuits 
Table 3 Typical Performance Data (from Mini-Circuits), JSPHS-2484+ Phase Shifter

\begin{tabular}{|c|c|c|c|c|c|c|c|c|c|}
\hline \multirow{3}{*}{$\begin{array}{c}\text { Control } \\
\text { Voltage } \\
\text { (V) }\end{array}$} & \multicolumn{3}{|c|}{$\begin{array}{c}\text { Phase Shift" } \\
\text { (Degrees) }\end{array}$} & \multicolumn{3}{|c|}{$\begin{array}{l}\text { VSWR } \\
(: 1)\end{array}$} & \multicolumn{3}{|c|}{$\begin{array}{l}\text { Insertion Loss } \\
\text { (dB) }\end{array}$} \\
\hline & 2150 & 2300 & 2484 & 2150 & 2300 & 2484 & 2150 & 2300 & 2484 \\
\hline & $\mathrm{MHz}$ & $\mathrm{MHz}$ & $\mathrm{MHz}$ & $\mathrm{MHz}$ & $\mathrm{MHz}$ & $\mathrm{MHz}$ & $\mathrm{MHz}$ & $\mathrm{MHz}$ & $\mathrm{MHz}$ \\
\hline 0.0 & 0.01 & 0.00 & 0.00 & 1.20 & 1.33 & 1.46 & 1.50 & 1.60 & 1.87 \\
\hline 1.0 & 5.06 & 4.69 & 4.22 & 1.17 & 1.31 & 1.45 & 1.51 & 1.60 & 1.85 \\
\hline 2.0 & 10.50 & 9.70 & 8.68 & 1.15 & 1.29 & 1.45 & 1.53 & 1.60 & 1.83 \\
\hline 3.0 & 17.42 & 16.05 & 14.29 & 1.12 & 1.26 & 1.44 & 1.56 & 1.60 & 1.82 \\
\hline 4.0 & 27.60 & 25.25 & 22.27 & 1.11 & 1.21 & 1.42 & 1.65 & 1.63 & 1.80 \\
\hline 5.0 & 42.79 & 38.72 & 33.71 & 1.17 & 1.15 & 1.38 & 1.83 & 1.70 & 1.80 \\
\hline 6.0 & 63.72 & 56.65 & 48.52 & 1.28 & 1.11 & 1.31 & 2.17 & 1.87 & 1.84 \\
\hline 7.0 & 89.57 & 77.62 & 65.24 & 1.41 & 1.18 & 1.21 & 2.71 & 2.16 & 1.94 \\
\hline 8.0 & 119.07 & 99.77 & 82.32 & 1.46 & 1.29 & 1.12 & 3.35 & 2.55 & 2.11 \\
\hline 9.0 & 151.83 & 122.45 & 99.06 & 1.40 & 1.38 & 1.07 & 3.97 & 2.98 & 2.34 \\
\hline 10.0 & 187.02 & 145.74 & 115.49 & 1.29 & 1.42 & 1.12 & 4.37 & 3.39 & 2.63 \\
\hline 11.0 & 222.21 & 169.98 & 135.24 & 1.27 & 1.41 & 1.20 & 4.44 & 3.74 & 2.94 \\
\hline 12.0 & 254.14 & 195.10 & 148.56 & 1.37 & 1.37 & 1.28 & 4.17 & 3.96 & 3.27 \\
\hline 13.0 & 280.85 & 220.25 & 165.52 & 1.47 & 1.32 & 1.34 & 3.74 & 4.02 & 3.57 \\
\hline 14.0 & 302.85 & 244.62 & 183.15 & 1.53 & 1.32 & 1.39 & 3.27 & 3.92 & 3.83 \\
\hline 15.0 & 320.70 & 266.91 & 201.15 & 1.53 & 1.36 & 1.41 & 2.86 & 3.70 & 4.02 \\
\hline
\end{tabular}

\section{Attenuator}

The Mini-Circuits DAT-15RS-PP was selected for its single positive power supply requirement, low cost, 50 input impedance, $20 \mathrm{dBm}$ maximum input power, and digitally controlled attenuation. The DAT-15RS-PP, (Figure 23), is a DC-4GHz digital step attenuator with $0-15.5 \mathrm{~dB}$ attenuation in $0.5 \mathrm{~dB}$ steps. The leadless design (10 mil wide pads with 10 mil pad separation) minimizes attenuation, but presents manufacturing complications.
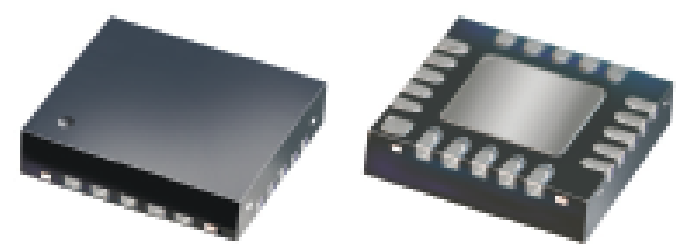

Figure 23 DAT-15RS-PP from Mini-Circuits 


\section{Layout}

The weighting board layout (Figure 24) includes one set of $50 \Omega$ microstrip lines (connecting the input to the phase shifter, attenuator, and output). All other traces accommodate DC biasing or logic.

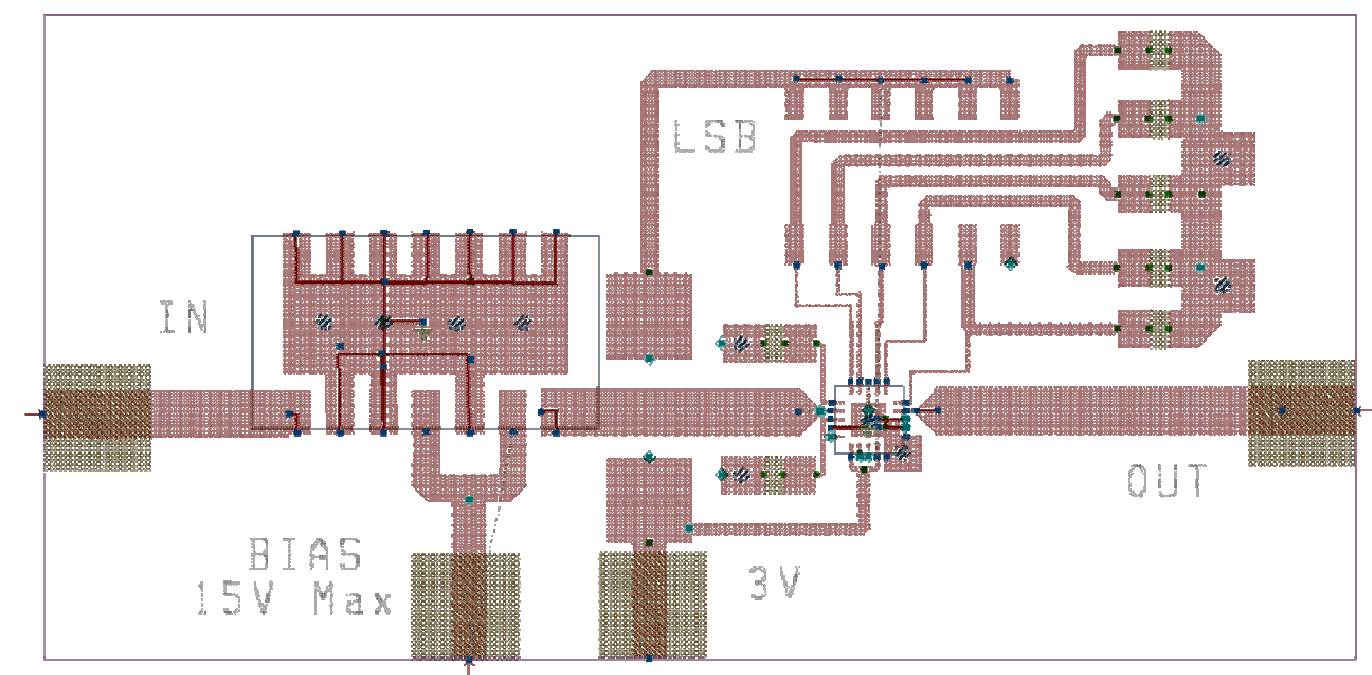

Figure 24 Weighting Board Layout

\section{Manufacturing}

Due to small pad size and inaccessible $2 \mathrm{~mm} \times 2 \mathrm{~mm}$ digital step attenuator ground pad, the board cannot be assembled using a soldering iron. Instead, a Heller reflow oven is used. A five-step process is used to attach the digital step attenuator to the PCB: 
1. Apply solder paste to pads

2. Reflow solder paste

3. Apply "tacky" paste flux (Kester TSF-6850) to the pads [3]

4. Place digital step attenuator onto pads

5. Reflow board

“Tacky" flux allows for attenuator positioning, while preventing attenuator movement when transferring the board from bench to reflow oven. Solder paste cannot be used because component movements could create solder bridges between pins.

The reflow oven houses five heating zones, with heating elements above and below the conveyer belt, except for zone 1 (one overhead element). The reflow oven's internal component layout is shown in Figure 25. The reflow oven consists of 5 zones, each zone referring to a top/bottom heating element pair. Reflow "recipes" specify temperatures for each heating zone, conveyer belt speed, and exhaust setting in cubic feet per minute (CFM). The reflow "recipe" used for the lead-free solder paste is shown in Table 4.

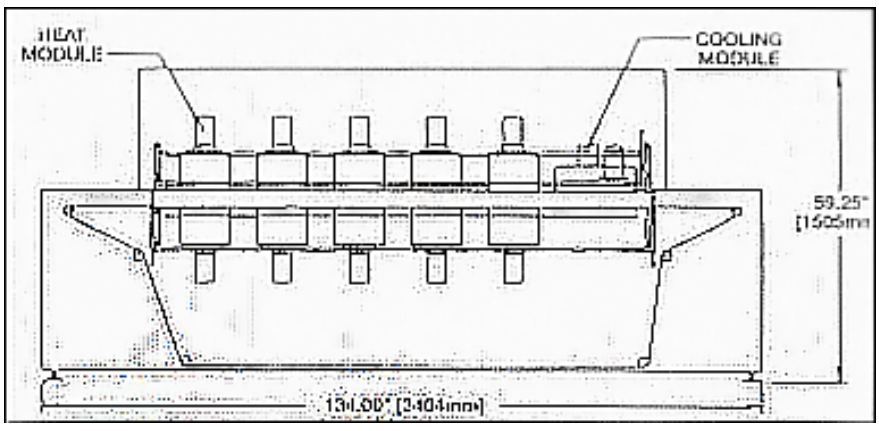

Figure 25 Reflow Oven, Internal Component Layout

Table 4 Reflow parameters used for the Heller oven

\begin{tabular}{|l|l|l|l|l|l|l|l|}
\hline & Zone 1 & Zone 2 & Zone 3 & Zone 4 & Zone 5 & Belt & Exhaust \\
\hline Top $\left({ }^{\circ} \mathrm{C}\right)$ & 165 & 150 & 185 & 220 & 260 & $30 \mathrm{~cm} / \mathrm{min}$ & $95 \mathrm{CFM}$ \\
\hline
\end{tabular}




\begin{tabular}{|l|l|l|l|l|l|l|l|}
\hline Bottom (ํㅡ) & & 150 & 185 & 220 & 260 & & \\
\hline
\end{tabular}

The completed weighting board is shown in Figure 26.

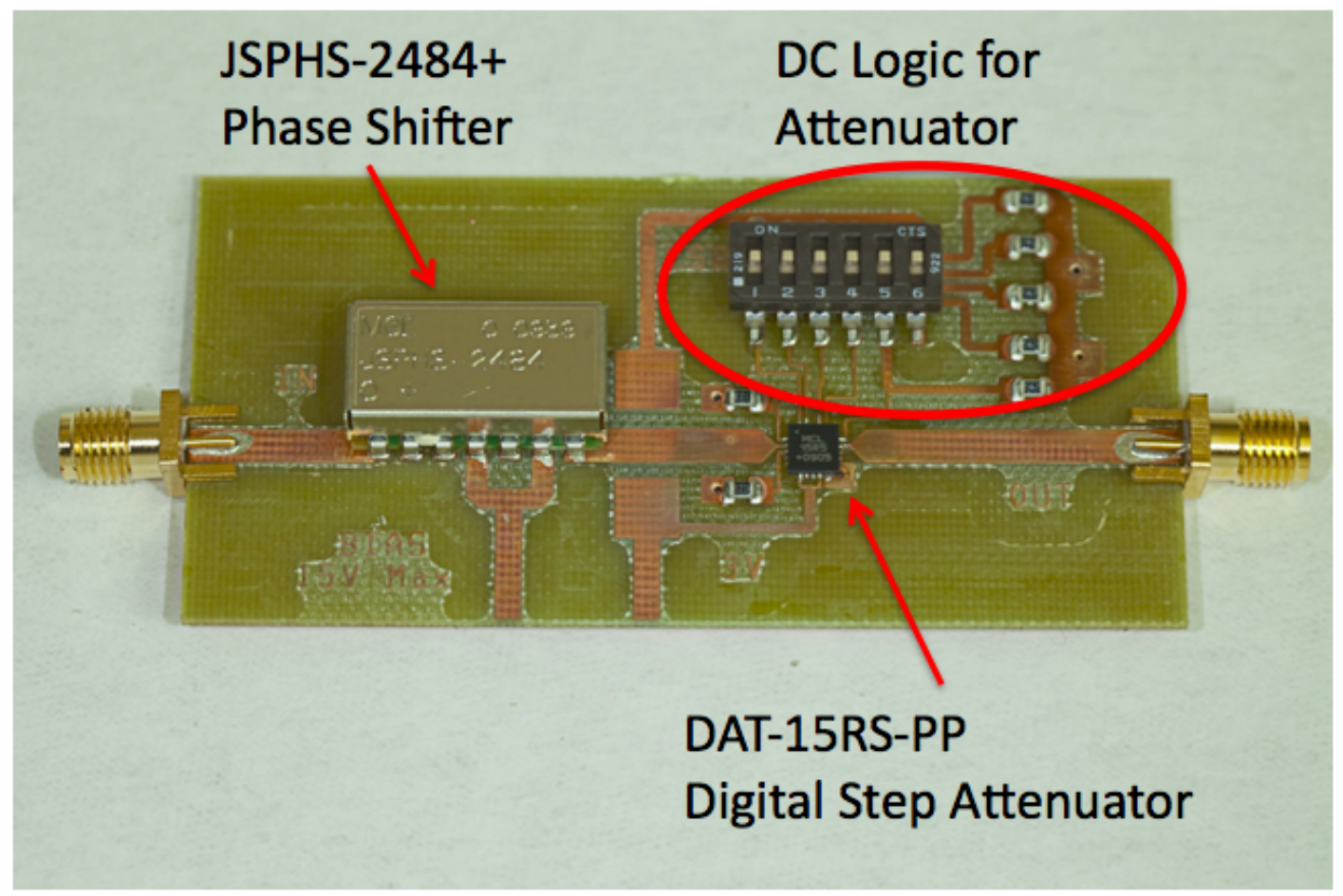

Figure 26 Assembled Weighting Board

The weighting board assembly travels through 3 stages in the reflow oven. In the first stage, the board is preheated, which allows the copper, board and components to safely reach high temperatures. As the temperature increases, the board enters the flux activation stage, where the flux is given time to clean the contacts. In the third stage, the solder reflows, creating an electrical and physical bond between components and the board. 


\section{Characterization}

An initial set of three boards was tested using 16 combinations of phase shift and attenuator settings. Bias and attenuation settings are shown in Table 5.

Table 5 Weighting Board Test Cases

\begin{tabular}{|r|r|r|r|}
\hline Test Case & Bias $(\mathrm{V})$ & Attenuation Bits & Attenuation (dB) \\
\hline 1 & 1.14 & 00000 & 0.0 \\
\hline 2 & 3 & 00000 & 0.0 \\
\hline 3 & 5 & 00000 & 0.0 \\
\hline 4 & 7 & 00000 & 0.0 \\
\hline 5 & 9 & 00000 & 0.0 \\
\hline 6 & 11 & 00000 & 0.0 \\
\hline 7 & 13 & 00000 & 0.0 \\
\hline 8 & 15 & 00000 & 0.0 \\
\hline 9 & 0 & 00001 & 8.0 \\
\hline 10 & 0 & 00010 & 4.0 \\
\hline 11 & 0 & 00100 & 2.0 \\
\hline 12 & 0 & 01000 & 1.0 \\
\hline 13 & 0 & 10000 & 0.5 \\
\hline 14 & 0 & 00000 & 0.0 \\
\hline 15 & 15 & 11111 & 15.5 \\
\hline 16 & 0 & 11111 & 15.5 \\
\hline
\end{tabular}

Figure 27-Figure 32 show test results for Board 2. Parameters of interest for all boards are shown in Table 6, Summarized Results. 


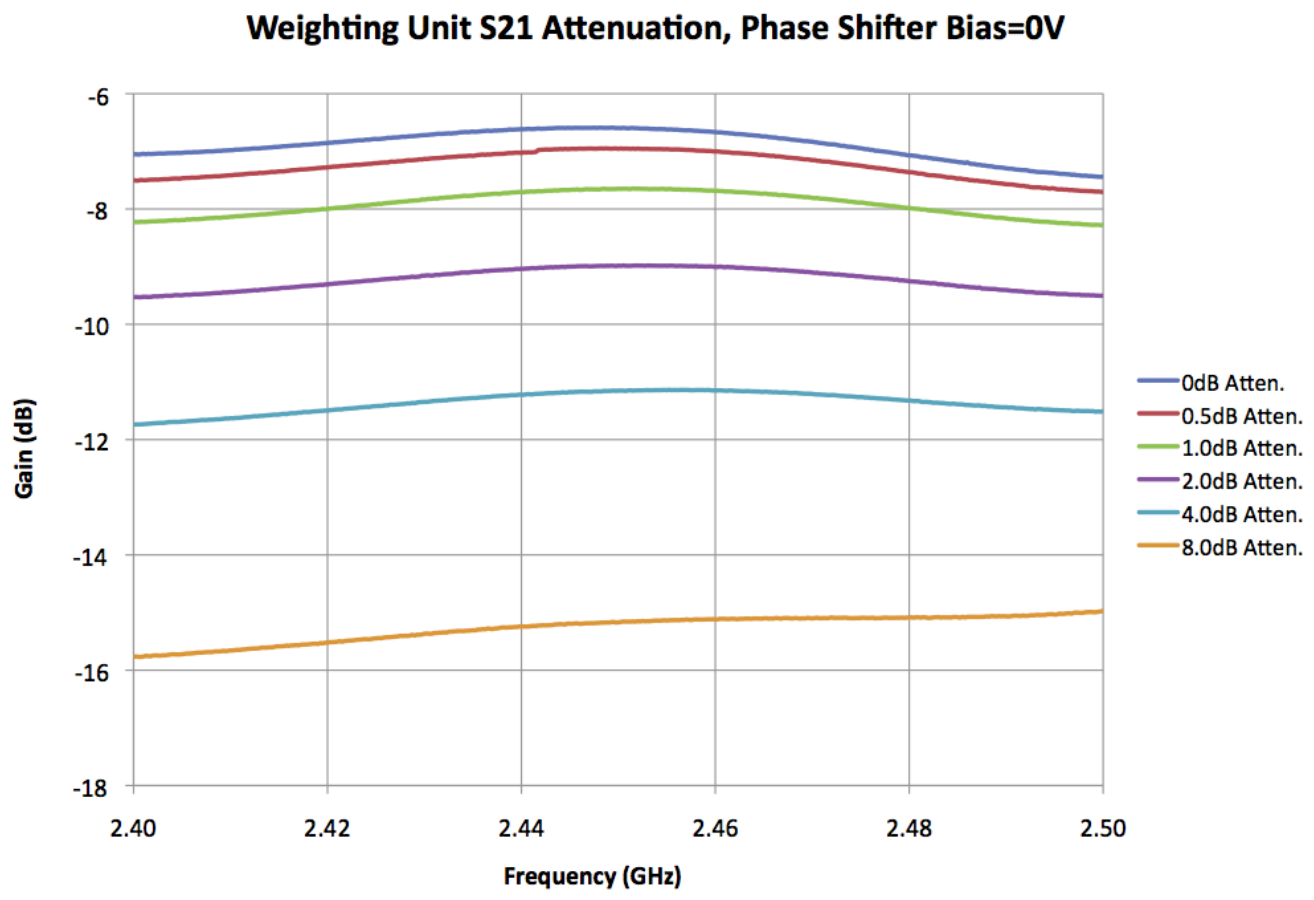

Figure 27 Weighting Board, Forward Attenuation

Weighting Unit S12 Attenuation, Phase Shifter Bias=0V

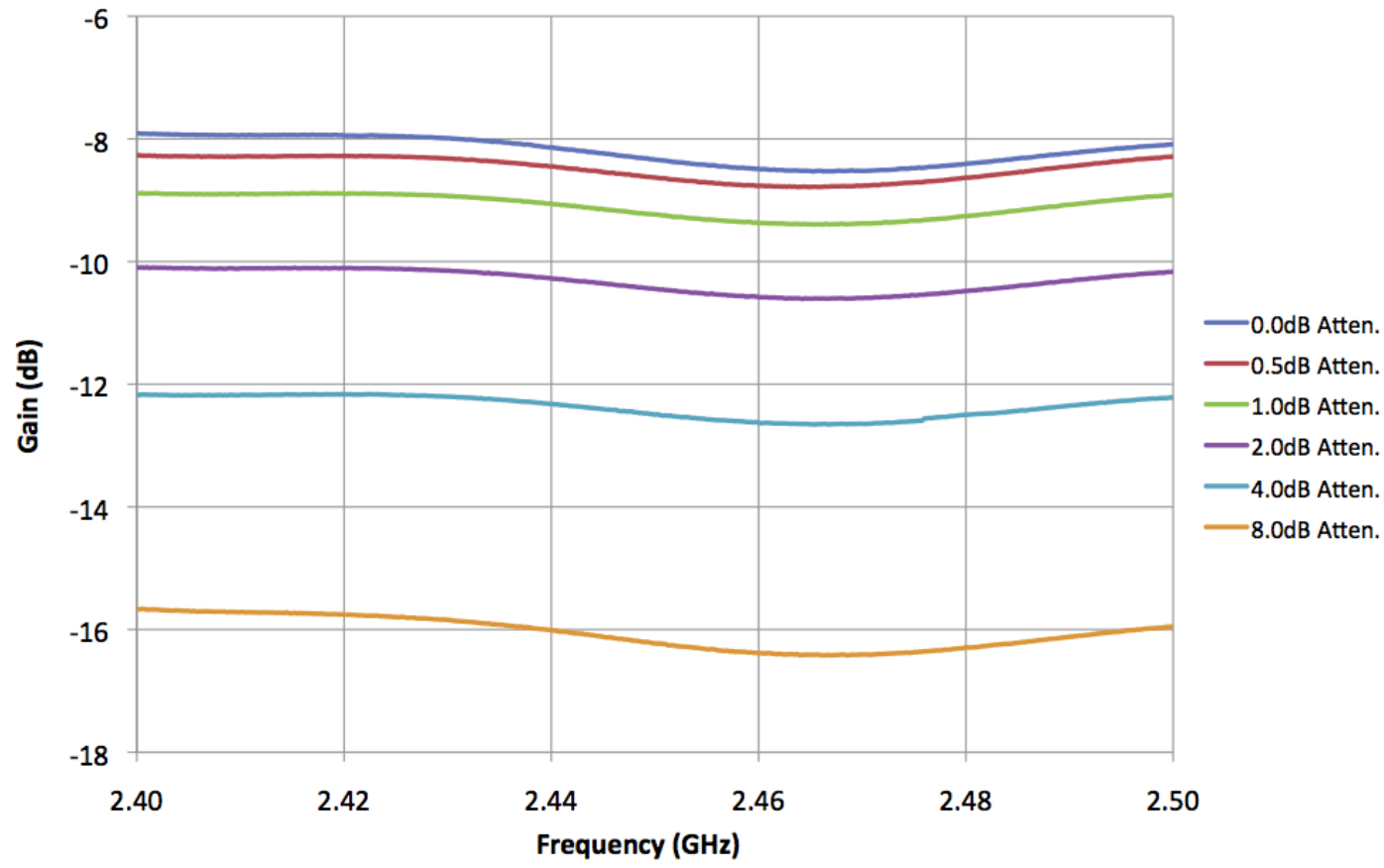

Figure 28 Weighting Board, Reverse Attenuation 
Weighting Unit S12 Phase Delay, Attenuator: 0dB

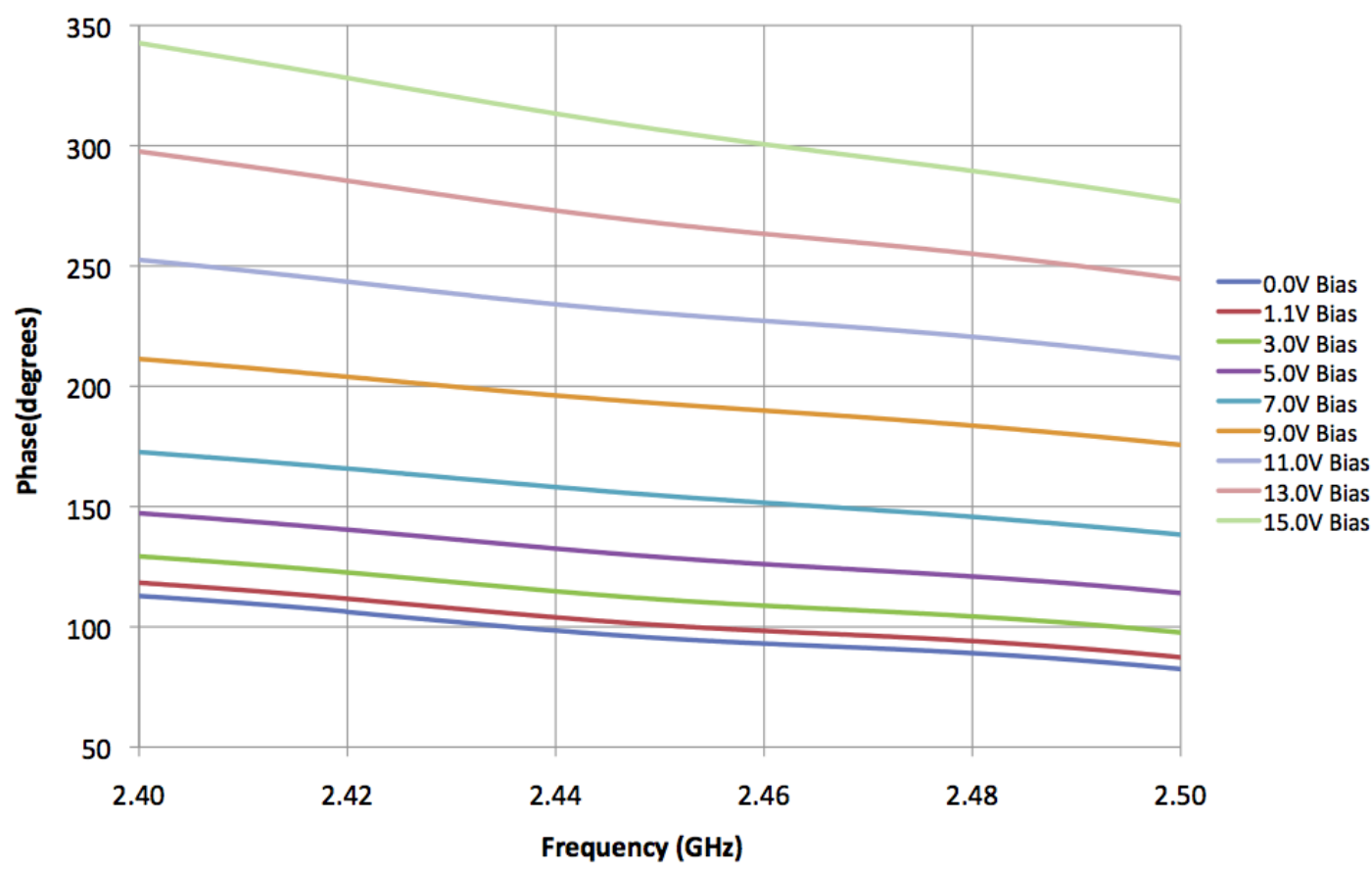

Figure 29 Weighting Board, Reverse Phase Delay

Weighting Board S21 Phase Delay, Attenuator: 0dB

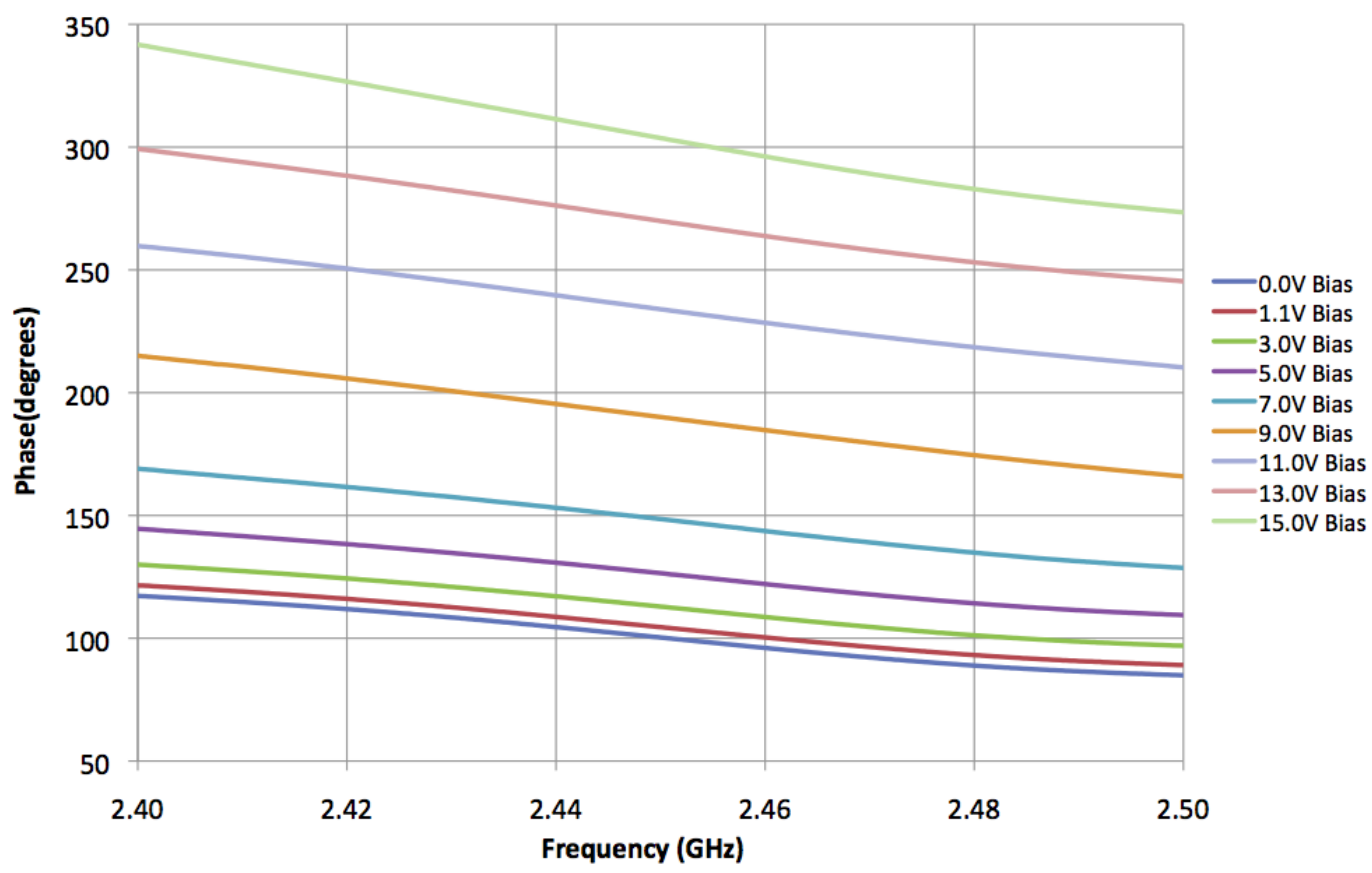

Figure 30 Weighting Board, Forward Phase Delay 


\section{Input VSWR}

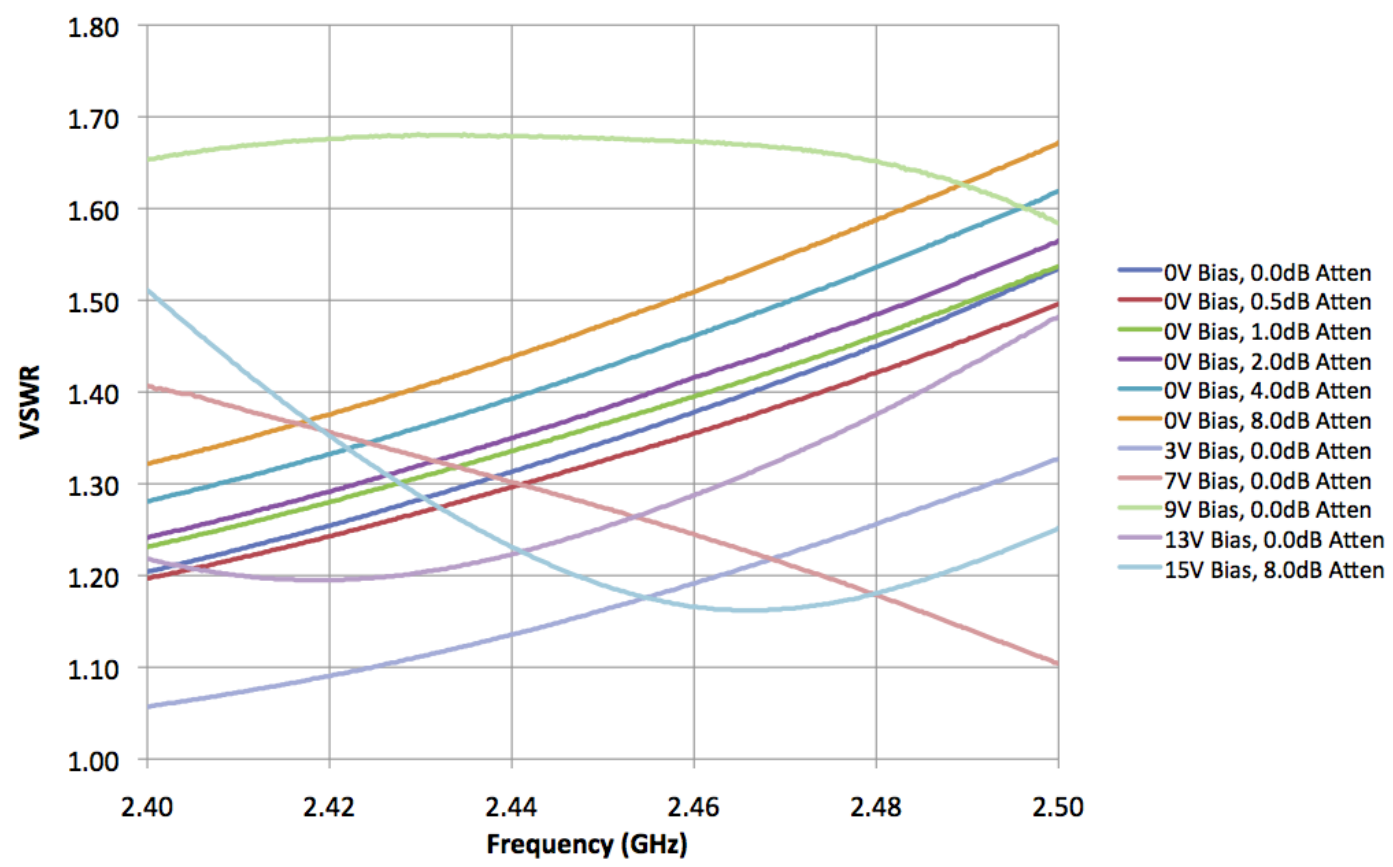

Figure 31 Weighting Board, Input VSWR

Forward and Reverse Phase Delay Comparison

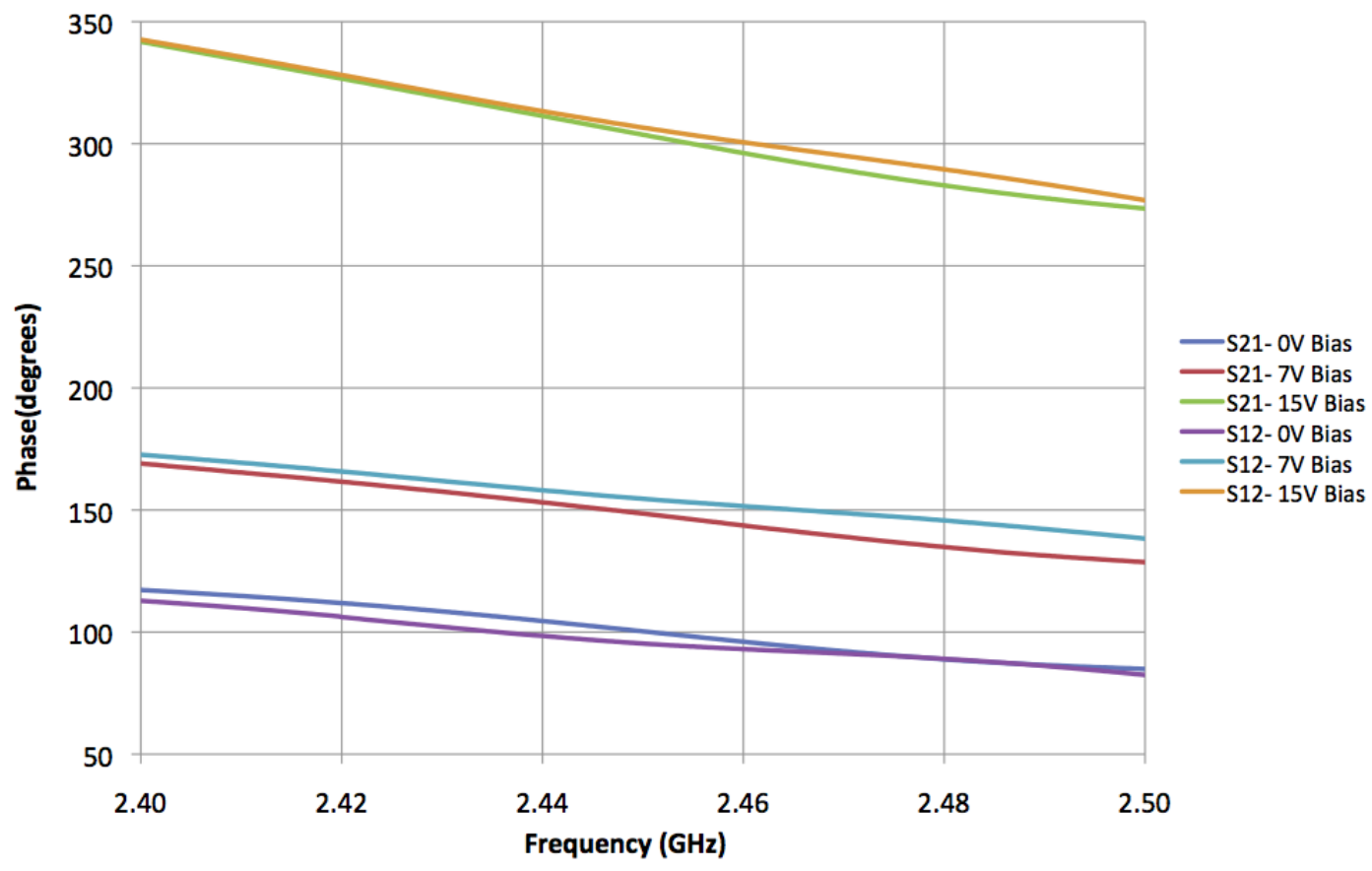

Figure 32 Weighting Board, Forward and Reverse Phase Delay Comparison 


\section{Summarized Results}

Table 6 summarizes the operating characteristics for each board. Worst-case performance values are displayed.

Table 6 Summarized Results of Key Measurements from all 8 Boards $(2.45 \mathrm{GHz})$

\begin{tabular}{|c|c|c|c|c|c|c|c|}
\hline Board & $\begin{array}{l}\text { Forward } \\
\text { IL (dB) }\end{array}$ & $\begin{array}{l}\text { 8dB Atten } \\
\text { Setting (dB) }\end{array}$ & $\frac{\text { Difference in }}{\text { Atten ( } \mathrm{dB})}$ & $\stackrel{\text { Max }}{\text { VSWRin }}$ & $\begin{array}{c}\text { Max Phase } \\
\text { Shift (degrees) }\end{array}$ & $\begin{array}{l}\text { Min Phase Shift } \\
\text { (degrees) }\end{array}$ & $\begin{array}{c}\text { |Forward/Reverse Phase } \\
\text { Discrepancy | (degrees) (7V Bias) }\end{array}$ \\
\hline 1 & 8.03 & 18.29 & 10.26 & 2.74 & 291.50 & 49.40 & 11.84 \\
\hline 2 & 6.60 & 15.17 & 8.57 & 1.68 & 303.67 & 100.31 & 3.60 \\
\hline 3 & 4.70 & 14.90 & 10.20 & 1.91 & 300.28 & 68.53 & 10.14 \\
\hline 4 & 4.42 & 13.54 & 9.12 & 2.35 & 299.93 & 59.40 & 12.01 \\
\hline 5 & 4.58 & 13.96 & 9.38 & 2.38 & 301.55 & 66.89 & 10.83 \\
\hline 6 & 9.65 & 20.79 & 11.14 & 5.05 & 294.24 & 43.26 & 0.67 \\
\hline 7 & 7.68 & 16.23 & 8.55 & 1.89 & 300.65 & 67.85 & 9.22 \\
\hline 8 & 8.22 & 16.53 & 8.31 & 1.54 & 325.18 & 109.13 & 8.21 \\
\hline $\begin{array}{l}\text { By Cascaded } \\
\text { Component Spec: }\end{array}$ & 4.50 & 12.50 & 8.00 & 1.50 & Min+201 & & \\
\hline Measured Max: & 9.65 & 20.79 & 11.14 & 5.05 & 325.18 & 109.13 & 12.01 \\
\hline Measured Min: & 4.42 & 13.54 & 8.31 & 1.54 & 291.50 & 43.26 & 0.67 \\
\hline Measured Delta: & 5.23 & 7.25 & 2.83 & 3.51 & 33.68 & 65.87 & 11.34 \\
\hline Measured Avg: & 6.73 & 16.18 & 9.44 & 2.44 & 302.13 & 70.60 & 8.31 \\
\hline
\end{tabular}




\section{Justification for Varied Results}

Board 6 exhibits unacceptable performance. The $9.7 \mathrm{~dB} I \mathrm{~L}$ is caused by a manufacturing defect. Excess flux caused attenuator misalignment during flux activation prior to solder reflow. To correct the problem, the attenuator was removed, repositioned using fresh flux, and reflowed again. No additional solder paste was added to minimize component damage caused by additional heating and cooling cycles. An insufficient amount of remaining solder, after part removal, created intermittent solder joints. Therefore, board 6 cannot be used in the final array. Each board's IL corresponds to manufacturing process changes. Boards 1 and 2 have insufficient solder under the attenuator; it was difficult to evenly apply the solder paste. With practice, solder paste application improved and the IL decreased to between $4 \mathrm{~dB}$ and $5 \mathrm{~dB}$. Boards 7 and 8 were manufactured on a different brand of FR-4, which increased IL to $7.68 \mathrm{~dB}$ and $8.22 \mathrm{~dB}$, respectively.

\section{Solution for Board 6}

Since board 6 is unreliable, the system is reduced to a 7-element array. This reduces the overall design efficiency by $1 / 8$ and requires a matched load at the omitted phase shifter board location. 


\section{Antenna Element and Antenna Mount Assembly}

\section{Antenna Element}

Nearson model 614 vertically polarized omnidirectional antennas are selected as the radiating elements. Model 614 is a multiband antenna with gain specified in Table 7. Other key features include: 50 impedance, VSWR<2.0 over the specified frequency range, and SMA connectivity.

Table 7 Nearson Model 614 Gain Specifications

\begin{tabular}{|l|l|}
\hline Frequency & Gain \\
\hline $2.45 \mathrm{GHz}$ & $4.0 \mathrm{dBi}$ \\
\hline $4.90 \mathrm{GHz}$ & $5.0 \mathrm{dBi}$ \\
\hline $5.25 \mathrm{GHz}$ & $5.0 \mathrm{dBi}$ \\
\hline $5.75 \mathrm{GHz}$ & $4.5 \mathrm{dBi}$ \\
\hline
\end{tabular}

\section{Antenna Mount}

The antenna mount is composed of 3/4" plywood: see Figure 33. Mounting holes are friction fitted to the array elements and are spaced /2 (2.42 in.) apart. Figure 34 shows the fully assembled phased array. In this image the array is positioned backwards to measure the rear $180^{\circ}$ of th e radiation pattern span without interference from the positioner.

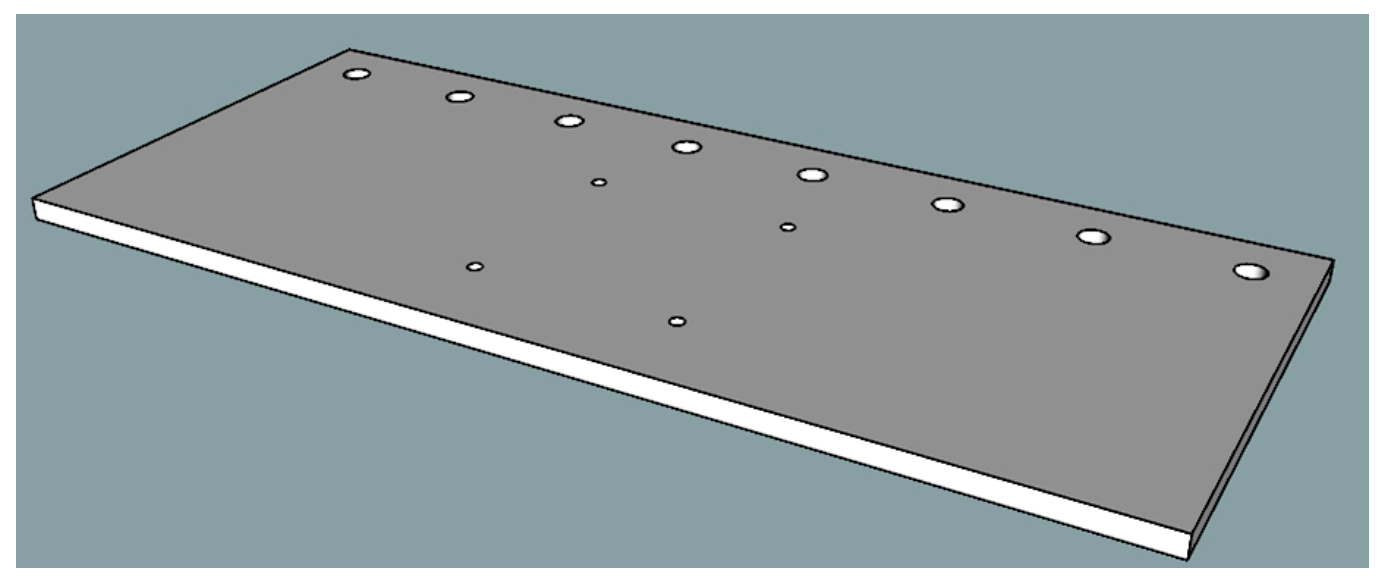

Figure 33 Mechanical Drawing, Antenna Mount 


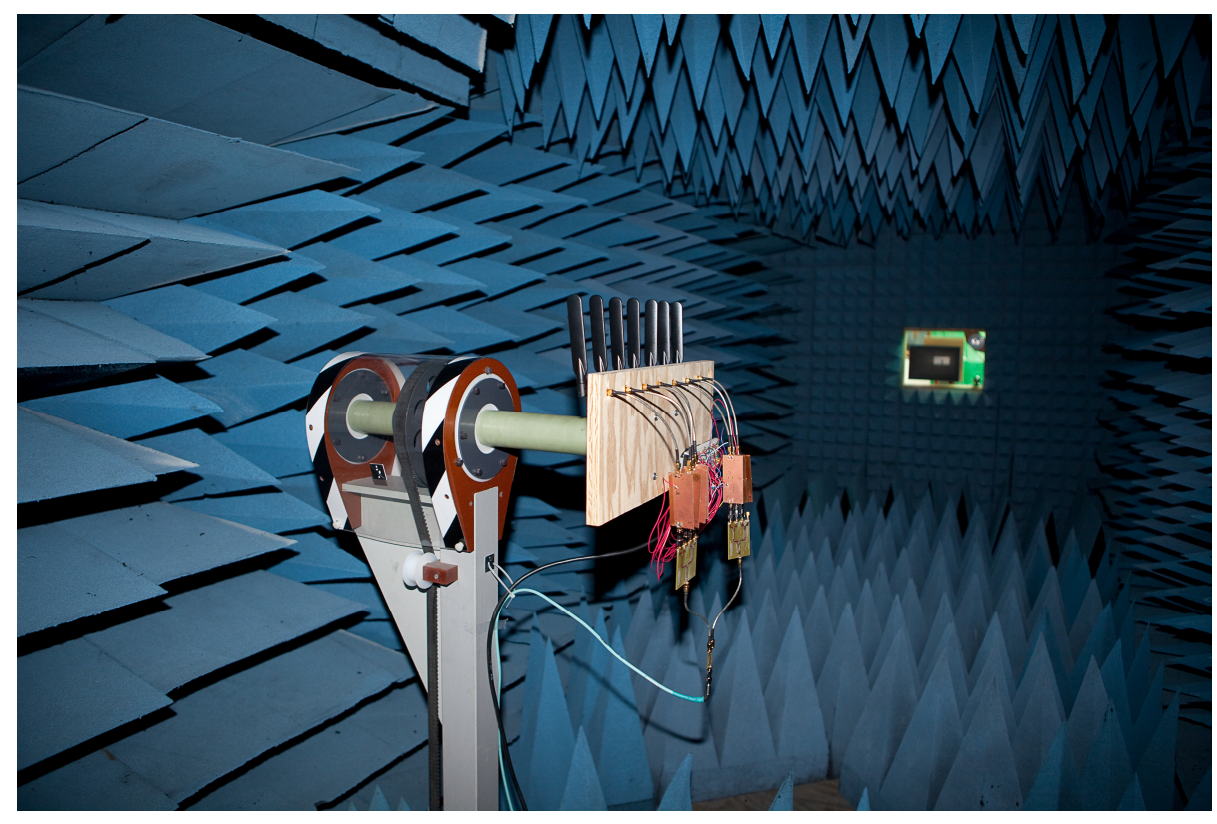

Figure 34 Fully Assembled Phased Array in Anechoic Chamber 


\section{Calculating Complex Element Weights}

Matlab code calculates the complex element weights required for arbitrary array factor patterns. The Matlab script (m-file) accepts the number of array elements, interelement spacing in wavelengths, and the number of desired signal sources and interference sources and corresponding incident angles. The m-file outputs attenuation $(\mathrm{dB})$ and phase shift (deg) requirements for each element to achieve the desired radiation pattern and a normalized AF plot.

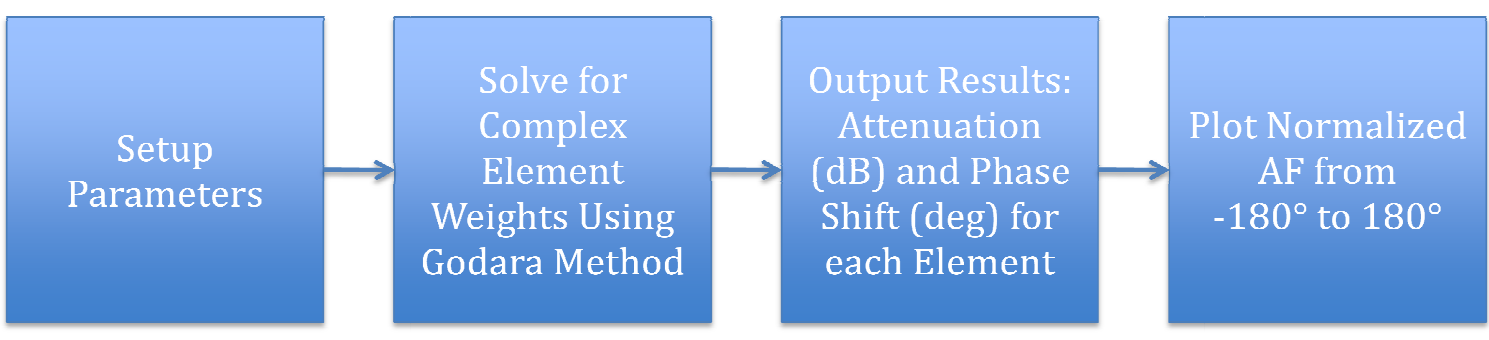

Figure 35 Matlab Script Block Diagram

\section{Complex Element Weights}

From antenna theory [3], the AF equation for a linearly spaced phased array takes the form:

$$
1+e^{j(\beta d \sin \theta+\delta)}+e^{j 2(\beta d \sin \theta+\delta)}+\ldots+e^{j(N-1)(\beta d \sin \theta+\delta)}
$$

where $=2 /$, is phase shift (radians) between elements, and $d$ is the interelement spacing. The AF terms are placed in a vertical array, called the array vector,

$$
\bar{a}(\theta)=\left[\begin{array}{llll}
1 & e^{j(\beta d \sin \theta+\delta)} & \mathrm{L} & e^{j(N-1)(\beta d \sin \theta+\delta)}
\end{array}\right]^{T}
$$

An array of optimized weights that provides the desired AF is defined as

$$
\left.1+n-n_{1}^{n} \quad \cdots\right]
$$


A system of multiple equations is developed. For example, a three-element array requires the following relations:

Condition 1: $y_{\text {signal }}=w_{1} e^{-j\left(\beta d \sin \theta_{\text {sig } 1}\right)}+w_{2}+w_{3} e^{j\left(\beta d \sin \theta_{s i g 1}\right)}=1$

Condition 2: $y_{\text {noise } 1}=w_{1} e^{-j\left(\beta d \sin \theta_{\text {noise } 1}\right)}+w_{2}+w_{3} e^{j\left(\beta d \sin \theta_{\text {noise } 1}\right)}=0$

Condition 3: $y_{\text {noise } 2}=w_{1} e^{-j\left(\beta d \sin \theta_{\text {noise } 2)}\right.}+w_{2}+w_{3} e^{j\left(\beta d \sin \theta_{\text {noise } 2}\right)}=0$

Recast in matrix form,

$$
\bar{w}^{H} \cdot \bar{A}=\bar{u}^{T}
$$

where $\bar{A}$ is a matrix of array vectors, defined in equation (2) in the form $\bar{A}=\left[\begin{array}{lll}\bar{a}_{0} & \bar{a}_{1} & \bar{a}_{2}\end{array}\right]$ and $\bar{u}=\left[\begin{array}{lll}1 & 0 & 0\end{array}\right]^{T}$ with 1's for desired signals and 0's for interference sources. $\bar{w}^{H}$ is determined using

$$
\bar{w}^{H}=\bar{u}^{T} \cdot \bar{A}^{-1}
$$

For cases where $\mathrm{A}$ is not invertible ( $\mathrm{NxN}$ matrix with $\mathrm{N}$-array elements and $\mathrm{N}$-arriving signals), the Godara method is used [4]. In this method, simulated noise, $\sigma_{n}^{2}$, is added to allow matrix inversion.

$$
\bar{w}^{H}=\bar{u}^{T} \cdot \bar{A}^{H}\left(\bar{A} \cdot \bar{A}^{H}+\sigma_{n}^{2} \bar{I}\right)^{-1}
$$

Where $I$ represents the identity matrix and the superscript $\mathrm{H}$ signifies the complex conjugate transpose of the matrix.

\section{Array Factor Plot}

The array factor is found using $y=\bar{w}^{H} * e^{-j(2-n) \pi \sin (\theta)}$, where $\mathrm{n}$ is a vector of integer values between 0 and $(\mathrm{N}-1)$ and $-180<<180$. The $\mathrm{m}$-file then plots $\frac{y(\theta)}{y_{\max }}$. 


\section{Array Characterization}

\section{Single Element Characterization}

The measured array radiation pattern is the product of the element pattern and array factor. Measured element patterns are displayed in Figure 36-Figure 39. Figure 36 contains the measured co-pol $\mathrm{H}$-plane element pattern, which is combined with the array factor to produce the total radiation patterns in the next section. The single antenna element has $4.12 \mathrm{dBi}$ average gain, $0.38 \mathrm{~dB}$ less than the $4.5 \mathrm{dBi}$ specification. The measured co-pol $\mathrm{H}$-plane radiation pattern has a relatively constant pattern (standard deviation of $1.95 \mathrm{~dB}$ ), as expected from a dipole radiator.

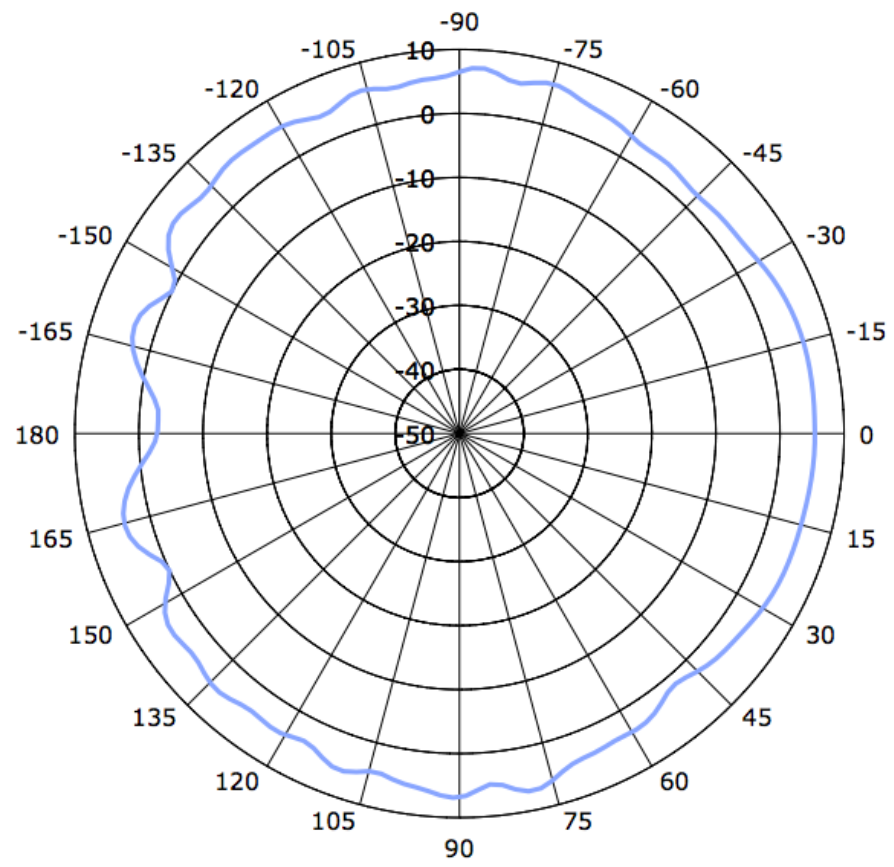

Figure 36 Co-Pol H-Plane Radiation Pattern, Single Antenna Element 


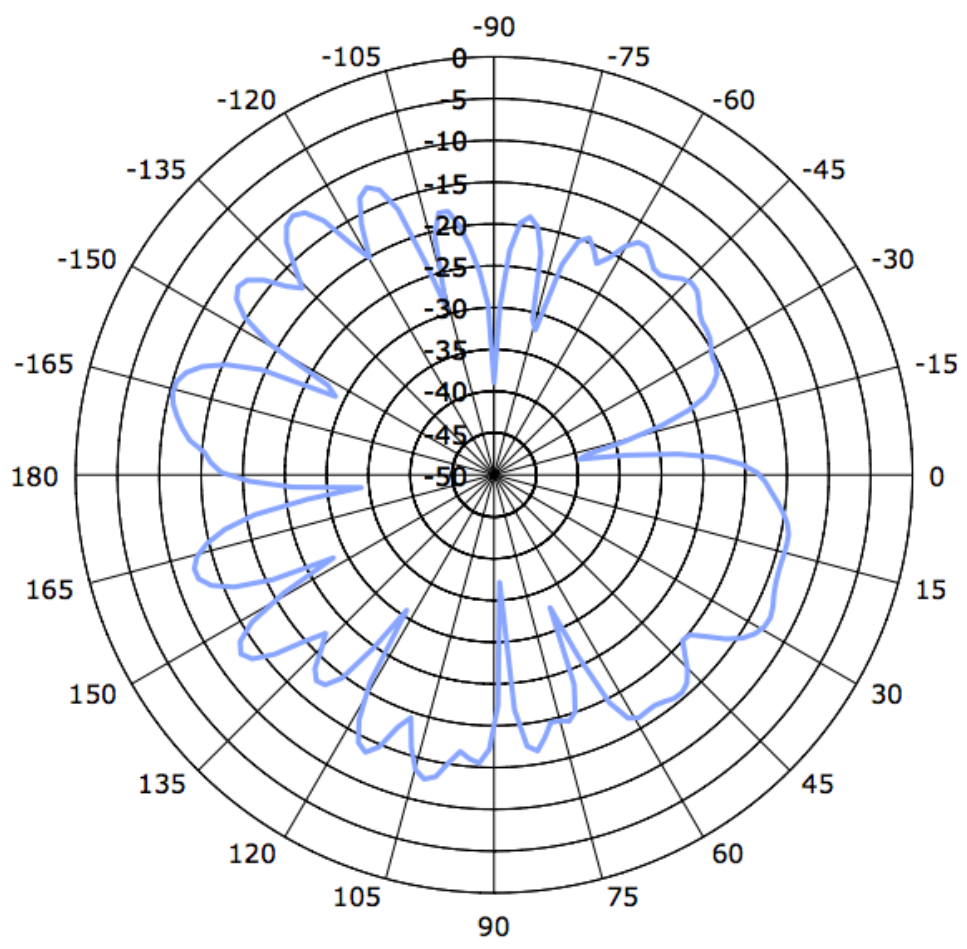

Figure 37 Cross-Pol E-Plane Radiation Pattern, Single Antenna Element

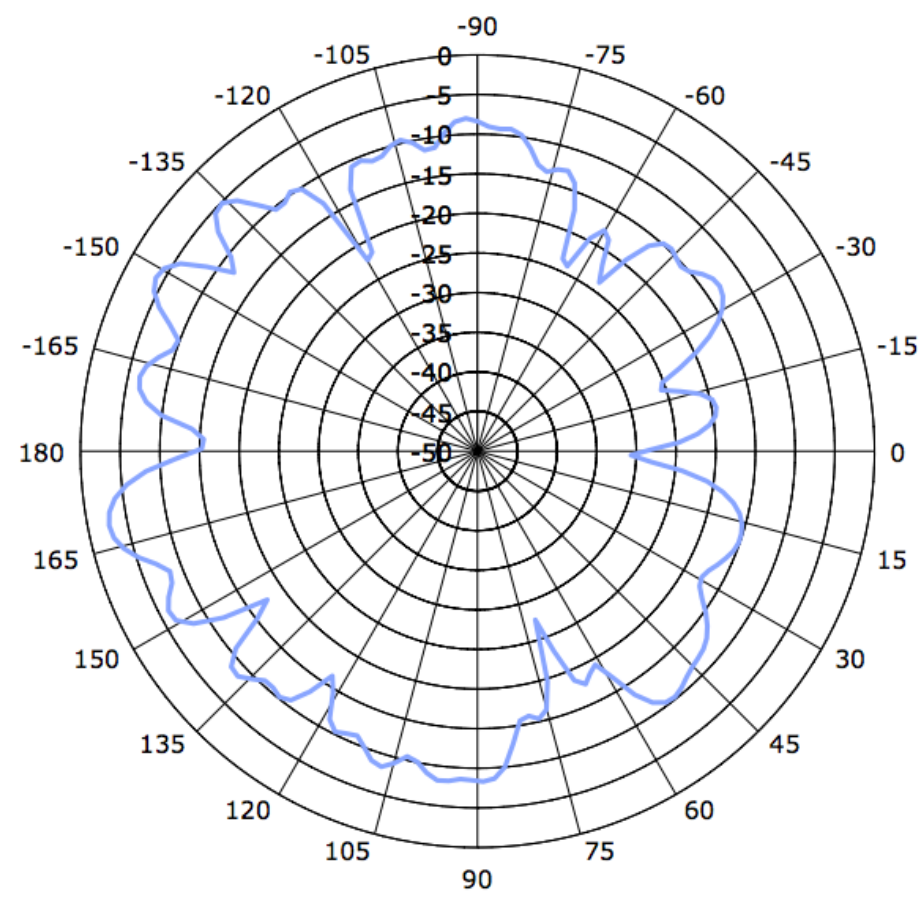

Figure 38 Cross-Pol H-Plane Radiation Pattern, Single Antenna Element 


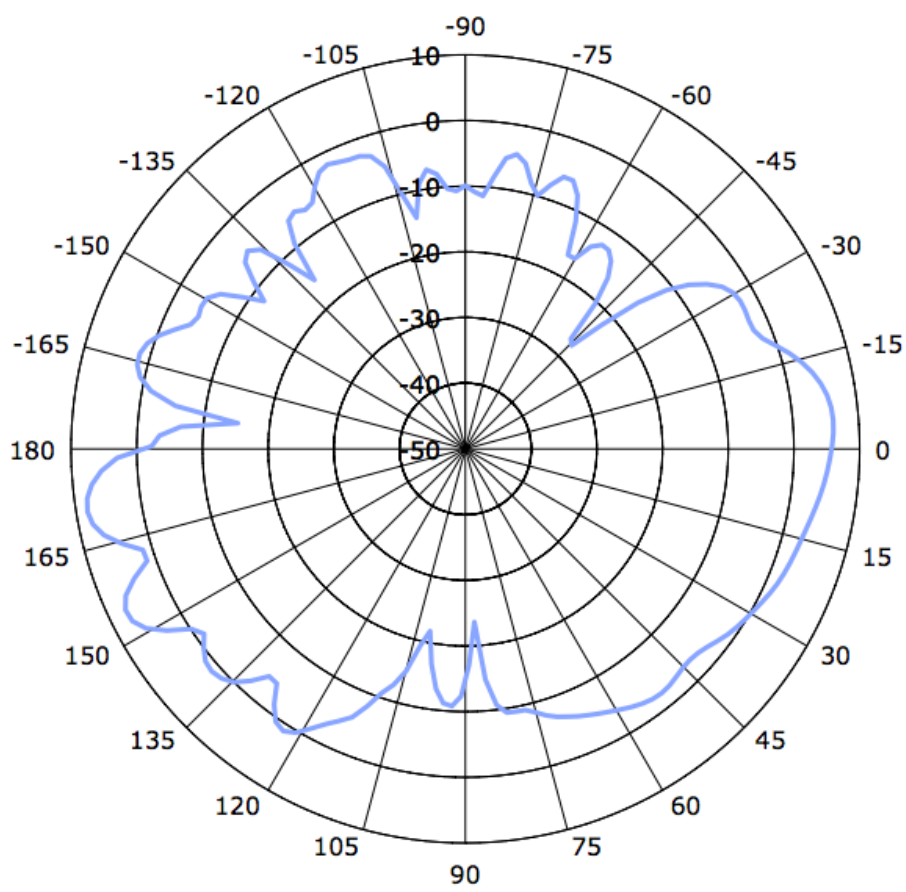

Figure 39 Co-Pol E-Plane Radiation Pattern, Single Antenna Element

\section{Test Cases}

Table 8 shows desired signal and interferer (maximums and nulls) incident angles for each test case. Test case 1 is designed to demonstrate a narrow mainbeam, test case 2 demonstrates multiple mainlobes, and test case 3 shows that arbitrary angle placement and non-alternating maximums and nulls are possible.

Table 8 Phased Array Test Cases

\begin{tabular}{|l|l|l|}
\hline Test Case & Maximum Angles (degrees) & $\begin{array}{l}\text { Null Angles } \\
\text { (degrees) }\end{array}$ \\
\hline 1 & 0 & $-25,25$ \\
\hline 2 & $-90,0,90$ & $-45,45$ \\
\hline 3 & 0,45 & $-45,-65$ \\
\hline
\end{tabular}




\section{Test Case 1}

The first test case includes a maximum at $0^{\circ}$ and nulls at $\pm 25^{\circ}$. wBarH is a vector containing complex valued (there are no imaginary components in this test case) weights required for Test Case 1. These weights are converted to attenuation(dB) and phase shift(deg) as shown in Figure 40.

$$
\mathrm{wBarH}=
$$
0.1113
0.0955
$0.1770 \quad 0.2320$
0.1770
0.0955
0.1113

For element 1, Mag: $-6.38 \mathrm{~dB}$ Phase:0 degrees

For element 2, Mag: $-7.71 \mathrm{~dB}$ Phase:0 degrees

For element 3, Mag: $-2.35 \mathrm{~dB}$ Phase:0 degrees For element 4, Mag: $0.00 \mathrm{~dB}$ Phase: 0 degrees For element 5, Mag: $-2.35 \mathrm{~dB}$ Phase:0 degrees For element 6, Mag: $-7.71 \mathrm{~dB}$ Phase:0 degrees For element 7, Mag: $-6.38 \mathrm{~dB}$ Phase:0 degrees

Figure 40 Complex Valued Weights, Test Case 1

The measured AF in Figure 42 is compared to the simulated array factor (AF) shown in Figure 41. The measured radiation pattern $(\mathrm{dBi})$ is shown in Figure 43. The SNR between $0^{\circ}$ and $25^{\circ}$ increased by $44.5 \mathrm{~dB}$ and th e SNR between $0^{\circ}$ and $25^{\circ}$ increased by $11.34 \mathrm{~dB}$. 


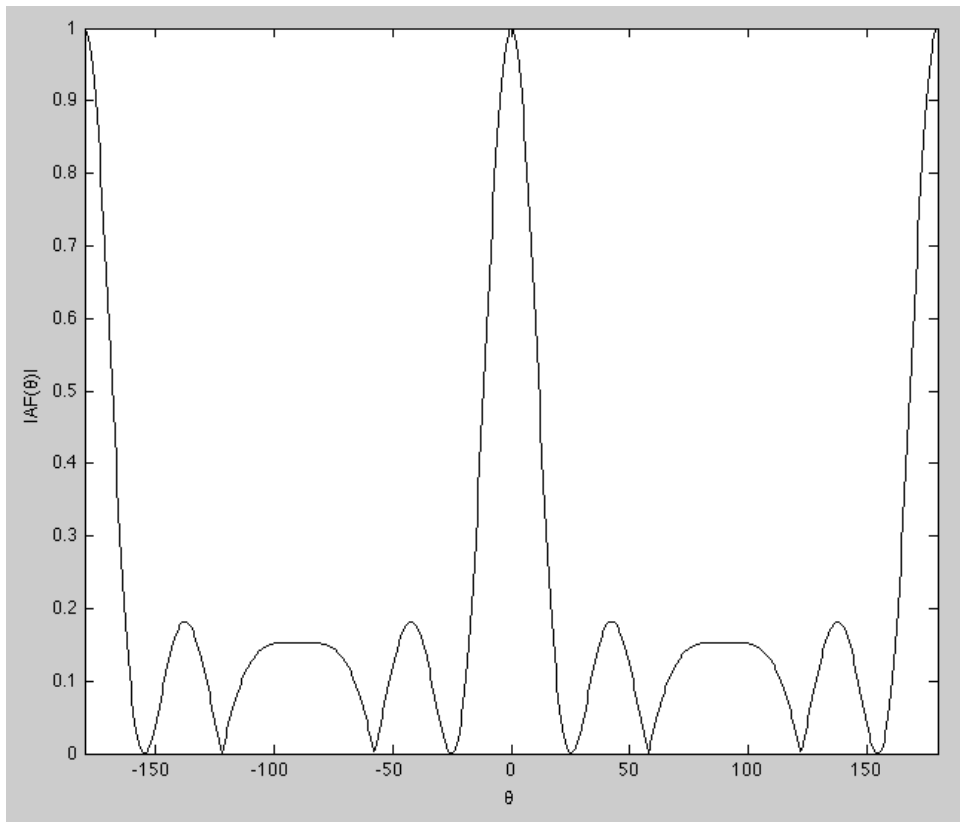

Figure 41 Simulated Normalized Array Factor, Test Case 1

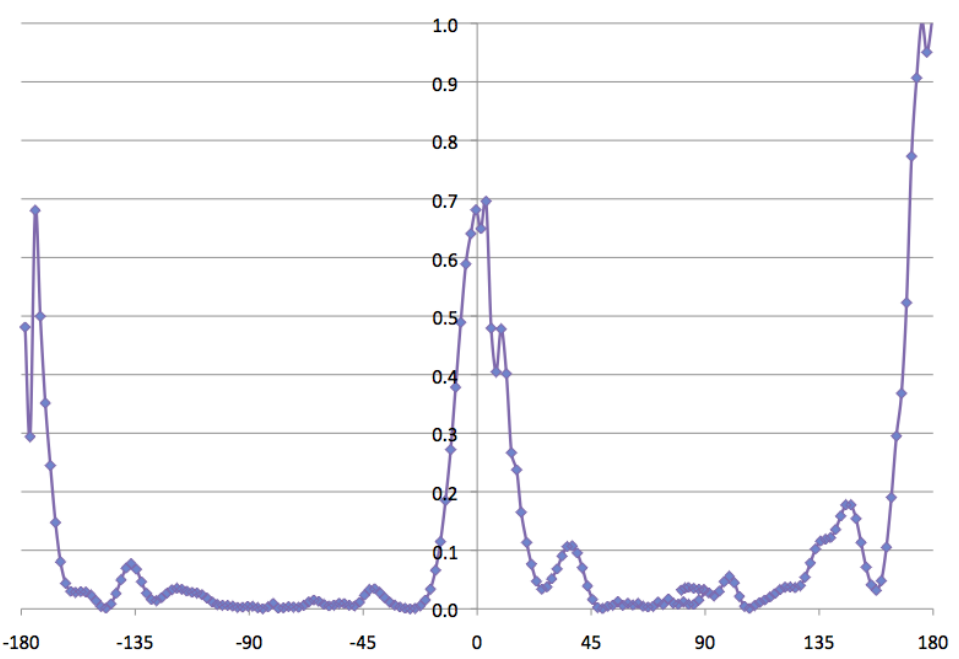

Figure 42 Measured Normalized Array Factor, Test Case 1 


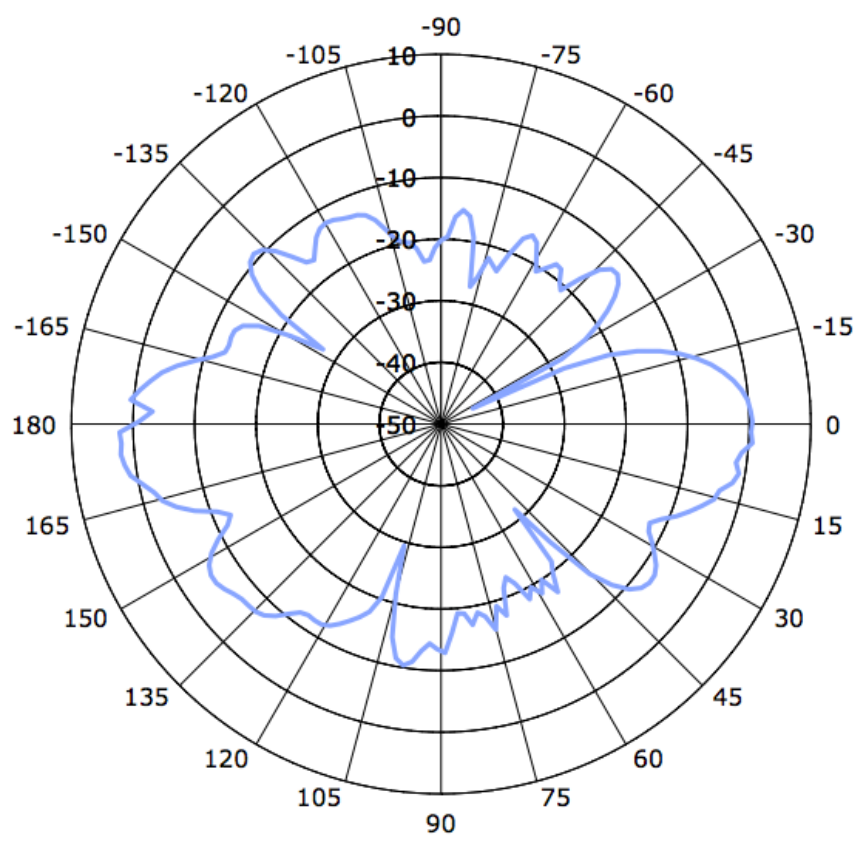

Figure 43 Measured Radiation Pattern (dBi), Test Case 1

\section{Test Case 2}

The second test case specifies maximums at $0^{\circ}, \pm 90^{\circ}$ and nul is at $\pm 45^{\circ}$.

Complex weighting coefficients required for this configuration are shown in

Figure 44 .

$\mathrm{wBarH}=$

$$
\begin{array}{lllllll}
0.2138 & 0.0199 & 0.2861 & -0.0398 & 0.2861 & 0.0199 & 0.2138
\end{array}
$$

For element 1, Mag: $-2.53 \mathrm{~dB}$ Phase:0 degrees

For element 2, Mag: $-23.16 \mathrm{~dB}$ Phase:0 degrees

For element 3, Mag: $0.00 \mathrm{~dB}$ Phase:0 degrees

For element 4, Mag: $-17.14 \mathrm{~dB}$ Phase:180 degrees

For element 5, Mag: $0.00 \mathrm{~dB}$ Phase:0 degrees

For element 6, Mag: -23.16 dB Phase:0 degrees

For element 7, Mag: $-2.53 \mathrm{~dB}$ Phase:0 degrees

Figure 44 Complex Valued Weights, Test Case 2 
This test case requires attenuation levels beyond the maximum $15.5 \mathrm{~dB}$ provided by the digital step attenuator. The boards with highest IL (1 and 8) are used for elements requiring the greatest attenuation (2 and 6); boards with lowest IL (4 and 5) are used for elements requiring lower attenuation ( 3 and 5). The digital step attenuators add significant phase shift to elements with relatively high attenuation. The additional phase shift must also be added to other elements through the phase shifter. The additional phase requirement on element 4 exceeds the weighting board's $180^{\circ}$ maximum phase shift. B ecause channel 4 requires $17 \mathrm{~dB}$ attenuation, the radiating element is replaced by a matched load. Actual weighting values were used to resimulate the normalized AF shown in Figure 46. The aforementioned deviations resulted in a gain decrease for the $\pm 90^{\circ}$ mainlobes as well as the sidelobes and a $3^{\circ}$ increa se in the $45^{\circ}$ null position. The simulated AF for the ideal configuration, shown in Figure 45, is compared to the measured AF in Figure 47. The measured radiation pattern (dBi) for Test Case 2 is shown in Figure 48. SNR improvements are shown in Table 9. The maximum SNR improvement $(19.14 \mathrm{~dB})$ is between the signal at $0^{\circ}$ and the interferer at $-45^{\circ}$. Minimum SNR improvement $(7.27 \mathrm{~dB})$ is between the signal at $90^{\circ}$ and the interferer at $45^{\circ}$.

Table 9 SNR Improvements, Test Case 2

\begin{tabular}{|l|l|l||l|l|l|}
\hline $\begin{array}{l}\text { Signal } \\
\text { Angles }\end{array}$ & $\begin{array}{l}\text { Interferer } \\
\text { Angle }\end{array}$ & $\begin{array}{l}\text { SNR } \\
(\mathrm{dB})\end{array}$ & $\begin{array}{l}\text { Signal } \\
\text { Angle }\end{array}$ & $\begin{array}{l}\text { Interferer } \\
\text { Angle }\end{array}$ & $\begin{array}{l}\text { SNR } \\
(\mathrm{dB})\end{array}$ \\
\hline $0^{\circ}$ & $45^{\circ}$ & 16.13 & $90^{\circ}$ & $-45^{\circ}$ & 10.28 \\
\hline $0^{\circ}$ & $-45^{\circ}$ & 19.14 & $-90^{\circ}$ & $45^{\circ}$ & 7.46 \\
\hline $90^{\circ}$ & $45^{\circ}$ & 7.27 & $-90^{\circ}$ & $-45^{\circ}$ & 10.47 \\
\hline
\end{tabular}




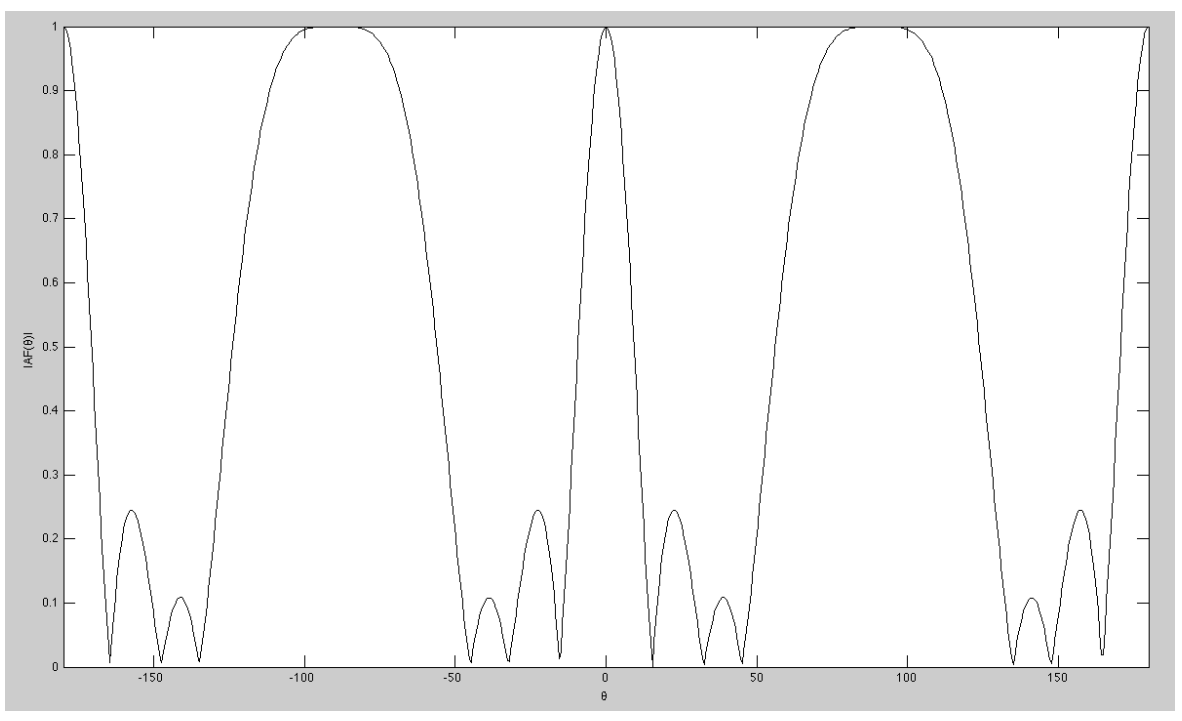

Figure 45 Simulated Normalized Array Factor, Test Case 2

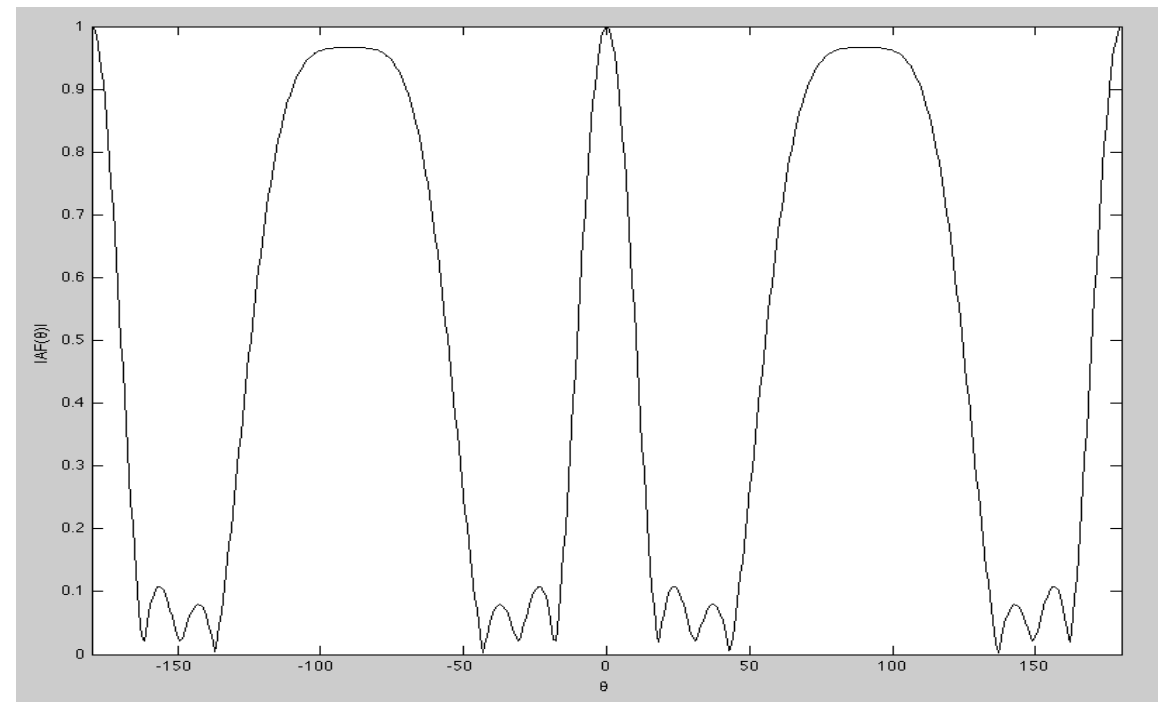

Figure 46 Simulated Normalized Array Factor Using Actual Weighting Values 


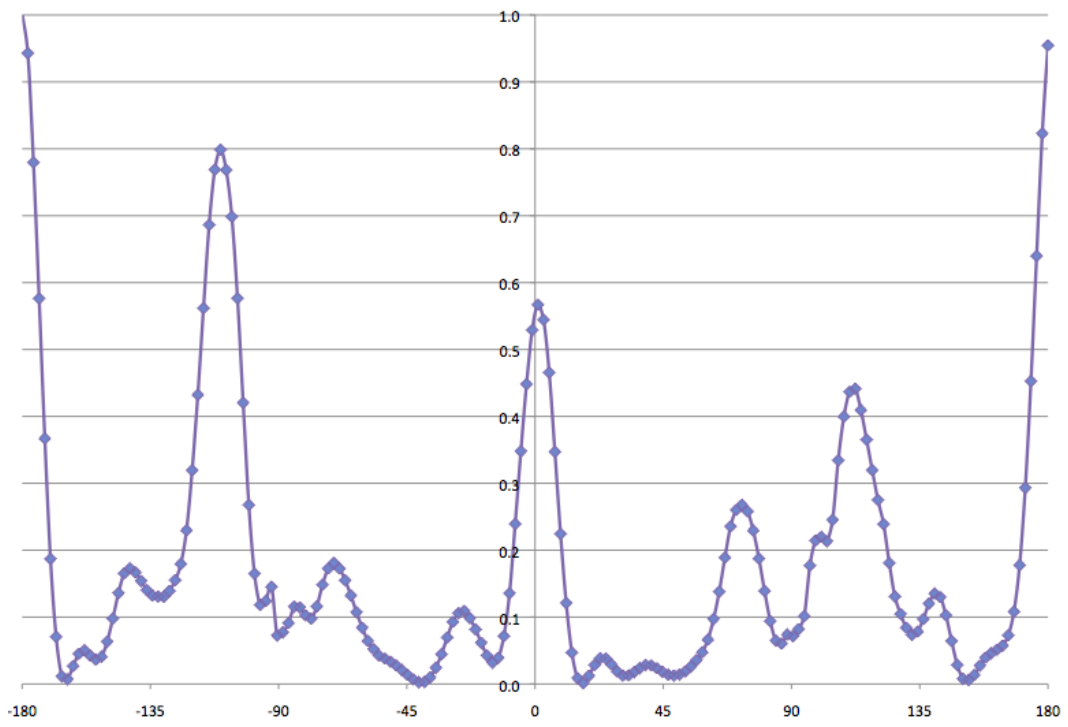

Figure 47 Measured Normalized Array Factor, Test Case 2

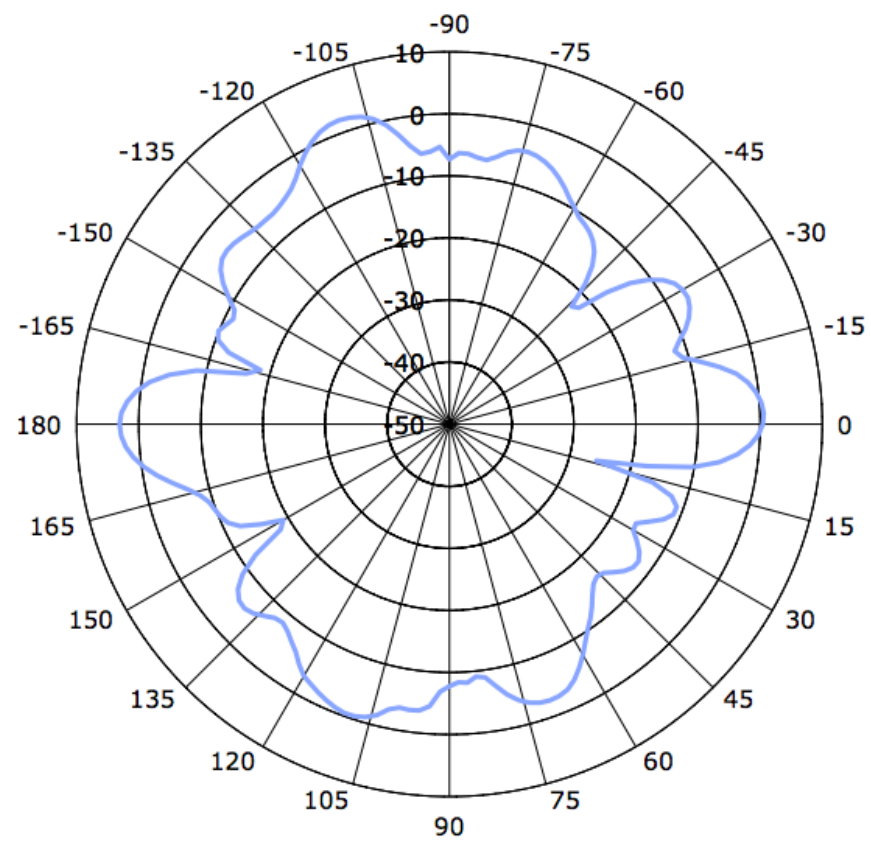

Figure 48 Measured Radiation Pattern (dBi), Test Case 2 


\section{Test Case 3}

The third test case includes maximums at $0^{\circ}, 45^{\circ}$ and nulls at $-45^{\circ},-65^{\circ}$.

Weighting coefficients required for this configuration are shown in Figure 49.

$$
\begin{aligned}
& \text { wBarH }= \\
& \begin{array}{lll}
0.0692+0.0977 i, & 0.0809-0.1046 i, & 0.3494-0.0403 i, \\
0.0244+0.1267 i, & 0.1505-0.1842 i, & 0.3090+0.0675 i, \\
0.0163+0.0372 i &
\end{array}
\end{aligned}
$$

For element 1, Mag: -9.37 dB Phase:106.9 degrees

For element 2, Mag: - $8.50 \mathrm{~dB}$ Phase:0.0 degrees

For element 3, Mag: $0.00 \mathrm{~dB}$ Phase:45.7 degrees

For element 4, Mag: - $8.71 \mathrm{~dB}$ Phase:131.3 degrees

For element 5, Mag: - $3.40 \mathrm{~dB}$ Phase:1.5 degrees

For element 6, Mag: $-0.92 \mathrm{~dB}$ Phase:64.6 degrees

For element 7, Mag: $-18.75 \mathrm{~dB}$ Phase:118.6 degrees

Figure 49 Complex Valued Weights, Test Case 3

Since attenuation levels required for element 7 could not be attained, the radiator was omitted and replaced with a matched load. Actual weighting values were used to resimulate the normalized AF shown in Figure 51. The simulated AF for the ideal configuration, shown in Figure 50, is compared to the measured AF in Figure 52. To show radiation pattern variation over the channel bandwidth, measurements are taken at $2.426 \mathrm{GHz}, 2.437 \mathrm{GHz}$, and 2.448GHz (Figure 53), the low, center, and high frequencies for channel 6 of the $802.11 \mathrm{~g}$ specification. SNR improvements achieved by the array in this configuration are shown in Table 10. Maximum SNR improvement $(16.47 \mathrm{~dB})$ at the center frequency is between the signal at $45^{\circ}$ and the interferer at $-45^{\circ}$. Minimum SNR improvement $(9.24 \mathrm{~dB})$ is between the signal at $0^{\circ}$ and the interfer er at $-65^{\circ}$. Over the entire channel, the maximum SNR variation is $2 \mathrm{~dB}$, indicating that the radiation pattern is relatively consistent. 
Table 10 SNR Improvement Measurements, Test Case 3

\begin{tabular}{|c|c|c|c|c|c|c|c|c|}
\hline Frequency: & & $2.437 \mathrm{GHz}$ & Frequency: & & $2.426 \mathrm{GHz}$ & Frequency: & & $2.448 \mathrm{GHz}$ \\
\hline $\begin{array}{l}\text { Signal } \\
\text { Angle } \\
\text { (degrees) }\end{array}$ & $\begin{array}{l}\text { Interferer } \\
\text { Angle } \\
\text { (degrees) }\end{array}$ & SNR(dB) & $\begin{array}{l}\text { Signal } \\
\text { Angle } \\
\text { (degrees) }\end{array}$ & $\begin{array}{l}\text { Interferer } \\
\text { Angle } \\
\text { (degrees) }\end{array}$ & SNR(dB) & \begin{tabular}{|l} 
Signal \\
Angle \\
(degrees)
\end{tabular} & $\begin{array}{l}\text { Interferer } \\
\text { Angle } \\
\text { (degrees) }\end{array}$ & SNR(dB) \\
\hline 0 & -45 & 13.8 & \begin{tabular}{|l}
0 \\
\end{tabular} & -45 & 13.1 & \begin{tabular}{|l|}
0 \\
\end{tabular} & -45 & 13.0 \\
\hline 0 & -65 & 9.2 & 0 & -65 & 10.8 & 0 & -65 & 10.5 \\
\hline 45 & -45 & 16.5 & 45 & -45 & 16.2 & 45 & -45 & 16.0 \\
\hline 45 & -65 & 11.9 & 45 & -65 & 13.9 & 45 & -65 & 13.6 \\
\hline
\end{tabular}

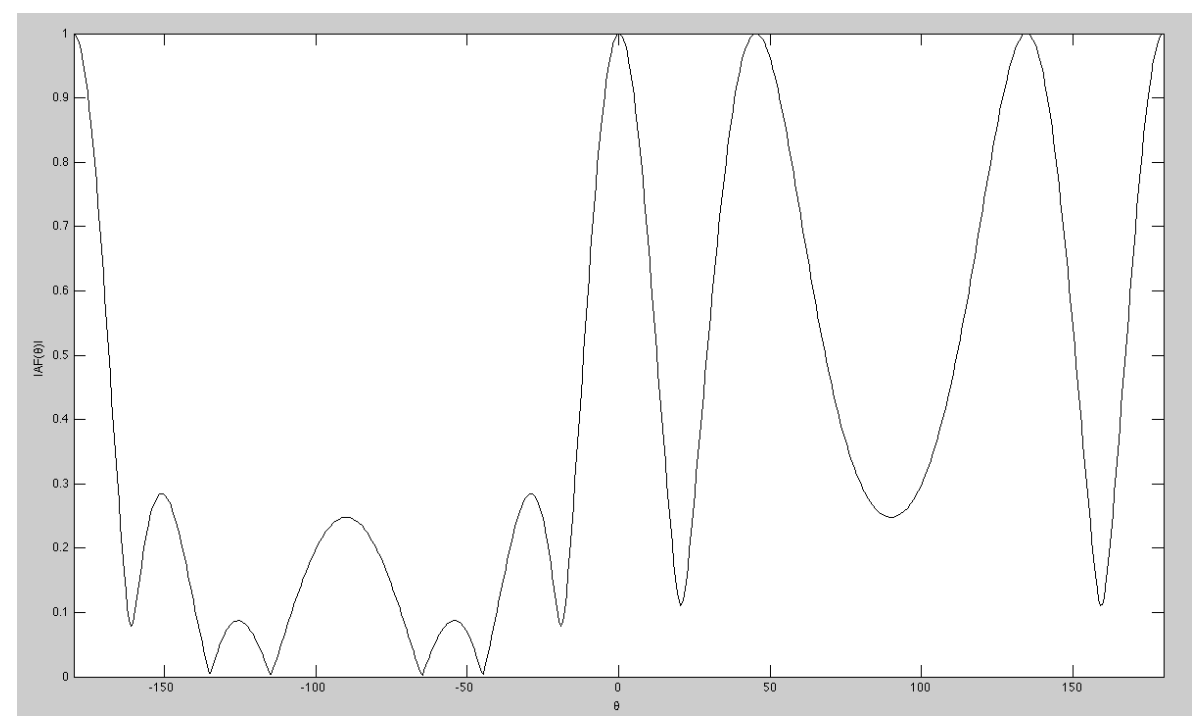

Figure 50 Simulated Normalized Array Factor, Test Case 3

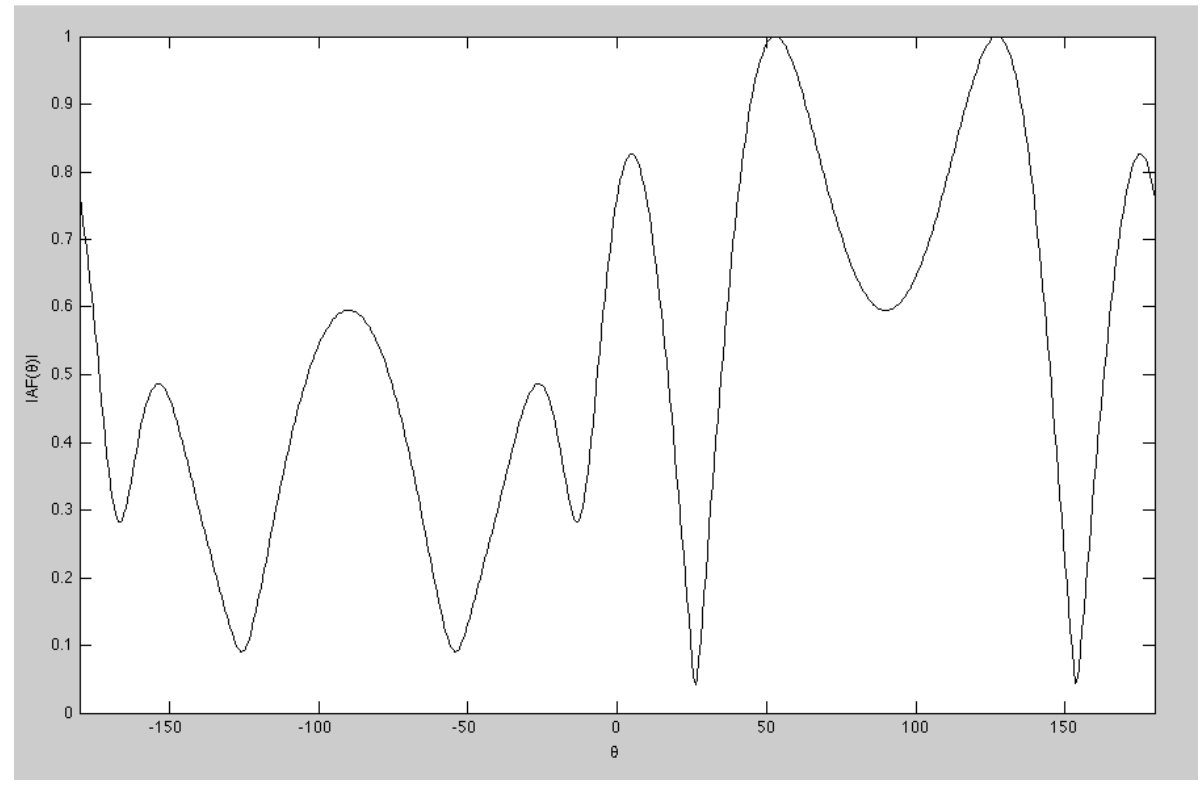

Figure 51 Simulated Normalized Array Factor Using Actual Weighting Values 


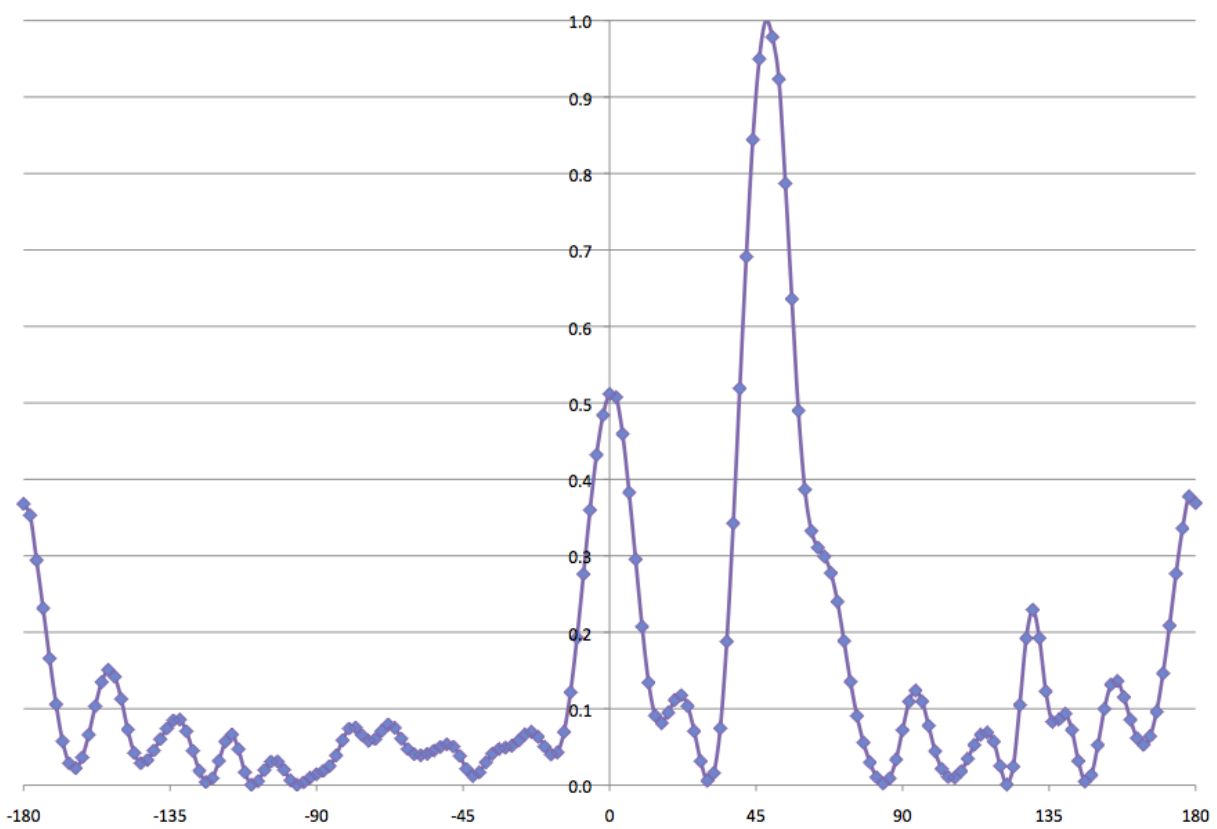

Figure 52 Measured Normalized Array Factor, Test Case 3
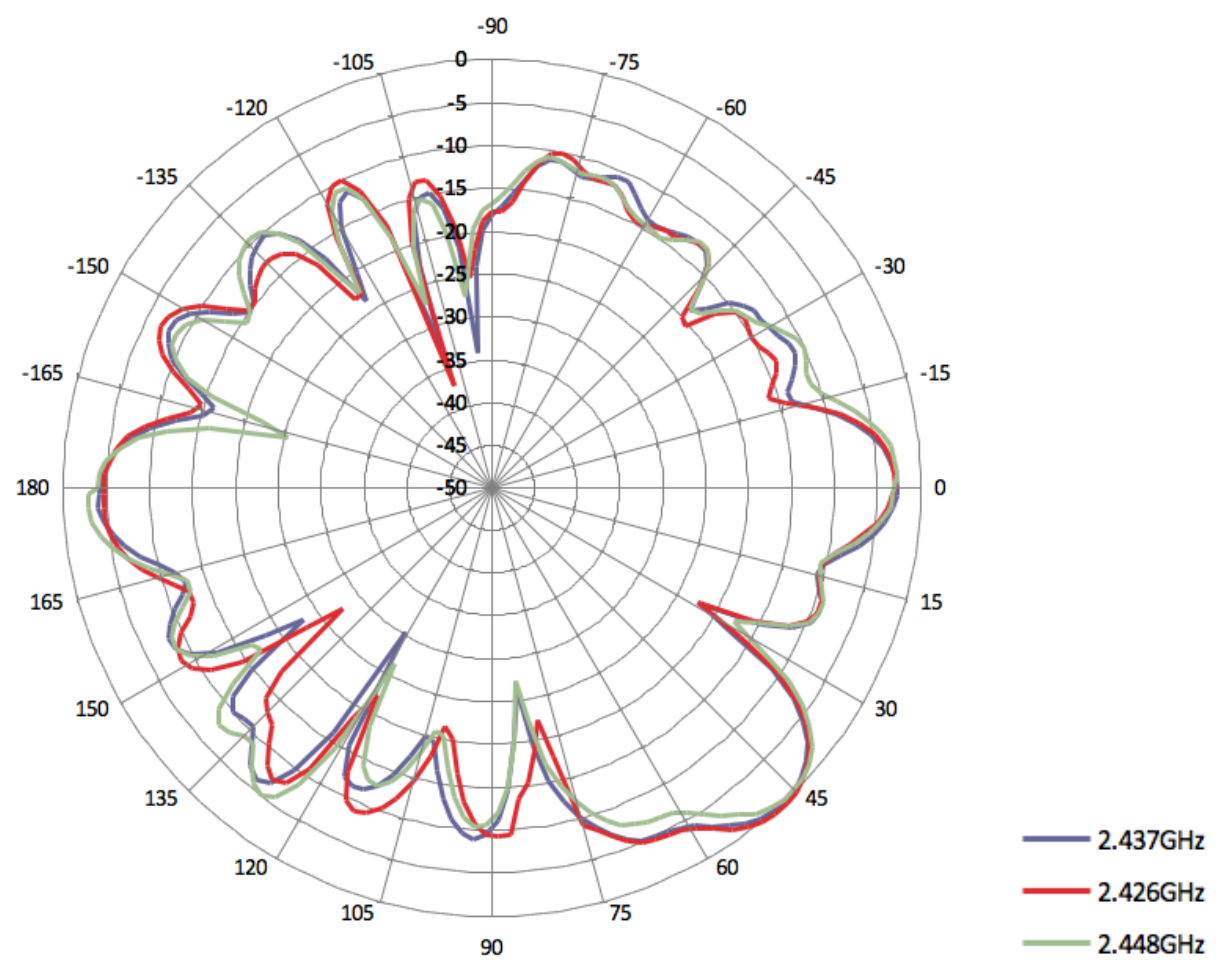

Figure 53 Measured Radiation Patterns (dBi), Test Case 3

VSWR 
Test case 3 phased array VSWR is shown in Figure 54.

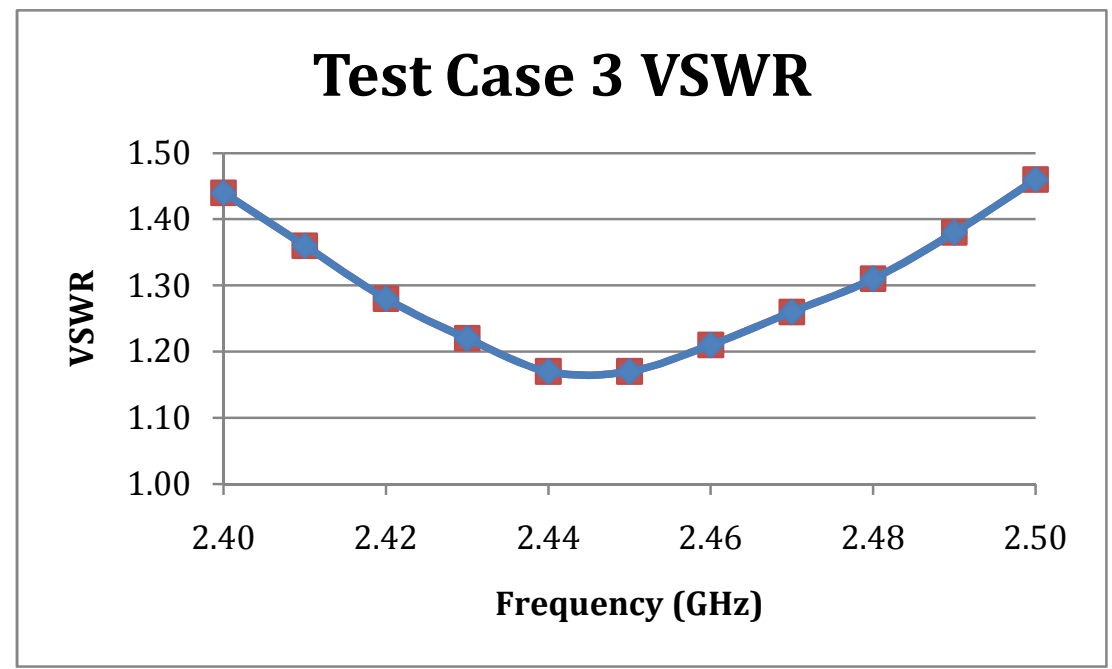

Figure 54 VSWR, Test Case 3

\section{Half Power Beamwidth}

In test case 1 , nulls are placed within $25^{\circ}$ of a maxim um. The mainbeam HPBW in Test Case 1 is $21 \pm 2^{\circ}$. Other HPBWs are shown in Table 11. HPBW measurements are accurate to within $2^{\circ}$, the measurement resolution. Deviations from simulated HPBWs are less than $9^{\circ}$ (Test Case 3: $45^{\circ}$ mainlobe).

Table 11 Array Test Case HPBWs

\begin{tabular}{|l|l|l|}
\hline Test Case & Simulated HPBW & Measured HPBW \\
\hline Case1- $0^{\circ}$ Mainlobe & $17^{\circ}$ & $21^{\circ} \pm 2^{\circ}$ \\
\hline Case2- $0^{\circ}$ Mainlobe & $14^{\circ}$ & $13^{\circ} \pm 2^{\circ}$ \\
\hline Case2- 90 Mainlobe & $58^{\circ}$ & $51^{\circ} \pm 2^{\circ}$ \\
\hline Case3- 45 Mainlobe & $28^{\circ}$ & $19^{\circ} \pm 2^{\circ}$ \\
\hline Case3- $0^{\circ}$ Mainlobe & $18^{\circ}$ & $17^{\circ} \pm 2^{\circ}$ \\
\hline
\end{tabular}




\section{Home Router Lab Network Test}

A Broadcom wireless $\mathrm{N}$ router is configured with all router radios disabled except wireless $\mathrm{G}$, set to channel 6 . With no antennas attached, the signal from the router is $-90 \mathrm{dBm}$, as measured by an internal Broadcom BCM43xx chipset at $20 \mathrm{ft}$. Windows XP cannot associate with the router at this signal level. The phased array is connected to the router. The signal at $25 \mathrm{ft}$ is greater than $-50 \mathrm{dBm}$. The laptop is able to connect to and browse the router configuration pages, showing full link functionality. 


\section{Sample Lab}

Introduction

This lab involves a 7-element linear phased antenna array and a comparison between theory and actual performance.

\section{Prelab}

1. Using the Godara method [5], write Matlab code to calculate element complex weighting values (phase shift and attenuation) required to produce a desired array factor

a. Code must calculate weighting values for any number of elements and any inter-element spacing (in )

b. Code must accept any number of pattern maximums and/or null angles as input (up to the number of elements)

c. Hint: Solving for 4 complex weights with 7 elements requires the addition of simulated noise to yield invertible matrices.

2. Find element weighting values for a phased array that produce maximums at $0^{\circ}$ and $45^{\circ}$ and nulls at $-45^{\circ}$ and $-65^{\circ}$
a. $\mathrm{N}=$ number of elements $=7$
b. $d=$ inter-element spacing $=0.5($ )
c. $\mathrm{f}=2.437(\mathrm{GHz})$

3. Use Matlab to plot the array factor using the weighting values found in step 2

\section{Turn in:}

1. Matlab code

2. Array Factor plot

3. Weighting value list

4. Bring an extra copy to the lab.

\section{Procedure}

1. Set two separate $D C$ voltage supplies to $3 \mathrm{~V}$ and $15 \mathrm{~V}$
a. 3V current limit: $40 \mathrm{~mA}$
b. $15 \mathrm{~V}$ current limit: $5 \mathrm{~mA}$

2. Connect supplies to array (locations labeled)

3. Adjust weighting parameters for each channel to coincide with prelab results.
a. The forward and reverse characteristics of phase shifters are different, which S-parameter should be used?
b. Note: the phased array is the chamber receive antenna. 
c. Include measurements of all coax cables and power splitters. Terminate any unused ports. Four 50 terminators are required.

d. Find an appropriate zero reference point for phase shift and attenuation created by the array. Find realizable weighting values for the array using your prelab.

Note: Attenuators also produce phase shift, and phase shifters also exhibit attenuation. Allow overhead in the settings. To achieve prelab settings, several adjustment iterations may be required.

4. Place the phased array inside the anechoic chamber. Reconnect the power supplies (outside the chamber) to the array using the provided power cable.

5. Replace the transmit antenna with the $2.4 \mathrm{GHz}$ standard gain horn antenna.

6. Measure the radiation pattern at $2.437 \mathrm{GHz}$

7. Include the following measurements
a. Cable loss to each antenna
b. Effective antenna distance
c. Horn antenna gain (obtain data sheet)

Report

1. Gain at $0^{\circ}$ and $45^{\circ}$ ?

2. If noise sources exist at incident angles of $-45^{\circ}$ and $-65^{\circ}$ on the $\mathrm{H}$-plane, what SNR does the array provide as opposed to an isotropic radiator?

3. Include $360^{\circ}$ radiation patterns.

a. Array radiation pattern $(\mathrm{dBi})$

i. Hint: Use Friis Transmission formula.

b. Single element radiation pattern (dBi)

c. Normalized AF

4. Compare radiation pattern and AF with theory

5. Measure array VSWR 


\section{Conclusion}

Beam steering provides a fixed direction SIR greater than $10 \mathrm{~dB}$ in seven of the nine signal to interference ratios calculated across the three test cases. A $10 \mathrm{~dB}$ increase corresponds to a $10 \%$ signal quality increase as measured (and defined) by the router. Fixed null phased arrays are ideal for installations with fixed location interferers causing degradation to wireless system performance. Mobile applications require "smart" phased arrays able to detect desired signals and interferers and dynamically update the array factor. Unfortunately, system cost is prohibitive; hundreds of dollars per element. FPGAs can directly synthesize array signals with required attenuation and phase delay. As high speed FPGAs decrease in cost, direct synthesis may become a viable option. 


\section{Further Development}

An exciting new application of array beam forming allows direct synthesis of array signals using high-speed FPGAs. Direct synthesis produces phase shifted, attenuated signals without the need for phase shifter or attenuators. Direct synthesis increases the overall efficiency and system gain. Although inhibitively expensive ( $\$ 500 /$ channel), a prototype board could be used for future senior/thesis projects.

The phased array discussed in this thesis utilizes passive potentiometers to set phase shifter bias. The array would benefit from an active biasing system, because as phase shift is increased, the current drawn by the phase shifters also increases. This makes it difficult to use passive potentiometers to set the bias. Also, the DIP switches for attenuator settings could be replaced by a digital control system. 


\section{Bibliography}

[1] Gast, M. S., 802.11 Wireless Networks. Sebastopol, Ca: O'Reilly, 2002, pp. 2326, 316-323

[2] Cisco System, Inc. 20 Myths of Wi-Fi Interference: Dispel Myths to Gain HighPerforming and Reliable Wireless, (2007, December 01). [Online]. Available: http://www.ciscosystems.com.ro/en/US/prod/collateral/wireless/ps9391/ps9393/p s9394/prod_white_paper0900aecd807395a9 ns736_Networking_Solutions_Whit e Paper.html [Acessed: April 18, 2010]

[3] F. B. Gross, Smart Antennas for Wireless Communication. New York, NY: McGraw-Hill, 2005, pp. 69-72, 95-98, 211-218

[4] "TSF-6850, Lead-Free Water-Soluble Tacky Soldering Flux, Preliminary DataSheet", Mar. 11, 2005. [online]. Available: www.amtest.net/pdf/materials/kester/TSF\%206850\%20Data\%20Sheet.pdf [Accessed: May 26, 2010]

[5] Godara, L. "Application of Antenna Arrays to Mobile Communications, Part II: Beamforming and Direction-of-Arrival Considerations," Proceedings of IEEE, Vol. 85, No. 8, pp. 1195-1245, Aug. 1997 


\section{Appendices}

\section{A. Materials}

Table 12 shows the materials and associated costs used for the project.

Table 12 Bill of Materials

\begin{tabular}{|c|c|c|c|c|}
\hline Part & $\begin{array}{l}\text { Model } \\
\text { Number/Desc }\end{array}$ & Ordered & Supplier & $\begin{array}{l}\text { Unit } \\
\text { Price } \\
\end{array}$ \\
\hline Phase Shifter & JSPHS-2484+ & 8 & MiniCircuits & $\$ 32.95$ \\
\hline Antenna & Nearson 614 & 8 & Donation & $\$ 0.00$ \\
\hline SMA Resistors (100) & 100ohm-805package & 7 & Donation & $\$ 0.00$ \\
\hline Attenuator & DAT-15R5-PP+ & 10 & MiniCircuits & $\$ 3.55$ \\
\hline SMA Switches & CT2196LPST-ND & 10 & Digikey & $\$ 0.79$ \\
\hline SMA board edge connectors & $\mathrm{n} / \mathrm{a}$ & 53 & SZWholesale & $\$ 0.76$ \\
\hline SMA patch cables & 6 inch & 15 & SZWholesale & $\$ 3.46$ \\
\hline Potentiometers & CT2254-ND & 10 & Digikey & $\$ 1.29$ \\
\hline SMA Resistors (4.7k) & 4.7kohm-805package & 56 & Donation & $\$ 0.00$ \\
\hline Solder Paste & ZLSP-2PAK & 1 & Zephytronics & $\$ 34.16$ \\
\hline Solder Paste Dispensing Needle & ZT-5-022-5-2pack & 1 & Zephytronics & $\$ 0.80$ \\
\hline Solder Paste Dispensing Plunger & ECO-1002 & 1 & Zephytronics & $\$ 5.95$ \\
\hline Tacky Flux & TSF-6850-30G & 1 & EIS & $\$ 35.40$ \\
\hline SMA male to SMA male adapters & A-AT7816 & 8 & Universal Radio & $\$ 2.29$ \\
\hline FR-4 Copper Clad Laminate & Assorted & 2 & Assorted & $\mathrm{n} / \mathrm{a}$ \\
\hline SMA female to SMA female adapters & SMA-F to SMA-F & 8 & Donation & $\$ 0.00$ \\
\hline
\end{tabular}




\section{B. Matlab Simulation Code}

The following code calculates required complex weights for each element to

produce an array factor with chosen maximums and null and plots the array

factor.

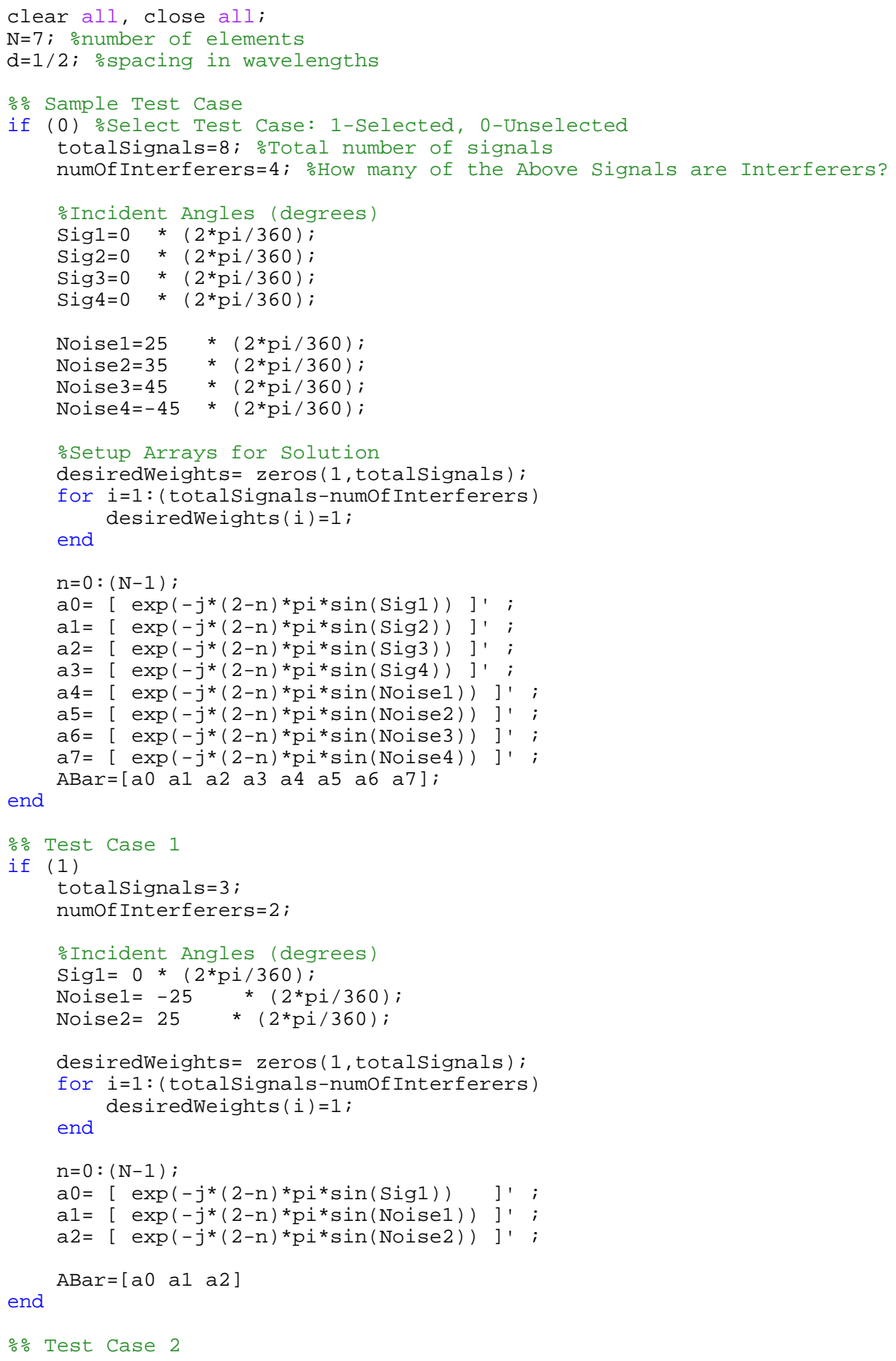




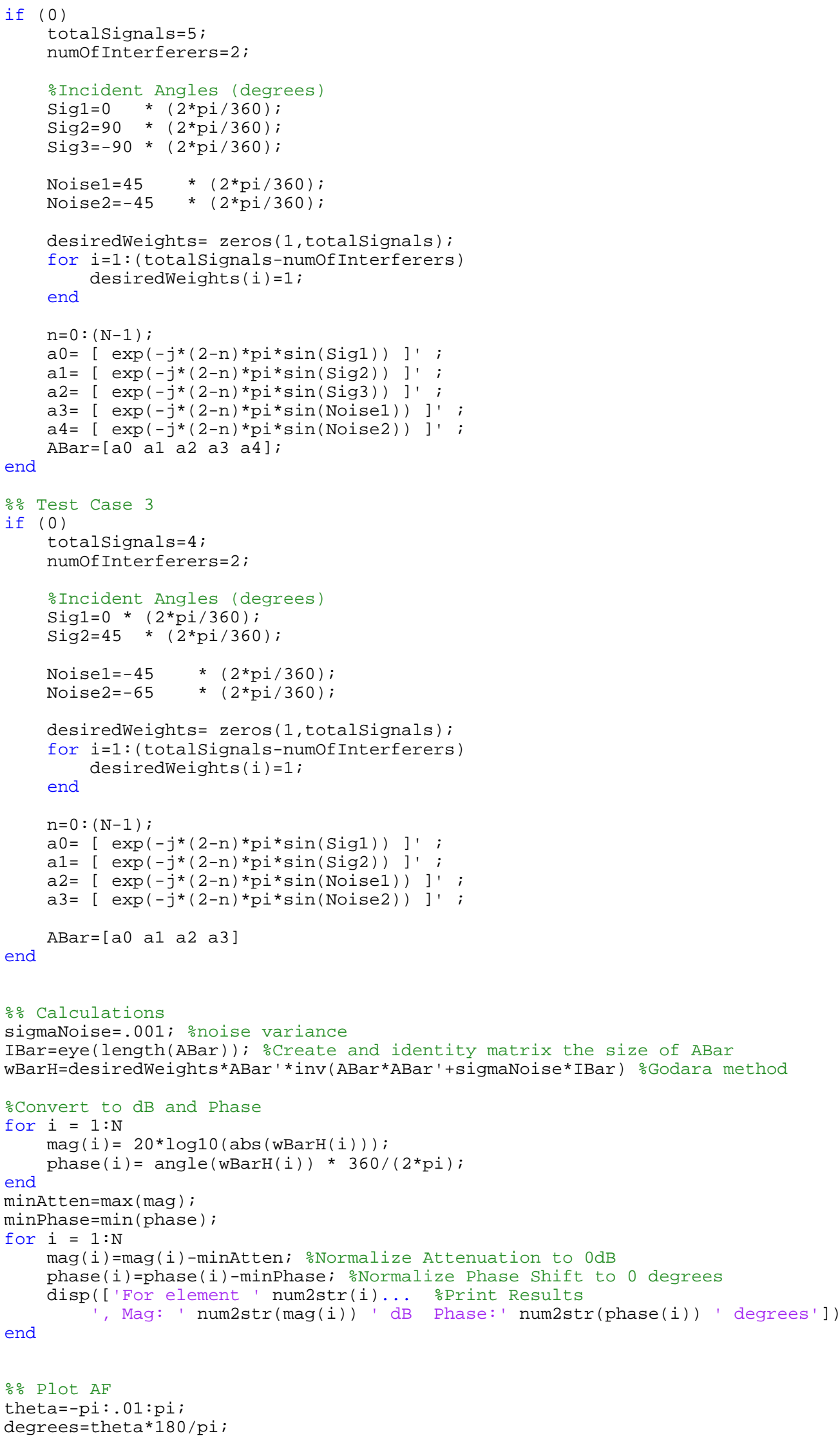




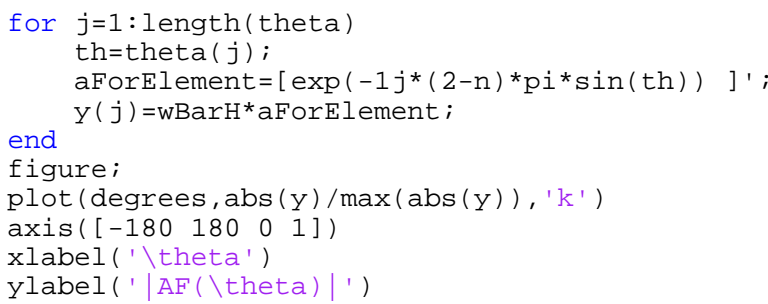

